University of Redlands

\title{
Wind Energy Development Under Military Airspace
}

A Major Individual Project submitted in partial satisfaction of the requirements for the degree of Master of Science in Geographic Information Systems

\author{
by \\ Gerald Scott Tabor \\ Committee in charge: \\ Mark Kumler, Ph.D., Chair \\ Scott Ryder, M.S.
}

December 2006 
Wind Energy Development

Under Military Airspace

Copyright (C) 2006

by

Gerald Scott Tabor 
The report of Gerald Scott Tabor is approved.
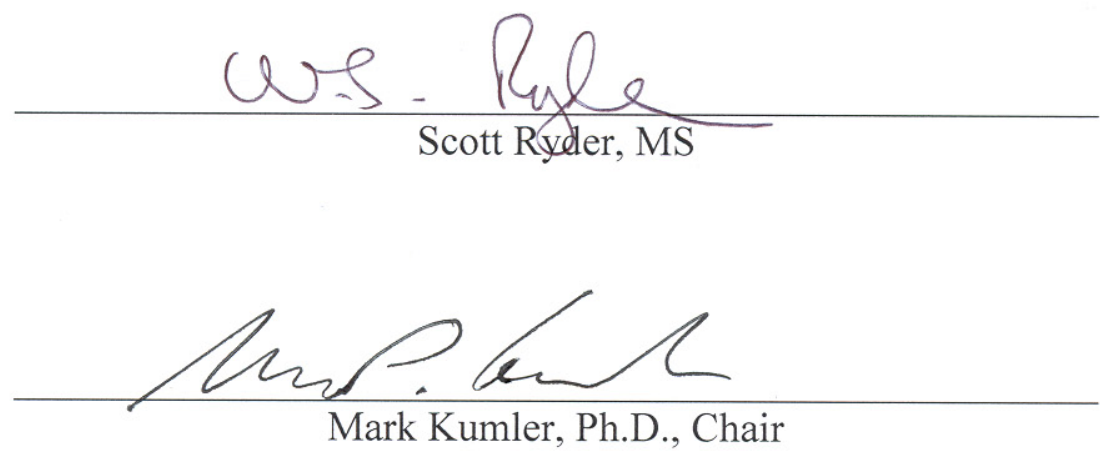

December 2006 



\section{ACKNOWLEDGEMENTS}

The following people provided the necessary support, facilitating my selection to the Vector Study Program: I would like to thank Frank Rush, Jacquie Hopkins, and John Goolgasian for offering their good names in support of my selection for Executive Development Training and for their stalwart leadership.

A project like this requires a client with vision and a good understanding of the risks involved. Therefore, I would also like to thank Captain Scott Ryder the commanding officer of Naval Air Station Fallon. Captain Ryder always understood the analytic power of Geographic Information Systems analysis and the importance of this project to both the DoD and our environment. He provided the leadership and support necessary to effect change to the paradigms within the relevant government agencies. Quoting Captain Ryder, "I'm tremendously supportive of his thought process and approach and (barring some unforeseen problem) feel it is one the entire DoD should apply to the issue of wind energy development." The GIS community needs more clientele like CAPT Ryder. 



\begin{abstract}
Wind Energy Development Under Military Airspace
\end{abstract}

by

Gerald Scott Tabor

Wind is a valuable renewable resource supporting a rapidly growing wind energy industry. Executive Order 13212, signed by President George W. Bush in 2001, tasks the Departments of the Interior, Energy, Agriculture, and Defense to work together in support of wind energy development on public lands in the eleven western states. Over $28 \%$ of the land area in the eleven western states that is suitable for wind energy production lies under U.S. military training airspace. Since the wind turbines are vertical obstructions to both Special Use Airspace (SUAS) and military training routes (MTRs), this level of geospatial convergence threatens to reduce the viability of this valuable renewable resource.

Technological innovation and modernization within the wind energy industry have pushed wind turbine heights higher into the airspace, beyond the minimum altitudes of some training airspace. This geospatial convergence creates a significant potential for encroachment. To support Executive Order 13212, while protecting training airspace from encroachment, this project assesses the geospatial relationship between military training airspace and wind energy development in the eleven western states.

In follow-on analysis, this project transitions from the regional eleven western states perspective to a focus on the Fallon Range Training Complex (FRTC) in northern Nevada, analyzing 17 areas of interest (AOI) and assessing the potential for encroachment. The objective of the FRTC analysis is to further examine the encroachment conditions around the FRTC and quantify potential encroachment scenarios. The client is Navy Captain Scott Ryder, the Commanding Officer of Naval Air Station Fallon who is responsible to a large extent for the oversight of northern Nevada's military training airspace.

From the perspective of the client, this project yields valuable knowledge and an improved geospatial understanding of the physical relationship between wind energy development and military training airspace. That knowledge and understanding will be directed towards the development of the most appropriate management policy and procedures.

This project effectively predicts the amount of wind energy related encroachment that could occur within the study areas. It also identifies the most likely encroachment points around the FRTC perimeter, where encroachment will most likely occur, and from what direction it will likely come. The project effectively demonstrates fundamental GIS problem solving concepts, integrating many relevant factors, and demonstrating the power and advantage of GIS. This analysis presented in this project does not limit wind energy development, but identifies potential encroachment as well as where wind energy developers should focus and where they should limit their exploration. 



\section{Table of Contents}

1. Project Background.................................................................................... 1

1.1. Problem Statement ................................................................................. 1

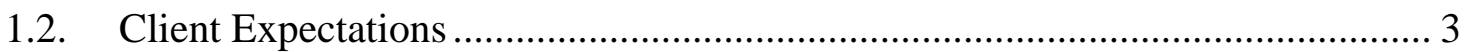

1.3. Background and Literature Review ………................................................ 4

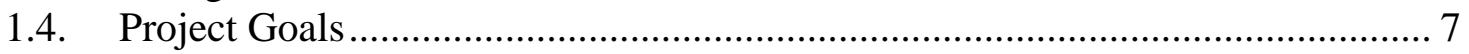

1.5. Analytic Paradigm ................................................................................ 7

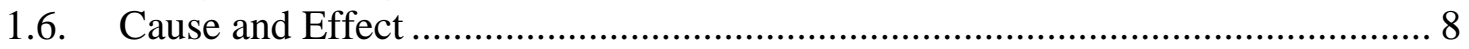

1.7. Encroachment Analysis .................................................................................. 9

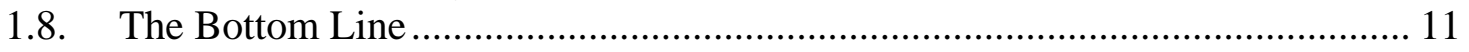

2. Data Immersion and Object Abstraction........................................................... 13

2.1. Wind Resource Model. ............................................................................ 13

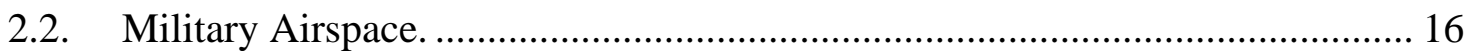

2.3. Wind Turbine Vertical Obstruction Zone (WTvoz)......................................... 20

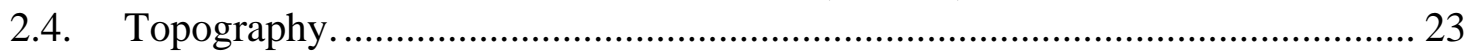

2.5. Data Immersion and Object Abstraction Findings.............................................. 26

3. Cause and Effect Observation........................................................................... 29

3.1. Vertical Obstruction Zone vs. Military Airspace Geometry............................... 29

3.2. Vertical Obstruction Zone vs. Stoplight Management Schema......................... 30

3.3. Wind Resource vs. The Revised Military Airspace Model. ................................ 31

3.4. Multivariate Observation, Indicating Encroachment Potential........................... 33

3.4.1. Encroachment Damage Control................................................................. 37

3.5. Topography and the Law of Diminishing Returns. .......................................... 38

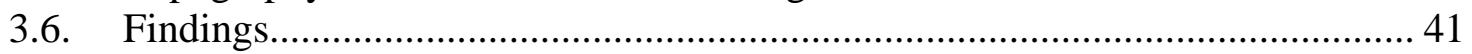

4. Fallon Range Training Complex Encroachment.................................................... 43

4.1. Encroachment Areas of Interest (AOI) ........................................................... 43

4.2. Roads, Electric Transmission, Elevation and Slope. ....................................... 47

4.3. Topography: Funnels, Plateaus, and Ridgelines.............................................. 48

4.4. Prevailing Winds...................................................................................... 50

4.5. Hawthorne (AOI-7 and AOI-8), Encroachment Analysis Prototype.................. 51

4.5.1. Hawthorne Topography...................................................................... 53

4.5.2. Hawthorne Encroachment Potential. ..................................................... 54

4.6. Area of Interest ONE (Reese River Valley) and TWO (Cortez Mountains).... 54

4.6.1. $\quad$ Reese River Valley/ Cortez Mountains Topography................................. 54

4.6.2. Reese River Valley/ Cortez Mountains Encroachment Potential............. 55

4.7. Simpson Park Mountains, Area of Interest THREE....................................... 56

4.7.1. Simpson Park Mountains Topography. .................................................... 57

4.7.2. Simpson Park Mountains Encroachment Potential.................................. 58

4.8. Monitor Valley, Area of Interest FOUR........................................................ 59

4.8.1. Monitor Valley Topography................................................................. 59

4.8.2. Monitor Valley Encroachment Potential. .................................................. 60

4.9. Big Smokey and Ione Valley, Area of Interest FIVE, SIX and ELEVEN. ........ 61

4.9.1. Big Smokey and Ione Valley Topography................................................ 61

4.9.2. Big Smokey and Ione Valley Encroachment Potential.............................. 62

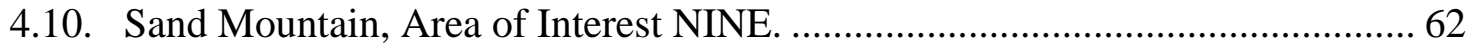


4.10.1. Sand Mountain Topography. ...................................................................... 63

4.10.2. Sand Mountain Encroachment Potential..................................................... 64

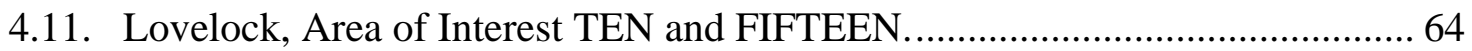

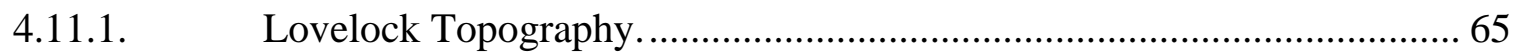

4.11.2. Lovelock Encroachment Potential ........................................................... 65

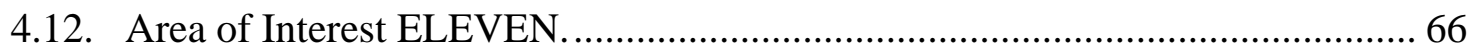

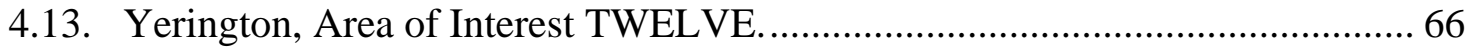

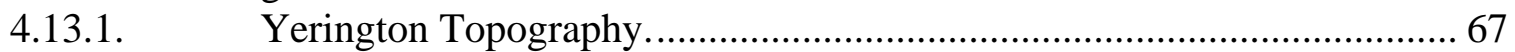

4.13.2. Yerington Encroachment Potential......................................................... 67

4.14. Lahontan, Area of Interest THIRTEEN and FOURTEEN. ................................ 68

4.14.1. Lahontan Topography........................................................................... 68

4.14.2. Lahontan Encroachment Potential........................................................... 69

4.15. Humbolt Wildlife Area, Area of Interest FIFTEEN. …………………….......... 70

4.16. Tobin Range, Area of Interest SIXTEEN and SEVENTEEN......................... 70

4.16.1. Tobin Range Topography................................................................. 71

4.16.2. Tobin Range Encroachment Potential. ................................................... 71

5. Techniques, Procedures and Metadata and Conclusions........................................ 75

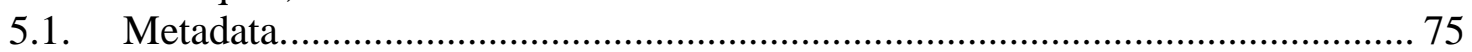

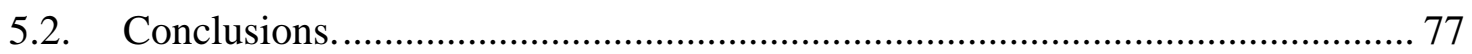

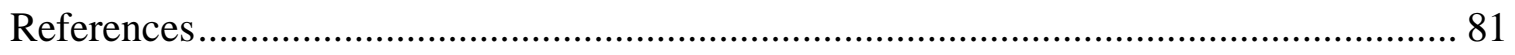

Appendix A. Topographic Planning Map Series.......................................................... 89

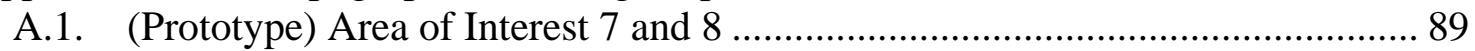

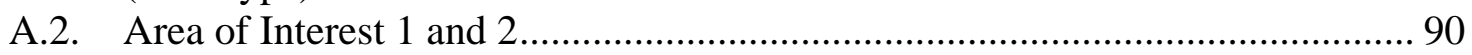

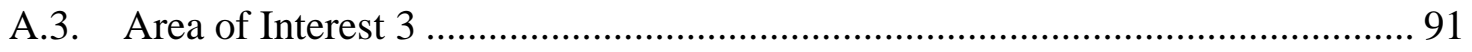

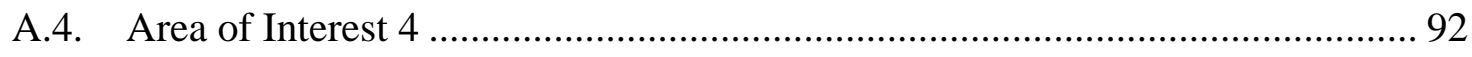

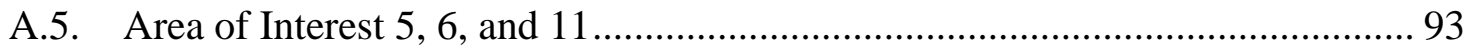

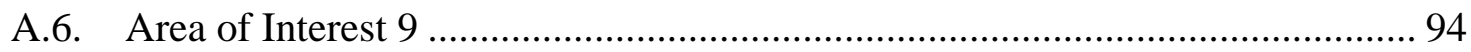

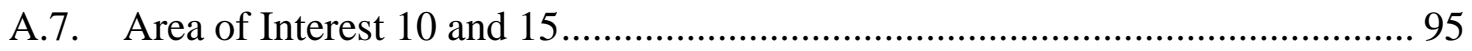

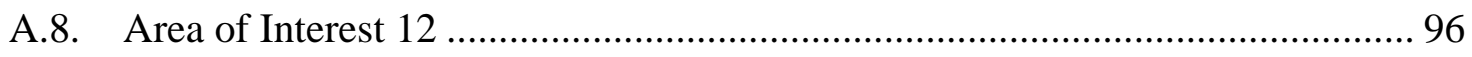

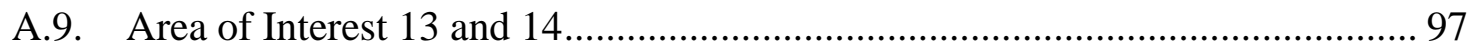

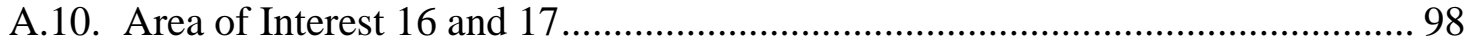

Appendix B. Wind Turbine Photo Tour ....................................................................... 99

B.1. Mountain Cloud (New Zealand Wind Energy Association, n.d.)...................... 99

B.2. Wind Farm (Purcell, n.d.).......................................................................... 100

B.3. Meridian01 (Haefner, n.d.).................................................................... 100

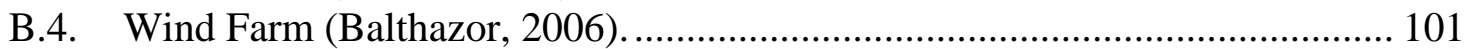

B.5. Wind Farms of Madison County, NY. (Albany Aerial Photo.com, n.d.)........ 101

B.6. Wind Farms of the World (Paul Gipe, n.d.).................................................. 102

B.7. Wind Farm Photo Gallery (PPM Energy, n.d.)................................................ 103

B.8. $\quad 3.6$ megawatt Turbine (General Electric, n.d.)................................................. 104

B.9. Novar (Npower Renewables, n.d.)............................................................ 105

B.10. Construction (Collett Transport Ltd, n.d.)...................................................... 105

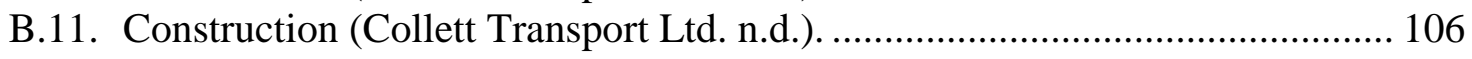

B.12. Blade Factory in Nakskov Denmark (Vestas n.d.). ........................................... 106

B.13. Construction (Windustry, n.d.). ....................................................................... 107 


\section{List of Figures}

Figure 1-1. Military Airspace Across The Study Area................................................... 2

Figure 1-2. BLM Managed Lands in Nevada................................................................. 4

Figure 1-3. Wind Energy Development Potential............................................................. 6

Figure 1-4. Phase-1 Analysis, Project Objectives And Milestones. ..................................... 8

Figure 1-5. Phase-2 Analysis, Project Objectives And Milestones.................................... 10

Figure 2-1. Wind Power Classes.................................................................................... 14

Figure 2-2. Wind Power Classes Displayed Across Eleven Western States. .................... 15

Figure 2-3. Military Training Route Coordination Dichotomy......................................... 17

Figure 2-4. Military Airspace in the Eleven Western States. ............................................. 19

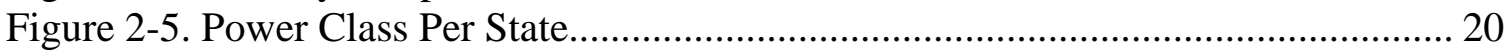

Figure 2-6. Nevada Wind Power Class Statistics. ............................................................ 21

Figure 2-7. Wind Turbine Vertical Obstruction Zone Orientation and Perspective......... 22

Figure 2-8. Switchbacks on Steep Slopes (Dorset, n.d.)................................................. 24

Figure 2-9. Foote Creek III Wind Farm in Arlington Wyoming........................................ 25

Figure 3-1. Effects of Wind Turbine Vertical Obstruction Zone...................................... 29

Figure 3-2. Stoplight Management Standard. ................................................................... 31

Figure 3-3. Wind Resources vs. Military Airspace........................................................... 32

Figure 3-4. Military Training Route and Wind Model Convergence Data......................... 33

Figure 3-5. Special Use AirSpace and Wind Model Convergence Data............................ 34

Figure 3-6. Intervening Aggregate, Multivariate Analysis................................................. 36

Figure 3-7. Wind Resources Within 25 Miles of Electric Transmission Grid................... 39

Figure 3-8. Wind Resources Above 7,000 Feet (2,134km) Mean Sea Level................... 40

Figure 4-1. FRTC Perimeter Encroachment Areas Of Interest.......................................... 44

Figure 4-2. Elevation, Slope and the Law of Diminished Returns.................................. 48

Figure 4-3. Funnel Topography................................................................................. 49

Figure 4-4. Highland Plateau Topography................................................................... 49

Figure 4-5. Northern Nevada Prevailing Wind Direction................................................. 50

Figure 4-6. Encroachment Analysis Prototype. ........................................................... 51

Figure 4-7. Hawthorne Encroachment Planning Map. .................................................... 52

Figure 4-8. Hawthorne Planning Map, Topography........................................................ 53

Figure 4-9. AOI-1 and AOI-2 Topographic Planning Map............................................ 55

Figure 4-10. AOI-1 and AOI-2, Encroachment Potential................................................ 56

Figure 4-11. AOI-3 Topographic Planning Map. ……………...................................... 57

Figure 4-12. AOI-3 Encroachment Potential................................................................. 58

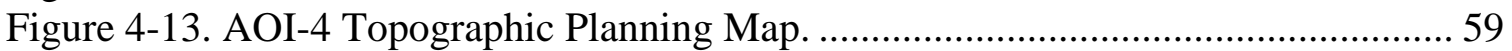

Figure 4-14. AOI-4 Encroachment Potential....................................................................... 60

Figure 4-15. AOI-5, AOI-6 and AOI-11 Topographic Planning Map................................ 61

Figure 4-16. AOI-5, AOI-6 and AOI-11 Encroachment Potential. .................................... 62

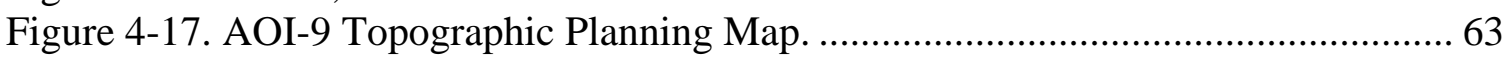

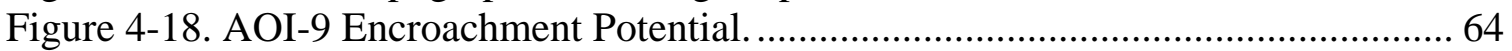

Figure 4-19. AOI-10 and AOI-15 Topographic Planning Map........................................ 65

Figure 4-20. AOI-10 and AOI-15 Encroachment Potential............................................... 66

Figure 4-21. AOI-12 Topographic Planning Map. ......................................................... 67

Figure 4-22. AOI-12 Encroachment Potential................................................................... 68 
Figure 4-23. AOI-13 and AOI-14 Topographic Planning Map.................................... 69

Figure 4-24. AOI-13 and AOI-14 Encroachment Potential.......................................... 70

Figure 4-25. AOI-16 and AOI-17 Topographic Planning Map....................................... 71

Figure 4-26. AOI-16 and AOI-17 Encroachment Potential........................................... 72

Figure 4-27. Calculating Development and Encroachment Potential............................ 73

Figure 4-28. Quantification of Encroachment Potential............................................ 74

\section{List of Tables}

Table 2-1. Turbine Generator Heights.............................................22

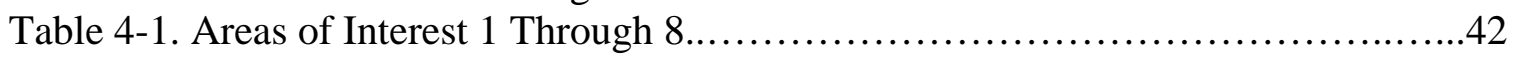

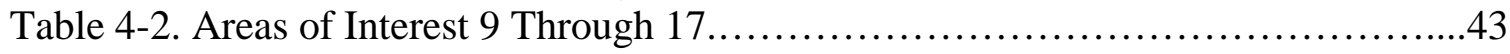




\section{List of Acronyms}

\begin{tabular}{|c|c|}
\hline AGL. & Actual Ground Level \\
\hline AOI............................... & Area Of Interest \\
\hline AP-1B $\ldots \ldots \ldots \ldots \ldots \ldots \ldots \ldots \ldots \ldots \ldots$ & Air Planning Publication One-Bravo \\
\hline AWEA.. & American Wind Energy Association \\
\hline BLM.... & Bureau of Land Management \\
\hline BRAC.. & Base Realignment And Closure Commission \\
\hline CE...... & Circular Error \\
\hline DAFIF. & Digital Aeronautical Flight Information File \\
\hline DoD.... & Department of Defense \\
\hline DOE... & Department of Energy \\
\hline DOI... & Department of Interior \\
\hline DOT.. & Department of Transportation \\
\hline DRI.... & Desert Research Institute \\
\hline EIA.... & Energy Information Administration \\
\hline ESRI... & Environmental Systems Research Institute \\
\hline FAA.... & Federal Aviation Administration \\
\hline FLIP.... & Flight Information Publication \\
\hline FRTC... & Fallon Range Training Complex \\
\hline GIS..... & Geographic Information System \\
\hline LE...... & Linear Error \\
\hline LWST.. & Low Wind Speed Turbine \\
\hline MSL..... & Mean Sea Level \\
\hline MTR... & Military Training Route \\
\hline NAS... & Naval Air Station \\
\hline NGA... & National Geospatial-Intelligence Agency \\
\hline NREL... & National Renewable Energy Laboratory \\
\hline NWTC... & National Wind Technology Center \\
\hline PEIS..... & Programmatic Environmental Impact Staten \\
\hline SUAS... & Special Use Air Space \\
\hline WTVoz.... & Wind Turbine Vertical Obstruction Zone \\
\hline
\end{tabular}





\section{Project Background}

In 2001, President George W. Bush signed Executive Order 13212, “Actions to Expedite Energy Related Projects,” establishing policy that tasks the Departments of the Interior, Energy, Agriculture, and Defense to work together in support of wind energy development on public lands (United States Department of Interior, Bureau of Land Management [US DOI BLM], June 2005, ES-1).

In response to this Executive Order, the Bureau of Land Management (BLM) produced an environmental impact statement proposing policy changes and management practices to optimize wind energy development and limit the impact on the environment (US DOI BLM, June 2005, ES-1). The geospatial foundation of the environmental impact statement is a maximum potential development scenario of wind energy in the study area (US DOI BLM, June 2005, ES-3). ${ }^{1}$

The Navy's Southwest Region adopted the management scheme of Kern County, California (i.e., also known as "Stoplight"), as policy for managing the placement of wind energy equipment on lands that would affect military airspace (D.M. Brasher personal communication, November 14, 2005). ${ }^{2}$ The Kern County scheme is based on a four hundred foot vertical obstruction height threshold. Under this policy, if a developer desires to place a vertical obstruction in military airspace with a minimum altitude of less than four hundred feet above actual ground level (AGL) he would be required to issue notification of a proposed wind energy action for review and comment. Any request to place vertical obstructions on lands under military airspace would likely be challenged by DoD when that airspace has a minimum altitude less than four hundred feet (S.M. Kramer, personal communication, September 6, 2006). ${ }^{3}$

\subsection{Problem Statement}

The BLM environmental impact statement programmatically addresses wind energy development on federal lands beneath military training airspace from the perspective of protecting the environment (US DOI BLM, June 2005, 2-7). But the impact statement does not address wind energy development on federal lands beneath military airspace from the perspective of protecting that airspace from encroachment (i.e., the placement of a vertical obstruction on lands beneath military airspace that will reach upward into military airspace, creating an airspace navigation hazard). Figure 1-1 demonstrates the amount of airspace across the study area (described in more detail and cited in subsequent chapters in this document). The impact statement notes military training airspace, but only to the extent of special use airspace (a type of military airspace restricted to only military aircraft operations), and only with the caveat that the military is consulted prior to authorizing development permits (US DOI BLM, June 2005, 2-7). For example, the

\footnotetext{
${ }^{1}$ The study area consists of the eleven western states: Washington, Oregon, California, Idaho, Nevada, Arizona, Montana, Wyoming, Utah, Colorado, and New Mexico.

${ }^{2}$ D.M. Brasher works for the Navy Southwest Region Environmental Office as one of the lead officials concerned with deconflicting the Navy's training airspace and wind energy development in the Southwest Region.

${ }^{3}$ Steven Kramer works for the Naval Air Station Fallon (NAS Fallon) Environmental Office as one of the lead officials concerned with deconflicting wind energy development on lands beneath Fallon Range Training Complex airspace.
} 
impact statement reads, "Incompatibility with military missions could be a basis for permit denial should there be no available mitigating option.” (US DOI BLM, June 2005, 4.34-4.36). This caveat may be considered counter-productive to the risk-reducing intent of the environmental impact statement, because it increases uncertainty of right of way adjudication for government policy makers, wind energy developers, and development investors(Lydersen, 2006).

Policy changes and management practices recommended by the environmental impact statement may not adequately address how adjudicating the placement of wind equipment on lands beneath military airspace would occur. The uncertainty of right of way adjudication could ultimately generate poor management practices for both the BLM and wind energy developers, as well as significantly increase risk of encroachment on military training airspace.

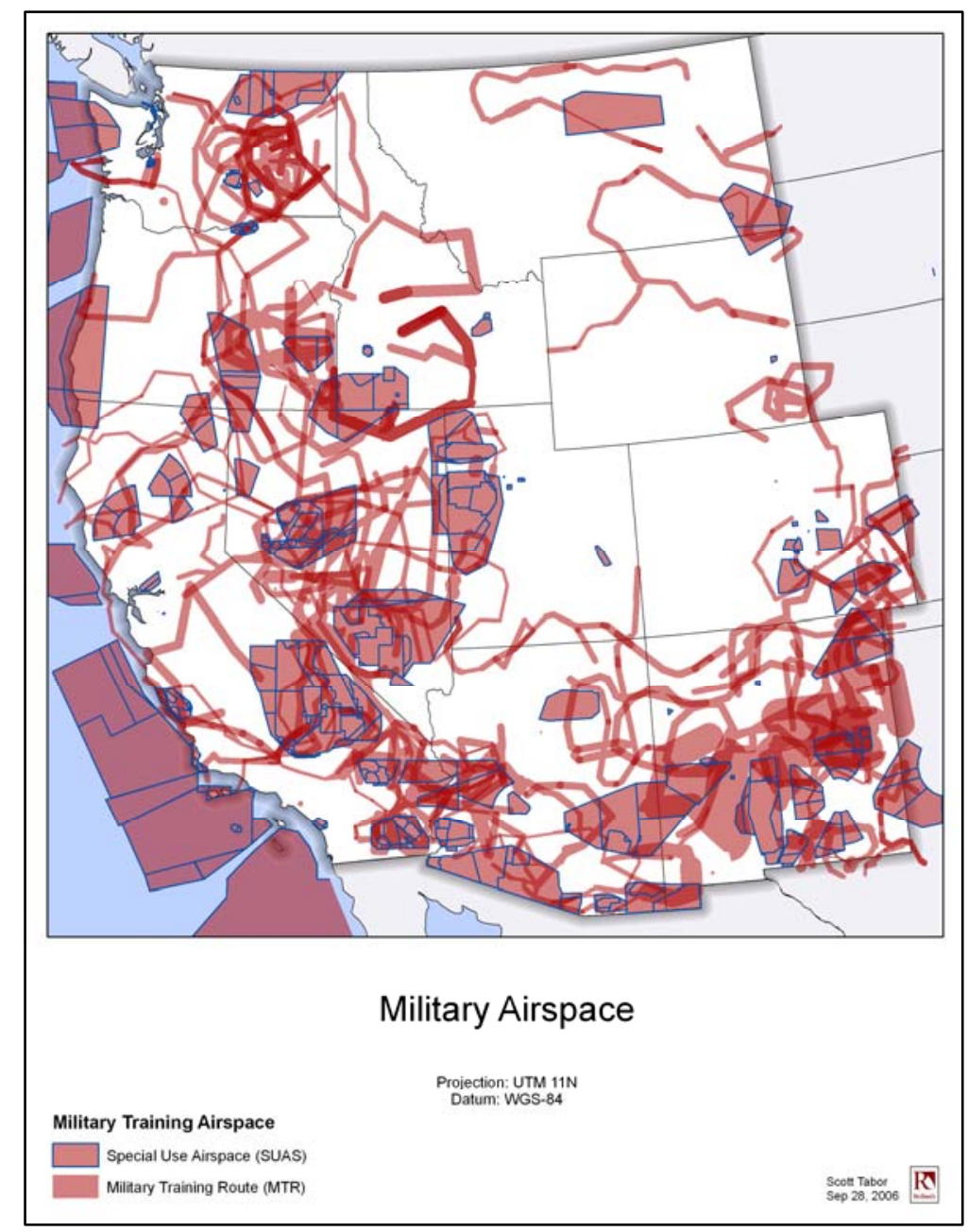

Figure 1-1. Military Airspace Across The Study Area. ${ }^{4}$

\footnotetext{
${ }^{4}$ Military airspace geometry is based on Digital Aeronautical Flight Information File (DAFIF, January 2006).
} 
The analysis in this project follows DoD wind energy policy in Kern County, California. The Stoplight management policy employed in Kern County is the original management scheme and the only policy in the Navy Southwest Region that addresses the placement of meteorological towers (for initial site testing) and wind turbine generators (D.M. Brasher, personal communication, November 14, 2005). Wind turbine research indicates that the wind turbine height specifications used to develop the Stoplight policy may be outdated (i.e., based on older wind turbine technologies), and therefore the four hundred foot threshold may be inadequate for management policy in Nevada (S. Ryder et al., personal communication, October 31, 2006).

From the perspective of the client and the senior government officials on his staff, neither the BLM environmental impact statement nor the DoD Stoplight policy adequately accounts for the impact that wind energy development will have on military training airspace. In particular, omission of designated military training airspace, and the impact this airspace will have on the final maximum potential development scenario, leaves the impact statement incomplete. Furthermore, the four hundred foot threshold of the Stoplight management scheme does not adequately account for the technological advancements within the wind turbine industry (Thresher, 2004), nor does it account for Nevada's unique wind energy requirements (US DOI BLM, 2005).

For effective policy development, additional analysis that accurately reflects the impacts these spatial phenomena have on each other is required. The first goal of this analysis is to assess the potential for wind development within the study area (with Nevada in particular), but also lands outside of military training airspace. This will provide the client with critical knowledge (i.e., prerequisite to policy development) of the geospatial relationship between wind development and military airspace in Nevada, as well as the threat of airspace encroachment. The second goal is to develop mitigating GIS analytic techniques, tailoring the Kern County management scheme to Nevada's unique airspace geometry.

\subsection{Client Expectations}

The primary audience for this project is Captain Scott Ryder, the NAS Fallon commanding officer; however, the list of potential beneficiaries of this analysis includes all governing parties in the study area. The client's expectations are straightforward. First, assess the potential for wind energy development on lands outside of military airspace, achieving a level of situational awareness, a prerequisite to updating or formulating effective management policy. Second, if the potential for wind energy development exists outside of military airspace, assess the effectiveness of current DoD management practices related to wind energy and then devise an analytic scheme to identify potential sites, in the vicinity of Navy training airspace, suitable for analysis in support of encroachment scenario visualization. The only analytical stipulation required by the client is to provide a project analysis with a similar standard as California's Stoplight management scheme (S. Ryder, personal communication, August 10, 2005). ${ }^{5}$

\footnotetext{
${ }^{5}$ Navy CAPTAIN, S. Ryder, is the commanding officer of Fallon Naval Air Station providing oversight of the airspace associated with the Fallon Range Training Complex.
} 


\subsection{Background and Literature Review}

The Bureau of Land Management has an inherent level of management authority over lands beneath DoD training airspace (United States House of Representatives, May 1999). Over $50 \%$ of the study area is managed by the BLM, including much of the land reserved for military aviation training (US DOI BLM, 2006). Figure 1-2 illustrates the amount of BLM managed lands in Nevada. In lieu of other agency policy governing wind development, the BLM's environmental impact statement (which includes the maximum potential development scenario) is the analytic foundation governing wind energy development policy changes and management practices. These practices not only affect military training lands, but also public lands beneath military training airspace.

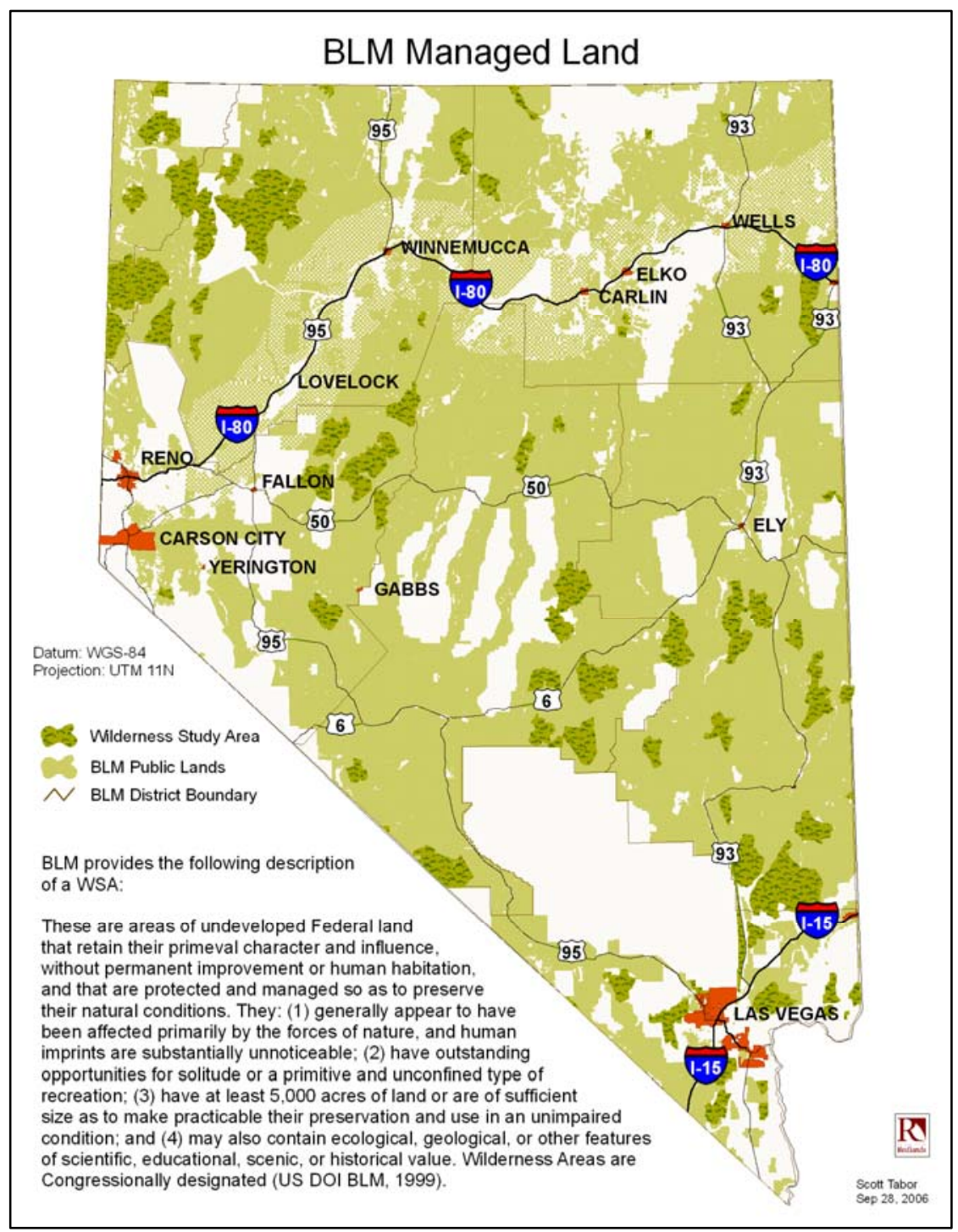

Figure 1-2. BLM Managed Lands in Nevada. ${ }^{6}$

\footnotetext{
${ }^{6}$ The National Defense Authorization Act for fiscal year 2000 assigned management authority of specific DoD land reserves to BLM (included as part of the BLM managed lands on this graphic). Lands not illustrated as Wildlife Study Areas or BLM Public Lands are managed under alternative authority.
} 
The Bureau of Land Management's maximum potential development scenario is a geospatial model constructed of geospatial phenomena specifically focused on minimizing wind energy development impact on the environment. Geographically visualized, these polygon features are based on the National Renewable Energy Laboratory's (NREL) wind resource model minus the BLM's screening criteria that include: government ownership, land designated as unprotected, land occupancy concerned with urbanization, civil-aviation safety immediately around airports and airfields, wetlands, and relatively flat topography (US DOI BLM, 2005, B.9).

The AWS Truewind Incorporation Company formulated the wind resource model used in the maximum potential development scenario, under the supervision of the NREL. Their wind resource model was classified into wind potential power classes, from poor to excellent on a scale of one to seven (United States Department of Energy, National Renewable Energy Laboratory [US DOE NREL], July 2005). The final model used power classes numbers three through seven, representing moderate (i.e., power class 3 ), good (i.e., power class 4), and excellent (i.e., power classes 5-7) wind resource potential. Figure 1-3 illustrates the output of the final wind model for the entire study area.

The goal of the Bureau of Land Management's abstraction formula (i.e., the geographic phenomena chosen to be geographically visualized in vector format), is to create a GIS development model that supports the preprogramming of management practices that would ensure right of way adjudication conformity to environment protection laws while optimizing wind development (US DOI BLM, 2005, B.9). Therefore, the model visualizes the potential magnitude of development across the entire study area in an effective, goal oriented, and programmatic manner (US DOI BLM, 2005, B.9).

The Bureau of Land Management proposes policy changes based on the development potential identified within the maximum potential development scenario and management guidelines that will outline wind energy project development rules (US DOI BLM, 2005, ES.1-ES.3). Therefore, the maximum potential development scenario will act as a starting point for this project-specific GIS analysis of wind energy development potential.

The maximum potential development scenario is essentially the Rosetta stone for analysts, managers, and developers. Integrating a foundation of analysis into the environmental impact statement will facilitate right of way adjudication and add a level of consistency to the program. This consistency will create a sense of reliability that will trickle down to developers, simplifying wind energy development and making it more cost effective. 


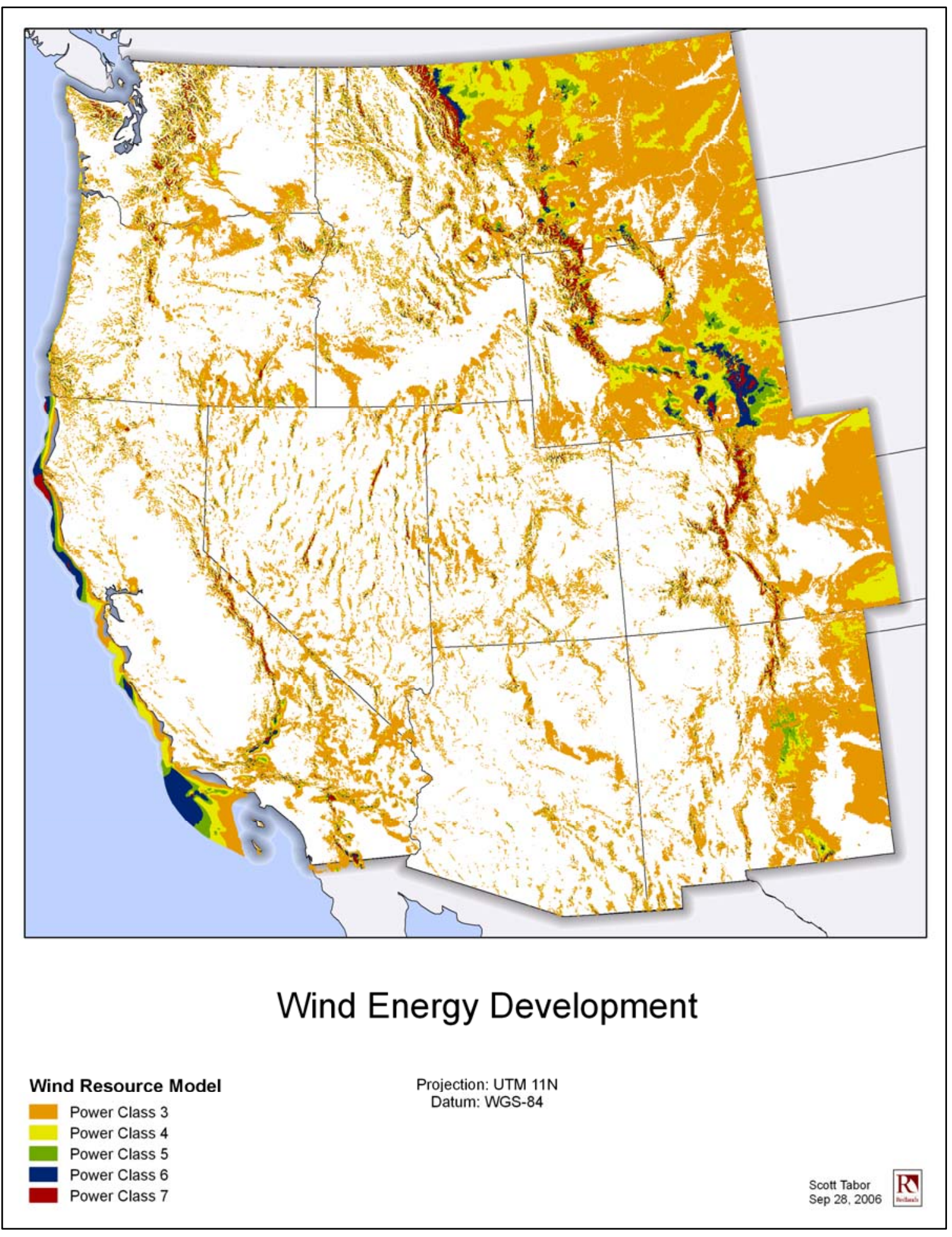

Figure 1-3. Wind Energy Development Potential. ${ }^{7}$

${ }^{7}$ The wind resource model database used in this graphic and throughout this project was provided by
Donna Heimiller (personal communication), at the National Renewable Energy Laboratory, Boulder, CO. 


\subsection{Project Goals}

This project presents GIS analysis that addresses programmatic voids (i.e., voids related to wind energy right of way adjudication on lands beneath military training airspace), which will improve the acumen of client policy.

The GIS analysis in this project has two phases. Phase-one analysis will identify the geospatial relationship between wind energy development and military airspace in Nevada. The insight gained will support client policy development with increased knowledge and understanding of possible impacts on military airspace.

Phase-two analysis will focus on exploring and developing GIS analytic techniques to identify sites with development potential surrounding military airspace. The programmatic goal of phase-two analysis is to demonstrate the potential for encroachment on military training airspace.

The benefit of GIS analysis to the client is the added knowledge of the physical relationship between wind energy development and military training airspace. Increased understanding will permit the client to develop policy and mitigating courses of action that can be integrated into client policy.

\subsection{Analytic Paradigm}

This project employs a hybrid of analytic processes. First, Richard Heuer's contribution to the analytic process comes from his argument that one single strategy alone is not enough to counter mind-traps such as bias (United States Central Intelligence Agency, Center For The Study of Intelligence [US CIA CSI], 1999, p. 4.2-4.7). ${ }^{8}$ In order to formulate hypotheses and make full use of relevant information, it is prudent to employ a combination of analytic strategies in order to optimize hypothesis formulation (US CIA CSI, 1999, p. 4.2-4.7). Most important, Richard Hueur warns of stand-alone cause and effect observation; arguing (using GIS term), the functional and physical relationships of geospatial variables should be observed and substantiated (US CIA CSI, 1999, p. 4.24.7). Second, Edward Tufte's contribution to the analytic process comes from his recommendation to statistically compare data, formulate alternative explanations and follow-up on these steps by effectively demonstrating analytic methods and procedures (Tufte, September 2004, pp. 6-15).

Applying Heuer's and Tufte's analysis recommendations to GIS, this project employed a four-step analysis strategy. First, gain a better understanding of the problem through an immersion in GIS data and relevant information until hypotheses are formulated. Second, observe the physical relationships of the geospatial phenomena, observing the effects of their physical characteristics on each other (proximity, terrain, orientation, direction and location) as they converge or are dispersed across a geographic landscape. Third, make useful and quantifiable comparisons of the aggregated geospatial phenomena, with the intent to identify potential alternate courses of action. Fourth, solidify analysis, adding credibility to and trust in the final assessments by

${ }^{8}$ Richard Hueur served for 24 years in the CIA's Directorate of Operations. In 1979 Hueur retired from the CIA as director of the methodology unit of the Directorate of Intelligence. Writings about Hueur reflect that his greatest legacy is his impact on the quality of analysis at CIA. 
demonstrating analytic methods and procedures in order to increase awareness and debunk potential bias within the target audience.

\subsection{Cause and Effect}

In review of the relevant geospatial phenomena identified through data immersion, and subsequently created and manipulated in GIS analysis, Figure-1.4 reveals a dichotomy of data relevant to the analysis of the entire study area and the influence GIS analysis will have on client policy. Validating the geographic phenomena chosen to abstract the cause and effect relationship of wind energy and military airspace, the aggregates listed on Figure 1-4 are similar to previous wind farm analyses described at the 1996 Environmental Systems Research Institute's (ESRI) European Users Conference held in London, England (Sparks, 1996).

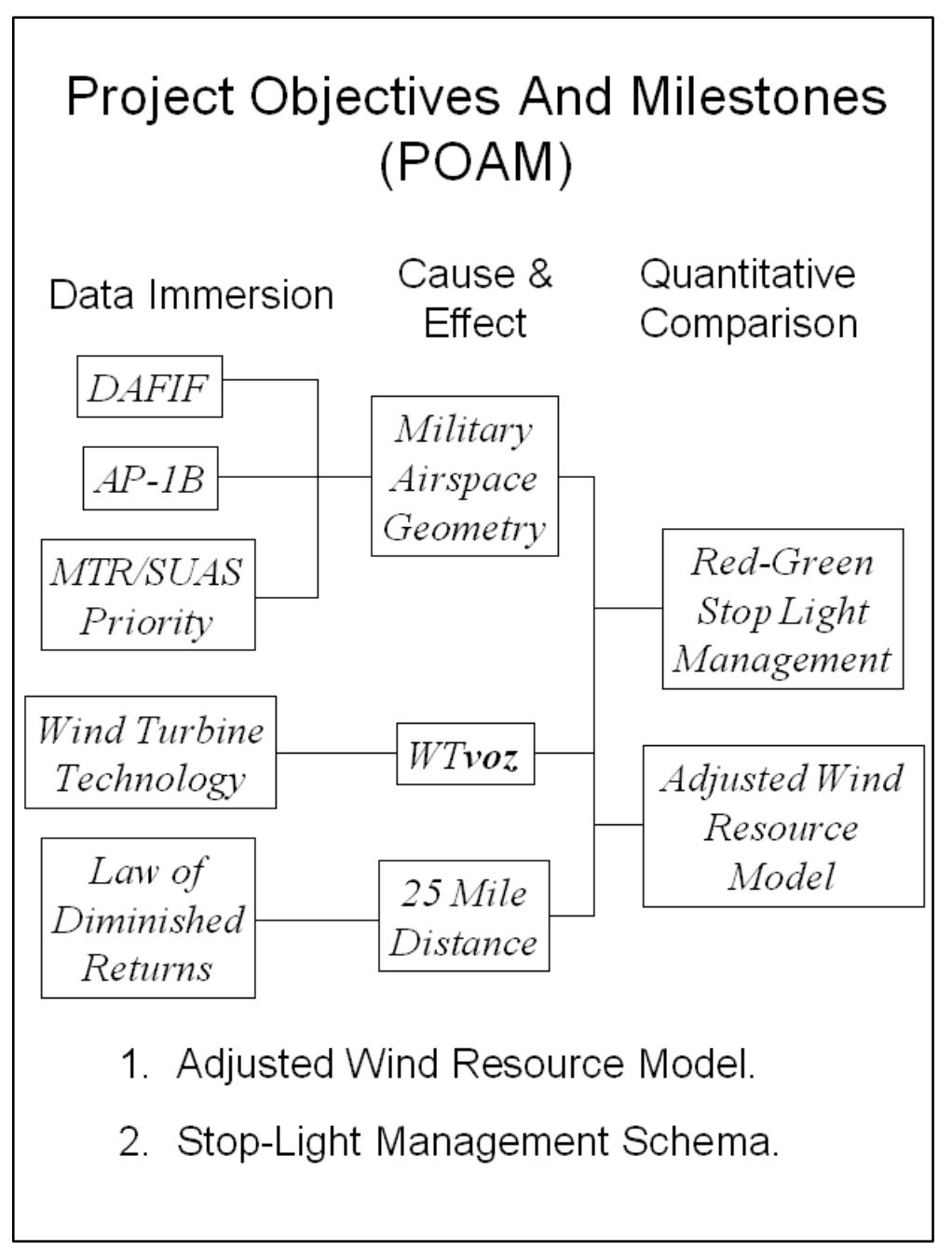

Figure 1-4. Phase-1 Analysis, Project Objectives And Milestones. 
The Digital Aeronautical Flight Information File (DAFIF) provides the required geometry in the form of line-vectors with the prerequisite geometric descriptions for twoand three-dimensional GIS construction of the military airspace. The geometry will be constructed using a GIS buffering tool, creating polygons with accurate right and left geometry based on descriptions provided in the attribute tables, essentially converting the polylines into a polygon with the option of expressing a vertical parameter (i.e., minimum altitude) when required. Air Planning Publication One-Bravo (AP-1B) provides the vertical description of each of the training route segments (United States Department of Defense Flight Information Publication Area Planning North and South America [US DoD FLIP AP-1B], March 2005).

Aggregating the horizontal data from the digital aeronautic flight information files with the vertical data provided by AP-1B permitted the creation of a third, three-dimensional polygon vector, required for cause-and-effect phase of analysis.

The priority given to the military training route (MTR) and special use airspace (SUAS) aggregates in this project is based on interviews with regional Federal Aviation Administration management. That research garnered expert opinion that the military is already training with minimal amounts of airspace (D. Trendle, personal communication, November 24, 2005). Military training route geometry has not been changed in many years, and is not likely to be changed in favor of wind energy development (D. Trendle, personal communication, November 24, 2005).

Analytic immersion into wind turbine technology consisted of the research and discovery of data and expert opinion related to an estimate of wind turbine heights (described and cited later in this document). The final height estimate is based on turbines employed in current projects and wind turbine technology height averages, combined with heights forecasted by experts. Current and future turbine heights, coupled with low power class requirements, support the logic of aggregating the one hundred eighty meters (i.e., rounded to 600 feet AGL) wind turbine vertical obstruction zone. The estimated wind turbine vertical obstruction zone, coupled with the high priority given to military training route geometry, ultimately resulted in the aggregation of the wind turbine vertical obstruction zone and military airspace.

Wind energy experts have identified several economic and topographic screening criteria necessary to realize an acceptable profit margin (US DOI BLM, 2003). This project focuses on four: distance from the existing electric power grid, distance from existing paved roads, elevation and slope. These four criteria are situationally more relevant to the site-specific analysis performed in the second half of this project.

\subsection{Encroachment Analysis}

Site-specific encroachment analysis is a GIS study in the geospatial relationship of the adjusted wind resource model (adjusted in initial analysis as described in previous paragraphs), Stoplight managed military airspace policy, and the geospatial phenomena relevant to site development identification and encroachment avoidance. Figure 1-5 demonstrates the geospatial phenomena relevant to site-specific analysis milestones and objectives. The adjusted wind resource model and polygons related to the Stoplight managed airspace policy are incorporated into high-resolution analysis in support of site- 
specific encroachment avoidance and site identification objectives. These geospatial phenomena are wind direction, funnel, ridgeline, and plateau topography; whereas the slope and elevation polygons are related to the economic feasibility of site development.

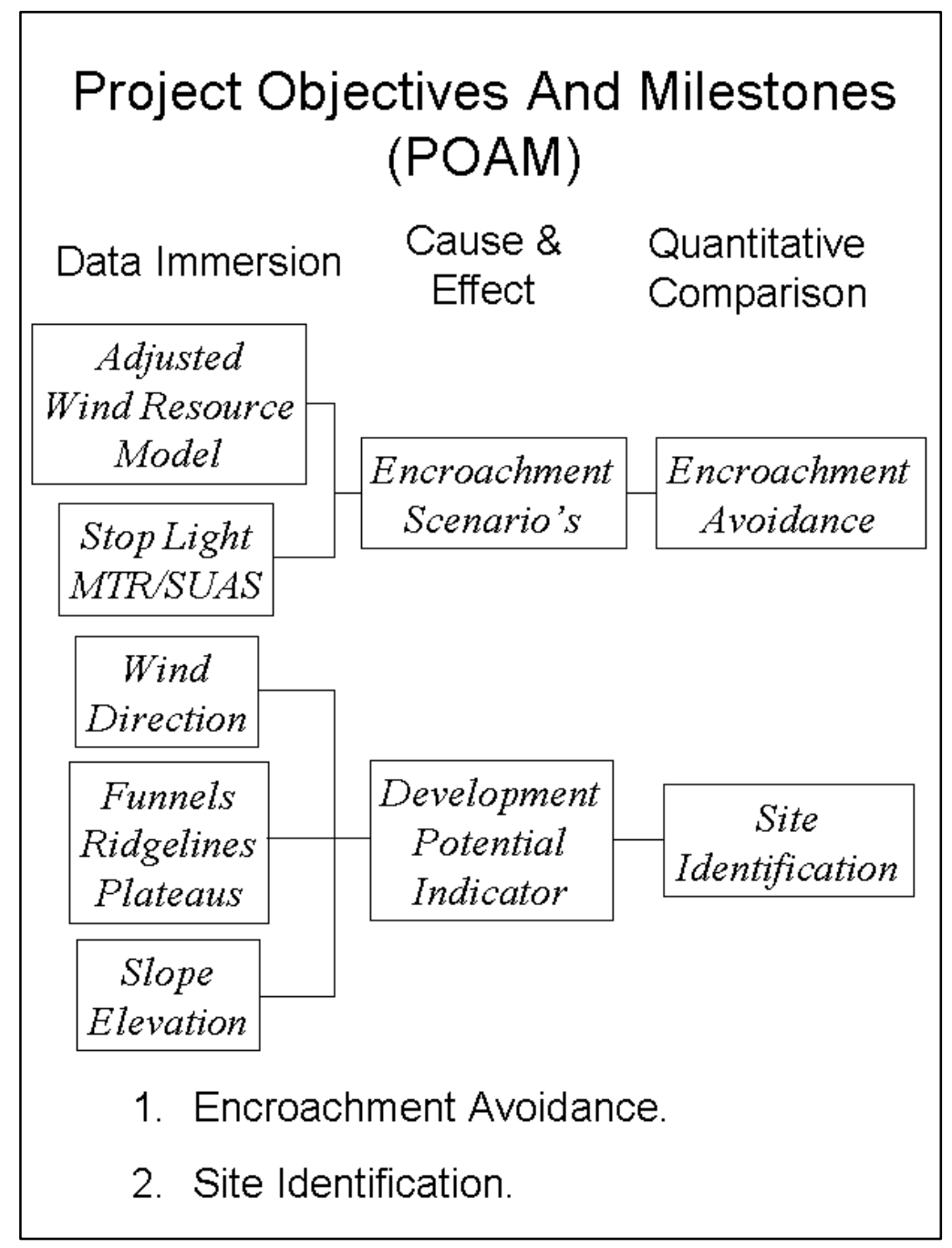

Figure 1-5. Phase-2 Analysis, Project Objectives And Milestones.

The geospatial phenomena selected for site-specific analysis are represented in the data immersion column of Figure 1-5, demonstrating the topographic features relevant to the development potential of a specific site, and at a resolution higher than phase one analysis. This approach is similar to the abstraction paradigms described in the BLM's environmental impact statement (US DOI BLM, 2005), and is an effective way to analyze possible encroachment scenarios. Ultimately, the insight gained from analyzing encroachment scenarios may enlighten policy makers (US DOI BLM, 2005, B.9).

The Hawthorne, Nevada, area was used to present these concepts as the prototype for analysis, demonstrating analytic techniques recommended for encroachment avoidance and site selection. Employing these analytic techniques, programmatically, will help 
avoid encroachment while reducing the economic risks associated with wind energy development, exploration, and investment.

\subsection{The Bottom Line}

This project provides value-added analysis to the BLM environmental impact statement related to military airspace and supports airspace management policy while providing risk-reducing analysis to client policy and the DoD Stoplight management scheme. This may inspire increased trust in the program and reduce risk to developers and investors. Giving policy a level of predictability and reliability is an important element in facilitating cooperation and cost effectiveness for developers and the federal government.

This project does not ignore the BLM analysis provided by the environmental impact statement but rather works past it, focusing on the topography vital to wind farm placement and the placement of wind turbines beneath military airspace. There are three reasons for this approach. First, the intent of this project is not to recreate or improve upon the BLM analysis. Second, this project worked around the BLM analysis in order to avoid dependency on the BLM policy or action. The reason for this is because if this project reduced encroachment potential, based on BLM management policy, and later, that policy changes, findings from this project would become invalid, rendering the findings of this project ineffective at protecting military training airspace from encroachment. Finally, if the BLM were to integrate this project into future analysis or policy, then keeping the analysis and subsequent findings independent, will make its integration, for BLM, less complicated. 


\section{Data Immersion and Object Abstraction.}

\subsection{Wind Resource Model.}

This section describes in greater detail the NREL's wind resource model, previously described in chapter 1.3. The wind resource model is an estimate of wind potential that visualizes geographic and spatial phenomena that affect the potentiality of wind. Those variables include: elevation, land and vegetation cover, soil moisture, and sea surface temperature (US DOE NREL, 2005 July). As demonstrated by the BLM maximum potential development scenario that employed the wind resource model and other geospatial phenomena relevant to BLM's environmental concerns, the wind resource model is only part of the final wind energy development potential model (US DOI BLM, 2005). The polygons that construct the wind resource model and the potential for wind development are not mutually exclusive. Development potential can also exist in the vicinity of the wind resource model where specific topographic features exist (D. Heimiller, personal communication, October 17, 2005). ${ }^{9}$

Under the direction of the NREL, AWS Truewind created a wind power density database using a numeric weather model called, Mesoscale Atmospheric Simulation System (MASS). The MASS is a low-resolution wind model, consisting of historical weather data, screened by geospatial variables such as, elevation, land and vegetation cover, soil moisture, and sea surface temperature. The final atmospheric model resolution was improved to one square kilometer by aggregating the MASS model with a higher resolution WindMap wind-flow model. The combination of MASS and WindMap data essentially created a wind resource map of simulated weather conditions for a 15 year period. For each day in the sample, the wind speed, direction, and weather variables such as temperature, pressure, and moisture were simulated at hourly intervals. The data was compiled and summarized to produce a mean wind speed and power density map at 30 and 50 meters AGL, respectively (US DOE NREL, 2005 July).

The NREL validated the WindMap model by comparing sampled data points with alternate wind data collected by the weather service, agricultural, transportation, and environmental agencies (US DOE NREL, 2005 July). Once validated, the WindMap model was used to produce the final model used in this project.

An important caveat related to the resolution of the final wind resource model used in this project is that the wind model was not intended for micrositing ${ }^{10}$ (US DOE NREL, 2005 July). The resolution was too low and the topography that would affect the wind potential at a specific site was not adequately assessed in this model. Additional wind testing is conducted during micrositing, after an area demonstrating wind development potential has been identified by the wind model (US DOE NREL, 1997).

\footnotetext{
${ }^{9}$ Donna Heimiller, a GIS analyst at the National Renewable Energy Laboratory, helped create the wind model.

${ }^{10}$ Micrositing is the process of placing meteorologic test equipment on a site to test the wind characteristics of the actual location. The wind model is used for general small scale queuing of wind potential while micrositing is the final determination of a desired site.
} 


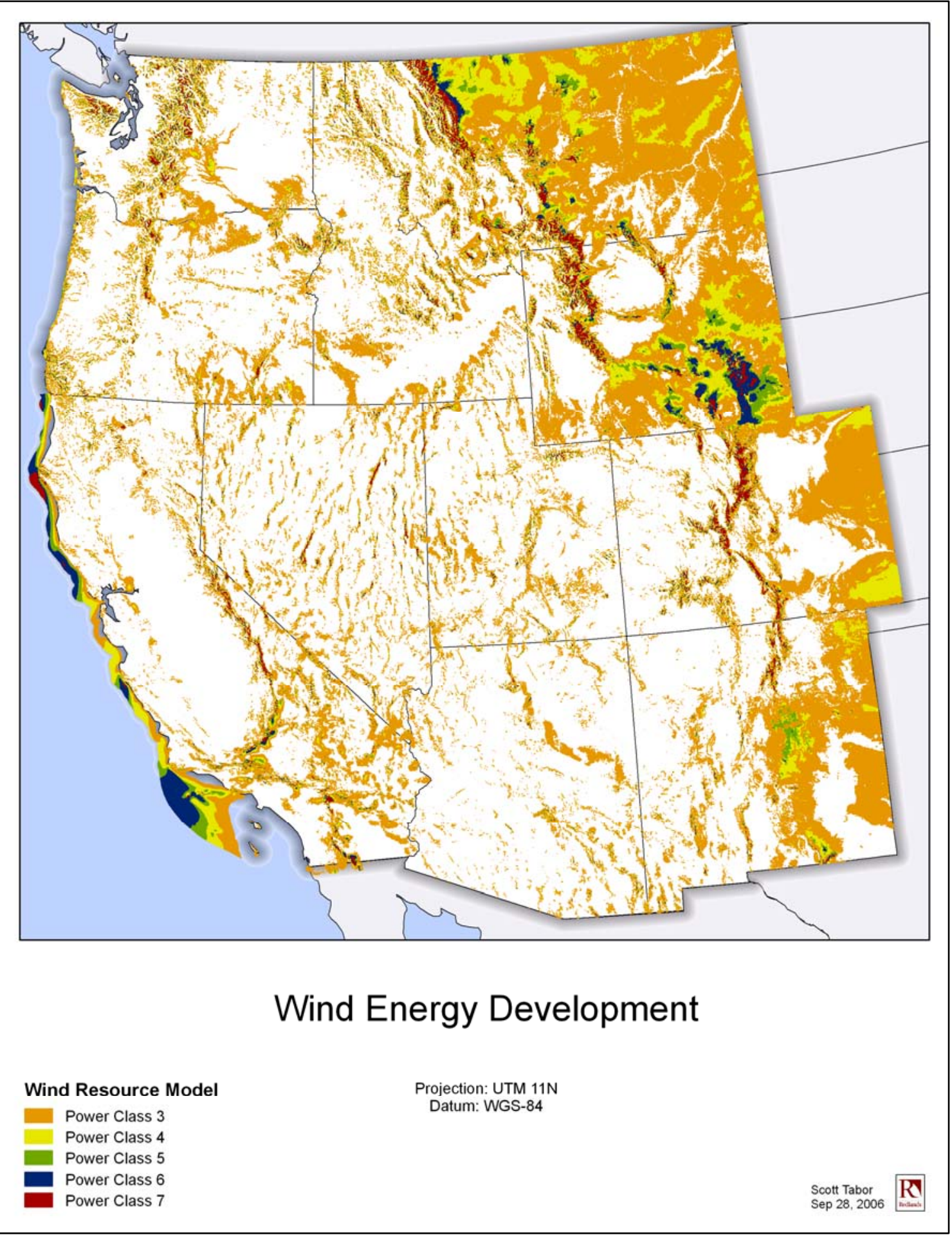

Figure 2-2. Wind Power Classes Displayed Across Eleven Western States. 


\subsection{Military Airspace.}

Although this project refers to the airspace of interest as military airspace, in actuality the airspace is administered by the Federal Aviation Administration, the government agency responsible for reserving airspace for the military pursuant to U.S. Code Title-14 law (Rex Maclean, personal interview, 2005). ${ }^{11}$

Military airspace across the study area consists of both military training routes and special use airspace. Military training routes are flight corridors (i.e., traffic lanes in the sky) that connect special-use airspace and are governed by planning rules to ensure coordination and airspace deconfliction that ultimately safeguards both military and civilian air traffic from air catastrophes.

Military training route geometry is defined by the left and right boundary descriptions provided within the Digital Aeronautical Flight Information Files (DAFIF), created by the National Geospatial-Intelligence Agency (NGA, 2006). ${ }^{12}$ These boundaries are also described in the AP-1B (US DoD FLIP AP-1B, 2005 March). In addition to other important flight safety data, AP-1B provides textual descriptions of minimum altitudes and operating instructions for all military training routes. It is the official source of route data for military flight operations (US DoD FLIP AP-1B, 2005 March). The left and right boundaries (i.e., the range the airspace extends out from either side of the centerline) of each training route centerline (polyline vector) are also provided in text format as a column of written distances in the attributes table of digital aeronautic flight information files.

Rules regulating military training route usage and management are detailed in the Department of Transportation's Federal Aviation Administration's Order 7610.4K, and Special Military Operations manual (United States Department of Transportation Federal Aviation Administration Order 7610.4K, Special Military Operations, 2004, February 19). This order specifies procedures for air traffic planning, and coordination for all military services (US DOT FAA Order 7610.4K, 2004). This order directs the amount of usage of military training routes to be kept to a minimum, with each route accommodating the maximum number of users and organizations determined by mission requirements, and authorized by higher echelon military command authority (US DOT FAA Order 7610.4K, 2004).

The geometry (i.e., length, width, and height) of military training airspace within the western states study area is a balanced network of coordinated and deconflicted airspace involving over forty military and civilian agencies and organizations (Personal communication, Rex Maclean, 2005, October 25). ${ }^{13}$ According to the Federal Aviation Administration's Western Terminal Operations office, changes in military training routes do not occur very often, not in several years; and, traditionally, only when the needs of an originating unit require it in support of that unit's training mission (Personal communication, Debra Trendle, 2005, October 24).

\footnotetext{
${ }^{11}$ Rex Maclean is the Federal Aviation Administration representative to Naval Air Station Fallon.

${ }^{12}$ The DAFIF data base is provided in a shape file format specifically for GIS cartographic and analysis support.

${ }^{13}$ Rex Maclean is the Federal Aviation Administration representative to the Naval Air Station Fallon.
} 
Coordinating and resolving military training routes with minimum altitude changes is a rigorous venture involving numerous military and civilian aviation organizations. As illustrated in Figure 2-3, the modification of a single military training route could easily affect a multitude of other military and civilian organizations. Altering military training routes can be costly, too. Among other publications requiring a rewrite or modification are the National Flight Data Digest, Department of Defense Flight Information Publications, Aviation Publication One Bravo, Aeronautical Charts; and changes to the Aeronautical and Published Information Manuals would require reprint and dissemination (US DOT FAA Order 7610.4K, 2004).

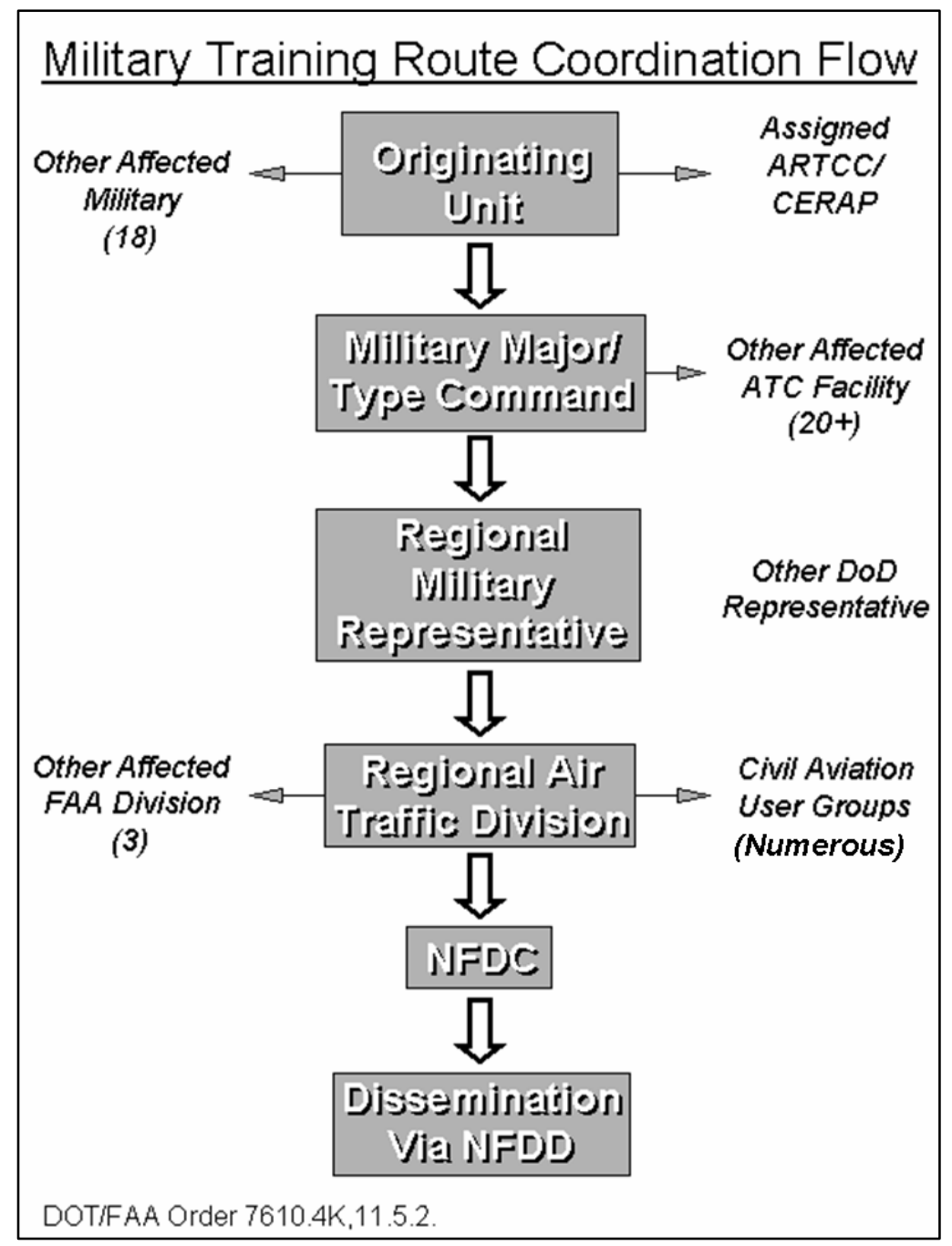

Figure 2-3. Military Training Route Coordination Dichotomy.

Because originating units are already operating with the minimum amount of military training route airspace, the opportunity to change existing airspace in support of wind energy development is low. Furthermore, the likelihood of a military unit risking the loss of military training route airspace by yielding to wind development is negligible (Personal communication, Rex Maclean - FAA, November, 2005). 
Special-use airspace is also a feature subset of the flight information file. Special-use air space is military airspace reserved for operations outside of the positive air traffic control area. This separation is enforced in order to separate potential hazardous military operations from other military and civilian instrument and visual flight traffic (United States Navy Fallon Range Training Complex User’s Manual, 2003, November 19).

There are two varieties of special-use airspace: regulatory and non-regulatory. Regulatory is essentially airspace restricted solely to military operations, whereas nonregulatory special-use airspace (i.e., military operating areas) is open to civil air traffic (United States Department of Transportation Federal Aviation Administration, Order 7450.1, Special Use Airspace Management System, 1999, June 21).

Because special-use airspace geometry (i.e., length, width, and height) would be less difficult to change in some cases, wind development could occur within special-use airspace without affecting the military aviation-training mission. That said, military commanders are less likely to allow this sort of encroachment before the areas presenting wind development potential outside of military airspace are exhausted (Personal communications, Captain Scott Ryder, 2005, November 30).

The areas left and right of military training route center lines, and the area within the boundaries of special-use airspace are only two of three spatial considerations that aviators use to plan for safe airspace navigation (i.e., the horizontal geometry, altitude, and time). Adhering to the horizontal geometry of military airspace is critical to aviation safety. Altitude is an important component of military airspace that requires analysis in a later phase of this project.

The geographical visualization of military training route and special use airspace geometry (Figure 2-4) is in itself an analytic technique, revealing in a glance the geospatial magnitude of military training airspace. ${ }^{14}$

As in the case with the wind resource model, the area and dispersion of military training route and special-use airspace are geospatially relevant to GIS analysis. The dispersion of military airspace is not constant across the study area. Military airspace components including left and right boundaries, route heading, minimum altitude, false deck, dispersion across the study area, and concentration - are the geospatial characteristics of military training route and special use airspace. ${ }^{15}$ These geospatial observations are related and are the topic of GIS analysis and quantitative comparison in a later stage of this project.

\footnotetext{
${ }^{14}$ After geographically visualizing airspace for the Joint Military Affairs Committee (August 18, 2005), Bureau of Land Management decision makers were surprised by the amount of military airspace in the eleven state study area.

${ }^{15}$ False deck is an operational risk management paradigm discussed in preceding analysis.
} 


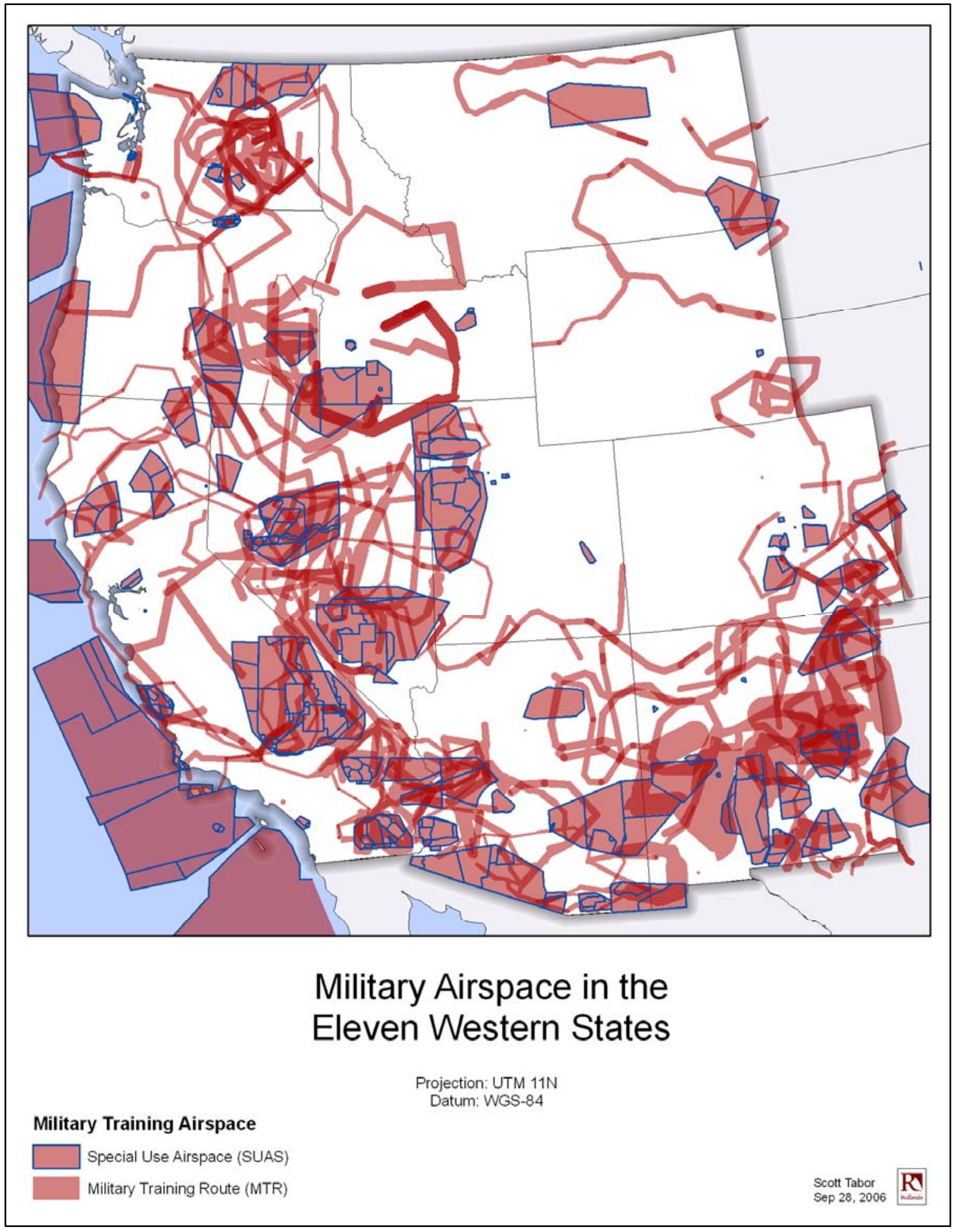

Figure 2-4. Military Airspace in the Eleven Western States. 


\subsection{Wind Turbine Vertical Obstruction Zone (WTvoz).}

In the wind energy industry, taller wind turbines are better (Livingston, 2004). Wind is more prevalent at higher altitudes above ground level (Livingston, 2004). Called wind sheer by the wind energy community, the meteorological phenomenon in which wind speed increases with height is the principal reason that wind turbines are getting taller (Livingston, 2004). The industry response to this is to build wind turbines taller, by extending the rotor and blades further from the ground. Industry experts agree on the trend to use taller towers for optimal energy production, and attest that wind turbine heights will likely reach one hundred fifty meters, 492 feet, within the bounds of current technology (Thresher, 1998).

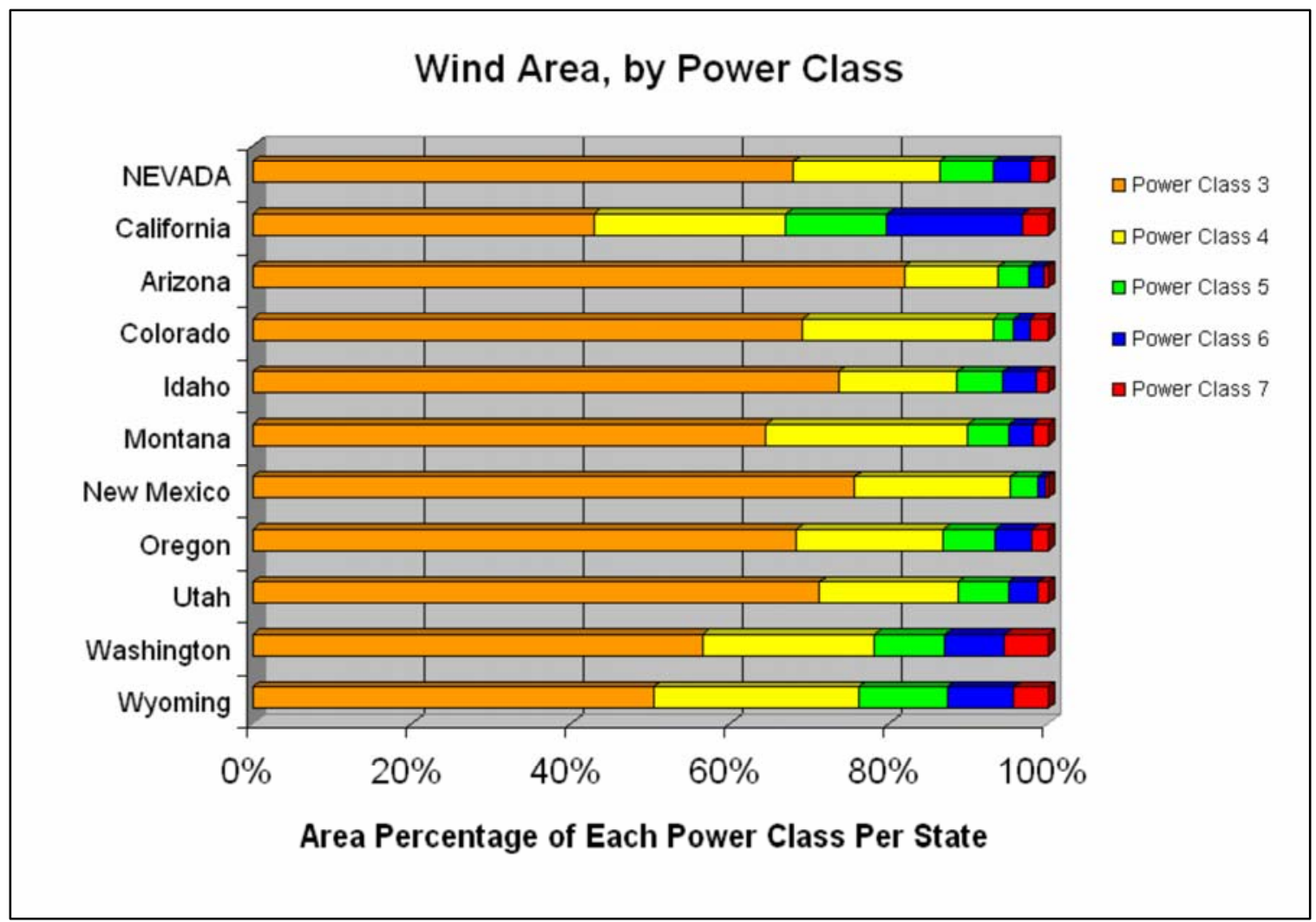

Figure 2-5. Power Class Per State.

In areas of lower wind power class, BLM and DoD managers can expect to see wind turbines with greater heights being utilized due to the need for turbines with larger rotor swept area (BLM, 2005). A larger swept area converts the kinetic energy of the wind into rotation more efficiently (BLM, 2005). For example, the Vestas V90 (2.0 and 1.8 Megawatt turbine) employs a newly designed aerodynamic blade measuring forty-four meters (144 feet) that can catch more wind in low wind areas, making the turbine more efficient and, making the height of the turbine, from base to its vertical blade tip, 132 meters (433 feet) tall (Vestas, 2003). Although wind power class is a vector more relevant to site-specific analysis, analysis of the entire study area is provided (see Figure 
2-5), lending additional argument to the wind industry's trend towards taller wind turbines.

In particular, this analysis demonstrates the likelihood of taller turbine utilization in areas with a predominantly low wind power class, such as Nevada. Figure 2-6 demonstrates both geospatially and statistically the abundance of power class three and four in Nevada.

In collaboration with these findings, the Desert Research Institute (DRI), the leading research institute for exploring techniques to identify wind farm site selection in Nevada, have also assessed the need for taller wind turbines. Their site-selection plan is focused on developing methods of site identification for emerging wind generation technology called Low Wind Speed Turbines (LWST), which is a wind turbine system that uses very tall towers with enormous blades that rotate at much slower speeds (Desert Research Institute, 2003). In the study area, for example, wind power classes three, four, five, six, and seven comprise $62 \%, 19 \%, 6 \%, 5 \%$, and $2 \%$ of the wind development potential, respectively.

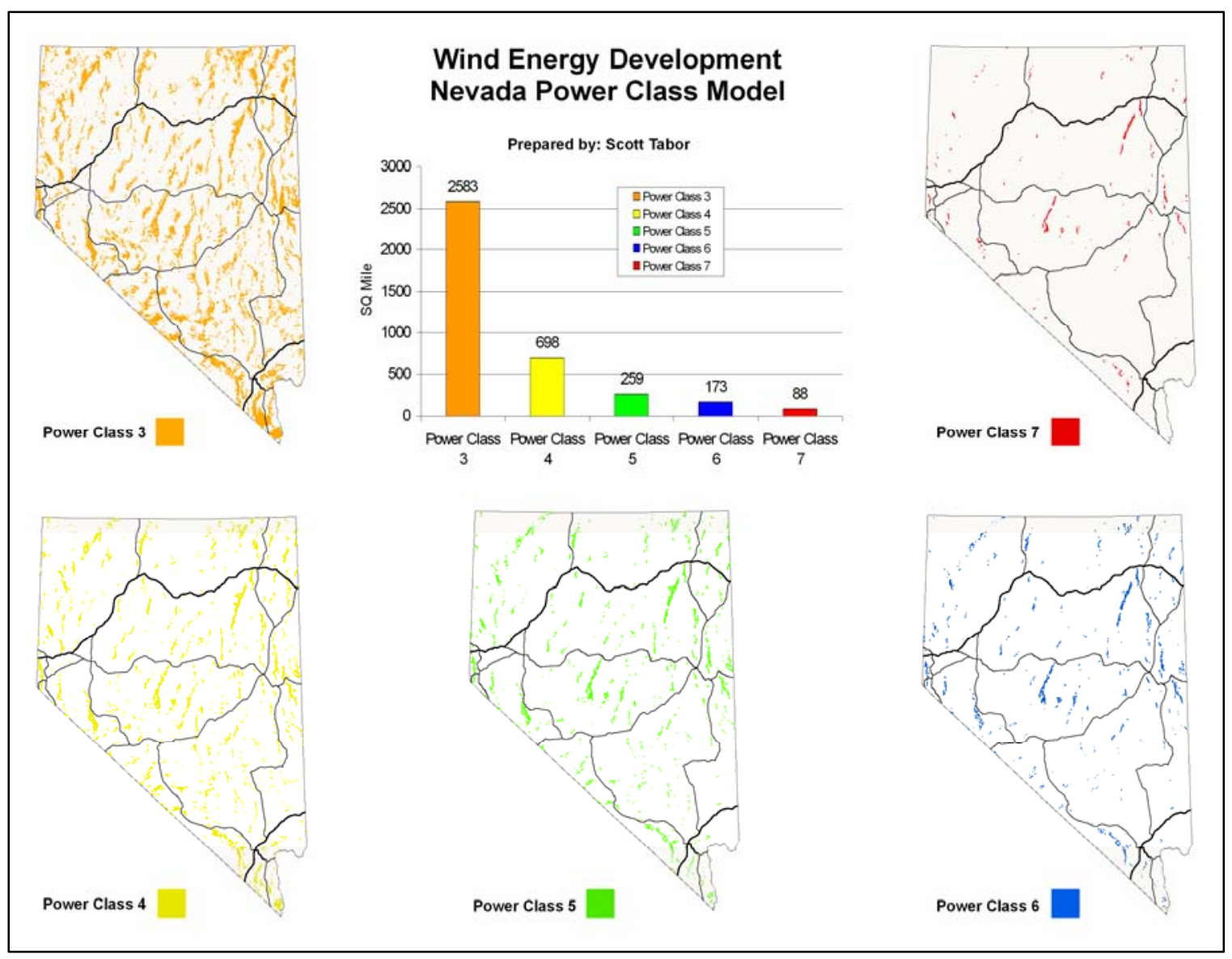

Figure 2-6. Nevada Wind Power Class Statistics. 
The data illustrated in Figure 2-6 suggests that encroachment managers of military airspace, concerned with turbine heights, should plan for the taller end of the turbine height spectrum in future wind development projects. ${ }^{16}$

In anticipation of pressure by the industry to use taller turbine towers, the logic of this project's calculation of a wind turbine vertical obstruction zone is based on the established wind turbine technology average, combined with published and forecasted heights (US DOE NREL, 2002). The heights associated with newer wind projects, coupled with the anticipated use of taller towers in future projects, and the need to use taller towers in the vicinity of lower wind power classes, give cause to this project to estimate the potential wind turbine height at 150 meters or 492 feet (US DOI BLM, 2005).

Most military training operations employ a 100 foot "false deck" concept of operation (i.e., $\mathrm{WT}_{\mathbf{v o z}}+100 \mathrm{ft}$ ) in order to minimize the risk of collision with vertical obstructions (S. Ryder et al., personal communication, September 6, 2006). The false deck concept is a flight safety related risk management paradigm within the military aviation community. Adding an additional 100 feet to minimum flight altitudes (illustrated in Figure 2-7) essentially adds an additional 100 feet to the heights of vertical obstructions (published in Aviation Publication One-Bravo), and low flying aircraft (US DoD FLIP AP-1B, 2005 March). Therefore, in light of the "false deck" requirement, the wind turbine vertical obstruction zone (WT $\mathrm{Voz}+100 \mathrm{ft}$ ) was increased to 180 meters (592 feet AGL, rounded up to $600 \mathrm{feet}$ ) in order to accurately characterize the geospatial relationship between the height potential of wind towers and the minimum altitudes of military training airspace.

\begin{tabular}{|l|l|}
\hline Heights associated with newer wind \\
towers coupled with the anticipated \\
use of taller towers in future projects, \\
and the need to use taller towers \\
near low wind power class, \\
established a maximum \\
potential wind turbine \\
height of 150 meters \\
(492 feet). \\
Military training operations \\
employ a 100 foot false \\
deck concept of operation, to \\
mitigate the risk of collision with \\
vertical obstructions. Therefore, the \\
wind turbine vertical obstruction zone \\
was increased to 180 meters (592 feet), \\
actual ground level.
\end{tabular}

Figure 2-7. Wind Turbine Vertical Obstruction Zone Orientation and Perspective.

\footnotetext{
${ }^{16}$ Study area power class percentages were extracted from the attributes of the wind model provided by NREL.
} 
Table 1-1, further illustrates the heights wind turbines can achieve (Organization for the Promotion of Energy Technology, 2004). The GE 3.6 megawatt and Vestes 3.0 megawatt wind turbine are land based wind turbines, whereas the remaining are offshore turbines. Offshore turbines are able to achieve greater heights because they do not share the same logistical limitations that on shore wind farm instillations encounter (discussed further in chapter 3).

Wind turbines and their mamufacturers in the $3 \mathrm{MW}+$ market segment (Source: Energimagasinet, 5/2003)

\begin{tabular}{|c|c|c|c|c|c|c|c|}
\hline Manufacturer & $\begin{array}{c}\text { Capacity, } \\
\text { MW }\end{array}$ & $\begin{array}{c}\text { Turbine } \\
\text { diameter, } \mathrm{m}\end{array}$ & $\begin{array}{l}\text { Est Height } \\
\text { Base-to-Tip }\end{array}$ & $\begin{array}{c}\text { Swept area, } \\
10^{3} \mathrm{~m}^{2}\end{array}$ & $\mathrm{~kg} / \mathrm{m} 2$ & Prototype & $\begin{array}{c}\text { Series } \\
\text { production }\end{array}$ \\
\hline Enercon & 4.5 & 112 & $180 \mathrm{~m}(540 \mathrm{ft})$ & 9.8 & 51 & 2002 & 2004 \\
\hline GEWind Energy & $\Leftrightarrow 3.6$ & $104 \Longleftrightarrow$ & $150 \mathrm{~m}(492 \mathrm{ft})$ & 8.5 & 33 & 2002 & 2003 \\
\hline Nordex & 5.0 & 115 & $173 \mathrm{~m}(565 \mathrm{ft})$ & 10.4 & - & 2004 & - \\
\hline NEG Micon & 4.2 & 110 & $\underline{165 \mathrm{~m}(541 \mathrm{ft})}$ & 9.3 & 23 & 2003 & 2005 \\
\hline PROKON & 5.0 & 116 & $174 \mathrm{~m}(571 \mathrm{ft})$ & 10.6 & 27 & 2004 & 2006 \\
\hline REPower & 5.0 & 125 & $187 \mathrm{~m}(615 \mathrm{ft})$ & 12.1 & 29 & 2004 & 2005 \\
\hline Vestas & $\Leftrightarrow 3.0$ & $90 \Longleftrightarrow$ & $135 \mathrm{~m}(442 \mathrm{ft})$ & 6.4 & 16 & 2002 & 2004 \\
\hline WinWinD & 3.0 & 91 & $137 \mathrm{~m}(448 \mathrm{ft})$ & 6.5 & 23 & 2004 & 2005 \\
\hline
\end{tabular}

The Organization for the Promotion of Energy Technologies -OPET Network-, is an initiative of the European Union that aims to promote public awareness of current energy research through a new and challenging series of activities.

Table 2-1. Turbine Generator Heights

Appendix B provides a photo tour of wind farms, currently operating around the world. Although none of these images reflect the heights achieved by the 3+ megawatt turbines, these images visualize the heights of modern wind turbines and help illustrate the logistical challenges in a more realistic and comprehensible manner.

\subsection{Topography.}

Utilizing the subject matter expertise of the NREL and select members of the National Wind Technology Center (NWTC), this project adopted the same wind screening criteria developed at the 2002 wind screening criteria development meeting that was held in support of the BLM environmental impact statement (US DOI BLM, 2003). Some criteria were not relevant to this project and were not used.

The relevant criteria adopted, in their order of importance, were as follows: wind resource classes three through seven, paved road access within 50 miles $(80 \mathrm{~km})$, and transmission access within 25 miles $(40 \mathrm{~km})$, of the development site. Additionally, the preferred elevation range is 3,000 (914m) to 4,500 (1372m) feet, not exceeding 7,000 $(2,134 \mathrm{~m})$ feet (i.e., mean sea level), and topographic grades of no more than $14 \%$ (i.e., eight degrees) in the areas leading into the development site (US DOI BLM, 2003). At their meeting in 2002, the screening committee responsible for choosing the relevant geospatial phenomena did not consider military airspace because it was not relevant to the BLM's impact statement. For this project, however, military airspace is the 


\section{paramount screening variable used to study the geospatial dynamics of wind energy development in the study area.}

The principal driving force behind the 25 and 50 mile distance requirements to electric power transmission and paved roads, respectively, is economics (US DOI BLM, 2003). The economic law of diminishing returns, simply stated, demands that the value of a developed wind turbine site, measured in electric power generation capacity and electric power market conditions, be more than the costs related to building it (United States Department of Energy, Energy Information Administration [US DOE EIA], 1998).

Wind farm developers absorb the costs of connecting wind turbine generators to the nearest existing transmission grid (US DOE EIA, 1998). While transmission costs tend to be approximately $2 \%$ of a wind farm's operating and maintenance costs, they typically represent $12 \%$ of the budget while in service (US DOE EIA, 1997). Expenses associated with transmitting electricity are typically related to the distance electricity is transmitted, the amount of electricity transmitted, and the amount of capacity reserve (US DOE EIA, 1998). What also compound transmission costs are the wind energy sites which tend to be further away from the existing grid, an ironic spatial condition given its relation to the remoteness of wind potential (US DOE EIA, 1998).

Albeit secondary to electric power transmission, the laws of diminished returns also apply to roads. The larger the road, the more road construction will cost. Typically, roads leading into the site are 10 to 30 feet wide in order to accommodate the large turning radius of a heavy equipment transporter (US DOI BLM, 2005). The eight-degree site ingress grade requirement is also related to road construction costs. Heavy equipment transporters can typically haul heavy loads on a grade up to eight degrees without assistance from tow-trucks (Vestas, 2004). In areas exceeding optimal slope conditions, roads are built to skirt the topography with switchbacks (see figure 2-8) winding up the grade into the site.

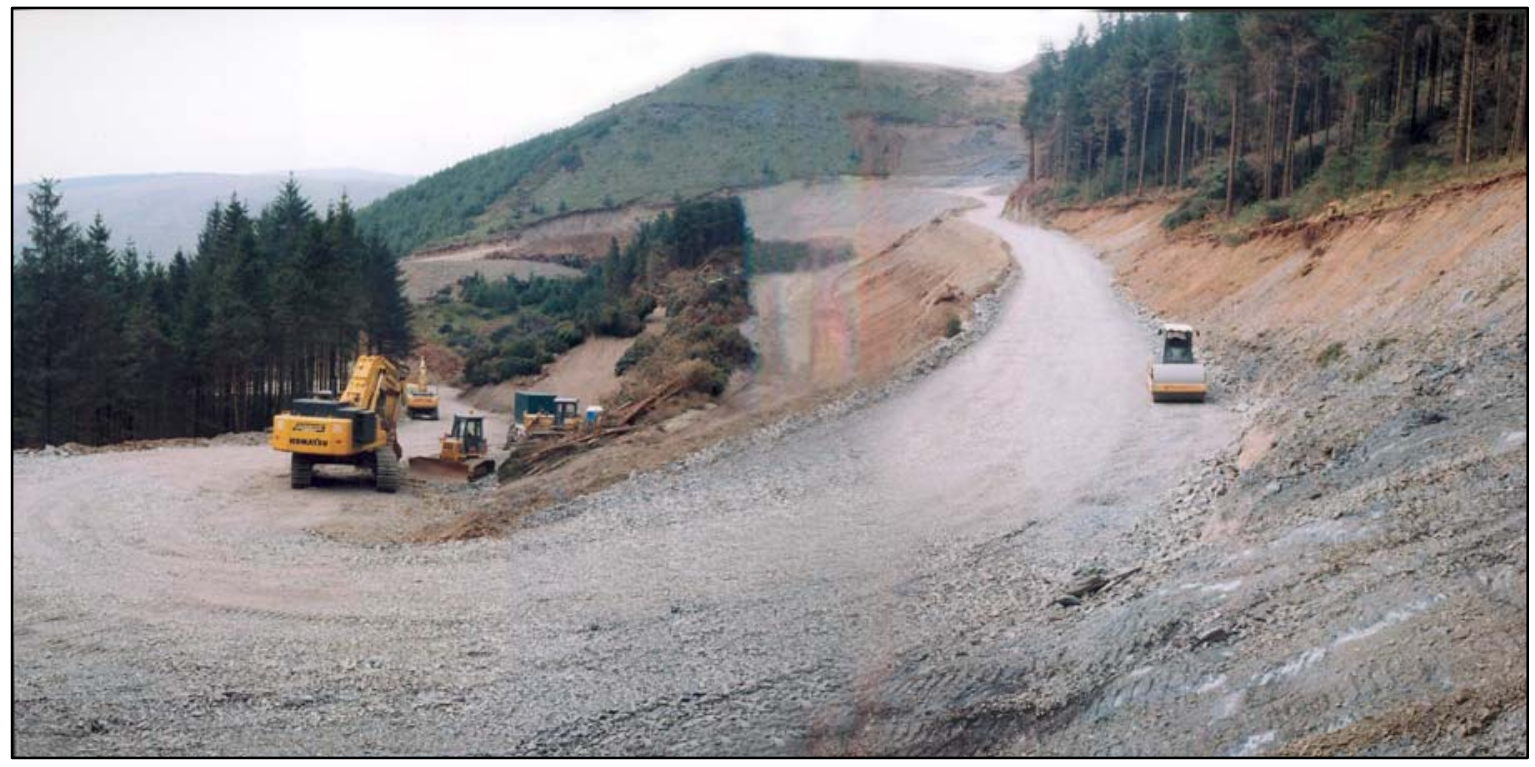

Figure 2-8. Switchbacks on Steep Slopes (Dorset, n.d.). 
Excessive slope translates into increased site construction costs associated with additional road construction (US DOI BLM, 2005). For example, Vestas, a major wind turbine producer builds a turbine that weighs 383 tons, when assembled. Unassembled, each tower section (or nacelle) weighs up to 68 tons, and each nacelle requires a dedicated heavy equipment tractor and trailer for transport to the equipment to the site for assembly (Vestas, N.D.). In addition to the actual turbine parts, support equipment needed for assembling the turbine assembly have significant transshipment requirements. Assembling the turbine on-site requires large specialized cranes requiring 15 to 50 truck loads (US DOI BLM, 2005).

Site-specific topographic features that favor wind energy development are: first, ridgelines that are oriented perpendicular to the prevailing wind direction; second, locations within an area with the highest elevation; and, finally, locations where topography is configured in a way that will funnel wind. Features to be avoided include areas immediately up or down wind of higher terrain, the leeward side of ridgelines, and excessively sloped terrain (US DOE NREL, 1997).

Elevation is a variable related to wind development that must be considered in the proper context. Although the subject matter experts on wind energy from the NREL and the NWTC say that the elevation of the site must be less than 7,000 (2134m) feet, this measure of 7,000 $(2134 \mathrm{~m})$ foot ceiling is a general rule of thumb for a small scale, areawide analysis. Sites at elevations greater than 7,000 (2134m) feet have been developed; however, other relevant variables were at play.

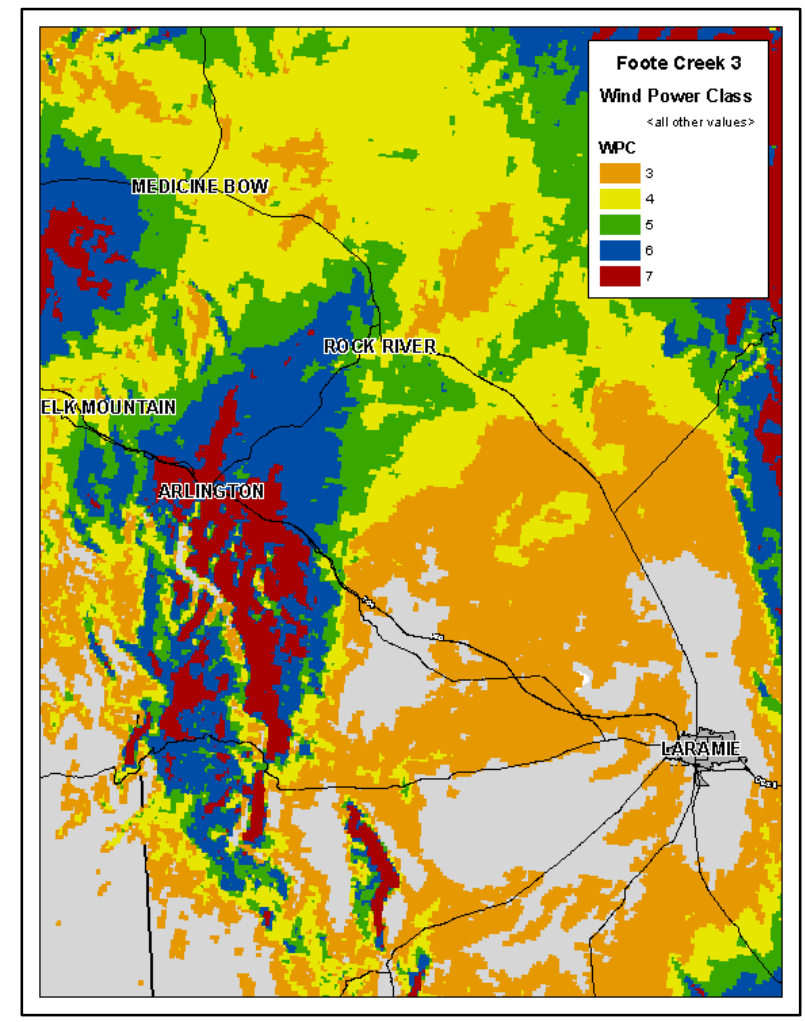

Figure 2-9. Foote Creek III Wind Farm in Arlington Wyoming. 
For example, the Foote Creek project in Arlington, Wyoming (Figure 2-10), approximately 50km Northwest of Laramie, Wyoming), is a wind farm of 33 NEG Micron Multipower-44 turbine generators. The elevation at the site is above 7,500 (2286m), feet and the air density is very low (American Wind Energy Association, n.d.).

The reason elevation is relevant to wind development is based on physics. The power available in wind is directly proportional to air density (Gipe, 2000). Since air density decreases at higher elevations, a wind turbine's ability to convert wind energy to rotate the blades and turn the rotor, which in turn runs the electric generator, is reduced.

There are two mechanical variables that can be manipulated to compensate for the loss of air density. The first variable would be to increase the wind speed by putting the turbine on higher ground where the wind is stronger and more stable, or in areas with a higher wind power class. The second variable would be to employ rotor blades with a larger swept area that will improve the efficiency and conversion of wind energy into rotor thrust (US DOE NREL, 2005).

The additional relevant factors supporting the development of Foote Creek, in light of the high elevation, are that Foote Creek is located in a high wind power class area, with an average annual wind speed of 23 miles (37km) per hour, (e.g., see Figure 2-9). Moreover, the topography of the surrounding terrain is flat, where the Great Divide Basin begins to descend into the Great Plains. The additional wind power and flat surrounding terrain compensate for the high elevation. Foote Creek's vicinity to paved roads and electric power grid also made the wind farms location economically feasible.

\subsection{Data Immersion and Object Abstraction Findings.}

Through data immersion and vector transformation, this project characterized the wind resource model, as not only a reliable model of wind potential power class vectors, but also identified its vertical characteristic that was critically relevant to this project. This was found within the wind turbine vertical obstruction zone. The wind turbine vertical obstruction zone is important to this project because it spatially characterizes the predicted heights of wind development, which is the principal-disqualifying factor of a development site because excessive turbine heights impact military airspace minimum altitudes.

With the aid of geographic visualization and data immersion, military airspace was divided into military training route and special use airspace polygons. A distinction between the two variables was identified by assigning a level of importance to military training routes, characteristic of its mission and shortages, and giving it priority over special use airspace and wind resource vectors. Regardless of type, however, this project assumes that wind development potential will not be the catalyst to effect a change in military training airspace geometry.

Finally, experts in wind energy identified spatial preferences related to the economic feasibility of a development site. Distance from paved roads and electric power transmission are relevant spatial limitations that can easily be converted into vector format and factored into a site-specific spatial analysis. The elevation and slope of the topography were also noted as being economically related to wind energy development. Although experts clearly identified the limitations of elevation and slope, these 
limitations, nevertheless, had to be observed and considered in the context of the immediate surrounding area and were, therefore, relevant to analysis and quantification. However, they required a follow-up observation and consideration in site-specific analysis.

Airspace managers from the FAA and DoD are executing their airspace management responsibilities under the premise that the military training airspace allocation is proportionate to the military training mission. Thus, in the remainder of this analysis this project assumes that wind energy development would not achieve the necessary momentum to effect changes to military airspace.

This project does not intend to improve the analysis of these topographic features already provided by the BLM environmental impact statement. The topographic features described in this phase of the analysis, which were analyzed in preceding phases, are relevant to the cohesion and transition from area-wide to site-specific analysis. 


\section{Cause and Effect Observation.}

In this chapter, the relevant geospatial phenomena identified in Chapter Two are analyzed to assess their physical relationship. As discussed in Chapter One, identifying the cause of the problem will yield valuable insight, providing direction as to how wind energy exploration and policy development should proceed.

\subsection{Vertical Obstruction Zone vs. Military Airspace Geometry.}

The overall geometry of military airspace was adjusted to reflect the wind turbine vertical obstruction zone, changing the overall airspace model to include only those airspace vectors with a minimum altitude of 600 feet AGL (i.e., 180 meters) or less. This is based on the assumption that the DoD and BLM managers adopt the wind turbine vertical obstruction zone, stemming from research and findings described in Chapter Two.

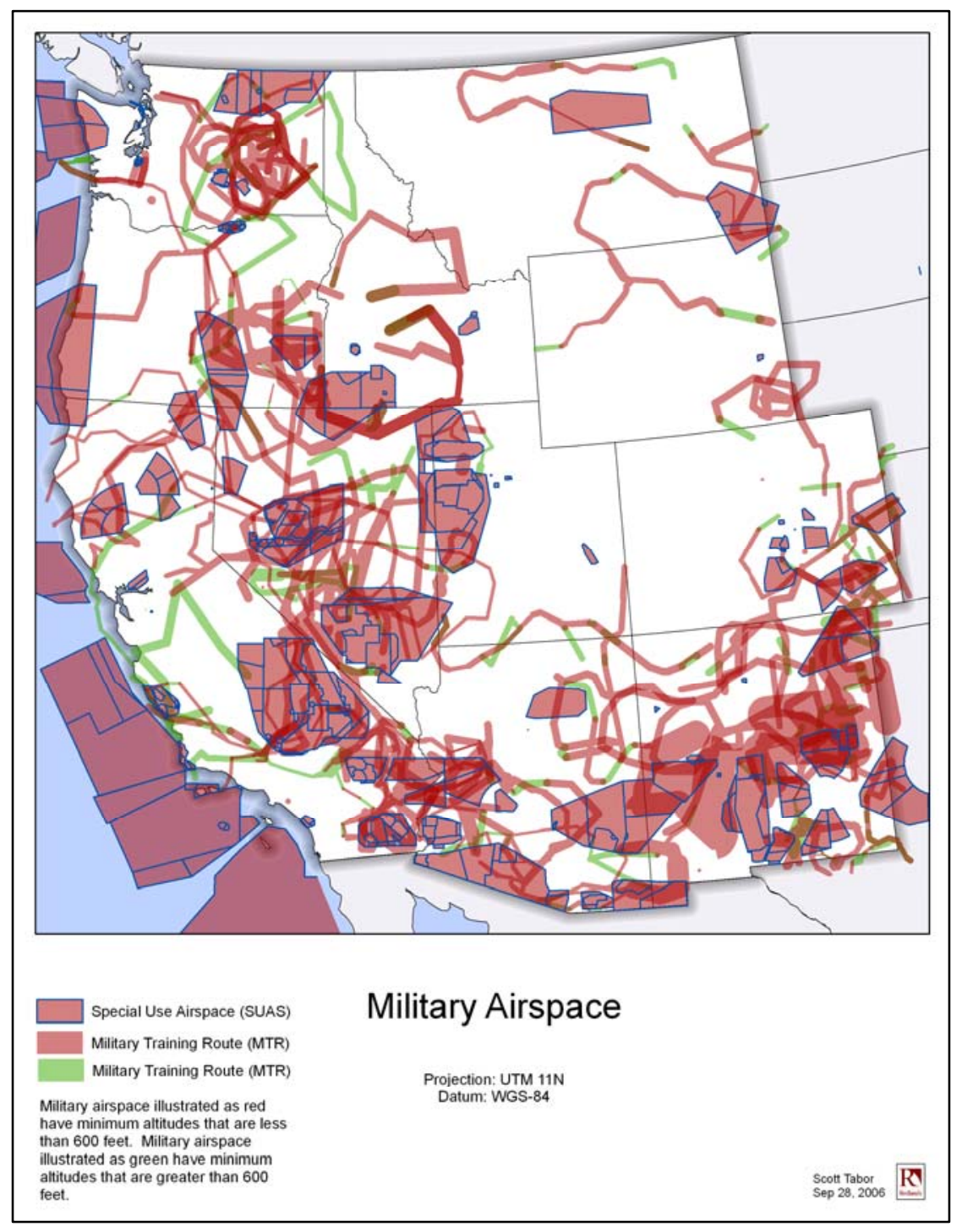

Figure 3-1. Effects of Wind Turbine Vertical Obstruction Zone. 
Figure 3-1 illustrates how military airspace, affected by the wind turbine vertical obstruction zone, will present itself across the study area. The areas colored red are military airspace vectors with a minimum altitude of 600 AGL $(180 \mathrm{~m})$ feet or less. In total, the wind turbine vertical obstruction zone affected $92 \%$ of the total military airspace model. The areas color-coded green are the remaining $8 \%$ of the military airspace model not affected by the wind turbine vertical obstruction zone.

\subsection{Vertical Obstruction Zone vs. Stoplight Management Schema.}

In lieu of specific military airspace analysis in the wind power class model and environmental impact statement, regional military commanders have adopted the "StopLight, Red, Yellow and Green color-coding of training routes as the primary management and vertical deconfliction schema. ${ }^{17}$ The stoplight schema was developed by the Kern County political leadership in California, having jurisdiction over private land use in the effected area, based on lessons learned from development that had already taken place (D. M. Brasher, personal communication, November 14, 2005).

Employing the current vertical obstruction values of the stop-light schema to Nevada's airspace, as demonstrated in Figure 3-2 (left), military training routes color-coded green have a minimum altitude greater than 400 feet $(122 \mathrm{~m})$ from actual ground level, and only require prior notification of proposed wind energy action for review and comment from the right-of-way adjudication authority (D. M. Brasher, personal communication, November 14, 2005). Military training routes color-coded yellow have a minimum altitude greater than 200 feet $(61 \mathrm{~m})$ from actual ground level. Military commanders feel that any wind energy related action in this airspace represents a significant concern regarding its impact on safety and training operation (D. M. Brasher, personal communication, November 14, 2005). Military training routes and special use airspace color-coded red have a minimum altitude less than 200 feet $(61 \mathrm{~m})$ from actual ground level. Military commanders also feel that any wind energy related action in this airspace represents a significant concern on its impact on safety and training operation (D. M. Brasher, personal communication, November 14, 2005).

Adjusting the values of the stop-light schema to the height value of the wind turbine vertical obstruction zone (i.e., 600 feet / 183m AGL), as demonstrated by Figure 3-2 (right), and in comparison to Figure 3-2 (left), all yellow routes turn red, as do several green routes. The visualization of the airspace affected by the vertical obstruction zone clearly demonstrates the geospatial relationship between potential wind turbine heights and military training airspace, and its effect on the stoplight management schema.

Based on the long-term considerations of this analysis project and the establishment of a wind turbine vertical obstruction zone, all training routes with minimum altitudes of 600 feet $(183 \mathrm{~m})$ or less were assigned the code red. Clarified by GIS analysis, these graphics reinforce the need to have geospatial analysis of military airspace and encroachment mitigation options programmed into the BLM environmental impact statement.

\footnotetext{
17 The Naval Air Station Fallon staff met to review and discuss, among other issues, the employment of the Kern County California “Stop-Light” airspace management schema in support of Nevada wind energy development, in preparation for the 18 August, Joint Military Affairs conference, [10 August 2005], Headquarters, Naval Air Station Fallon, Nevada.
} 

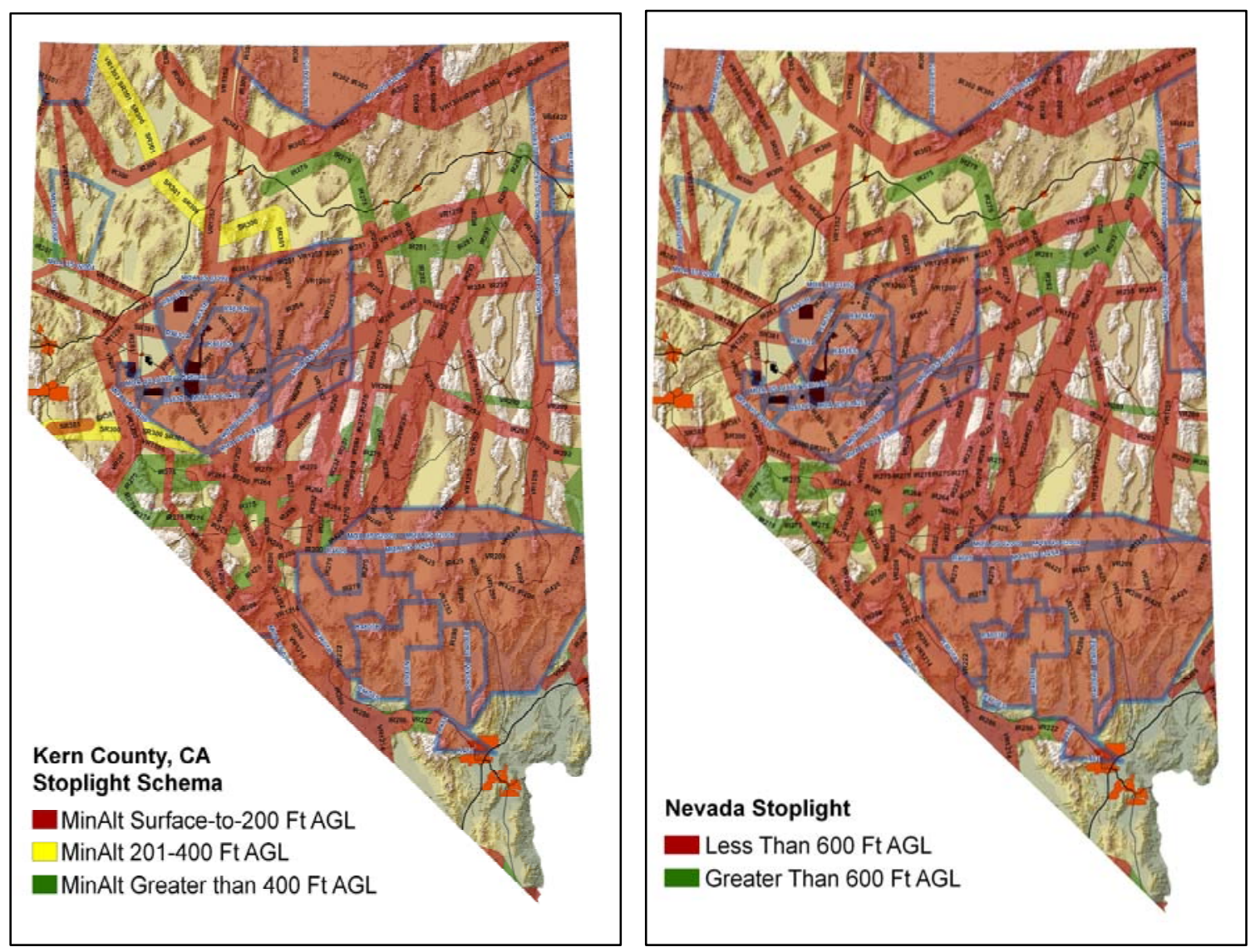

Figure 3-2. Stoplight Management Standard.

\subsection{Wind Resource vs. The Revised Military Airspace Model.}

During data immersion and vector transformation analysis, wind power classes three through seven were identified as power classes with development potential using current technology. Based on that insight, wind power classes three through seven were extracted into their own shape file in order to isolate only the power classes assessed to have enough potential for the twenty-year life span of the Bureau of Land Management's environmental impact statement (US DOI BLM, 2005).

Visualizing geographically the military training route and special use airspace aggregates and the wind resource model vectors together (see Figure 3-3), it becomes abundantly clear to what extent the wind resource model will affect military airspace. This observation alone, however, does not substantiate the geospatial relationships between the wind resource model, and the military training route and special use airspace models.

Based on insight gained from data immersion (i.e., the likelihood of not changing military training route geometry), further distinction between military training routes and special use airspace in this and preceding phases of analysis is required. Statistically segregating the models across the study area will support a more in-depth investigation of their physical relationships, and the dispersion and concentration of the military training route 
and special use airspace models in comparison to the wind resource model. In order to achieve the desired additional understanding, a random intervening vector is spatially introduced, and its physical relationship with the wind resource model and the military training route and special use airspace models is observed (Balding, 2002).

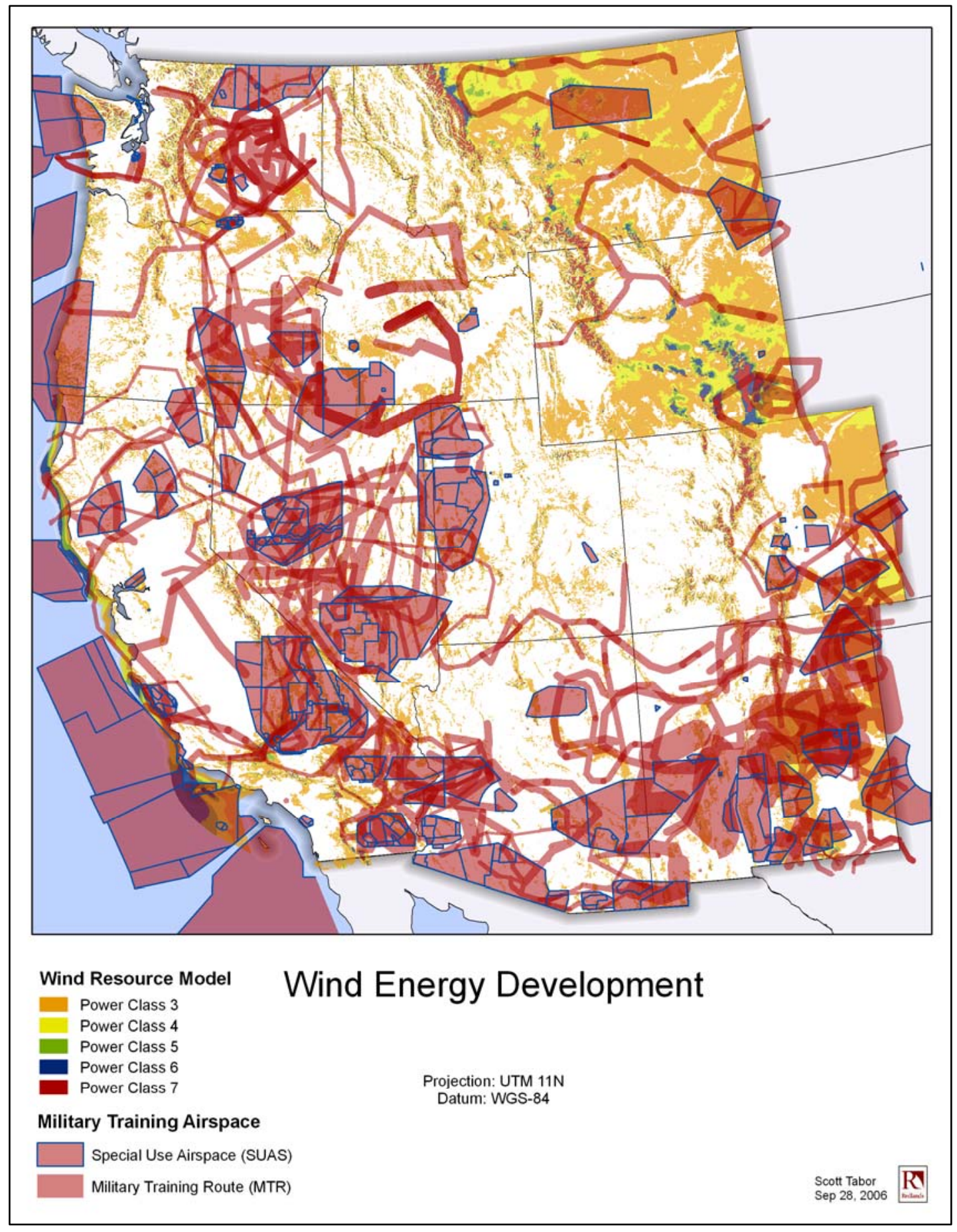

Figure 3-3. Wind Resources vs. Military Airspace. 


\subsection{Multivariate Observation, Indicating Encroachment Potential.}

Multivariate observation is a study of the vulnerability of the military airspace vector across the 11 western states study area. The multivariate observation is the spatial convergence of wind power class model and the models that comprise the total military airspace model (i.e., special use airspace and military training route airspace models) within each state in order to spatially characterize the threat of encroachment in each state. The study is based on the idea that you can measure how much two geospatial phenomena vary, for a given piece of geography, based on the amount of convergence. To the extent that they vary, there exists an apparent spatial relationship between them (Mitchell, 2005). Study objectives are achieved by measuring spatial convergence on the horizontal, two-dimensional plain while understanding that encroachment will occur vertically, largely based on the wind turbine vertical obstruction zone, as wind energy development occurs, encroaching upon, and in many cases intruding into the minimum altitudes of military airspace geometry. Military airspace and wind power class convergence is spatially equivalent to encroachment and therefore the higher the amount of convergence, the greater the level of encroachment potential.

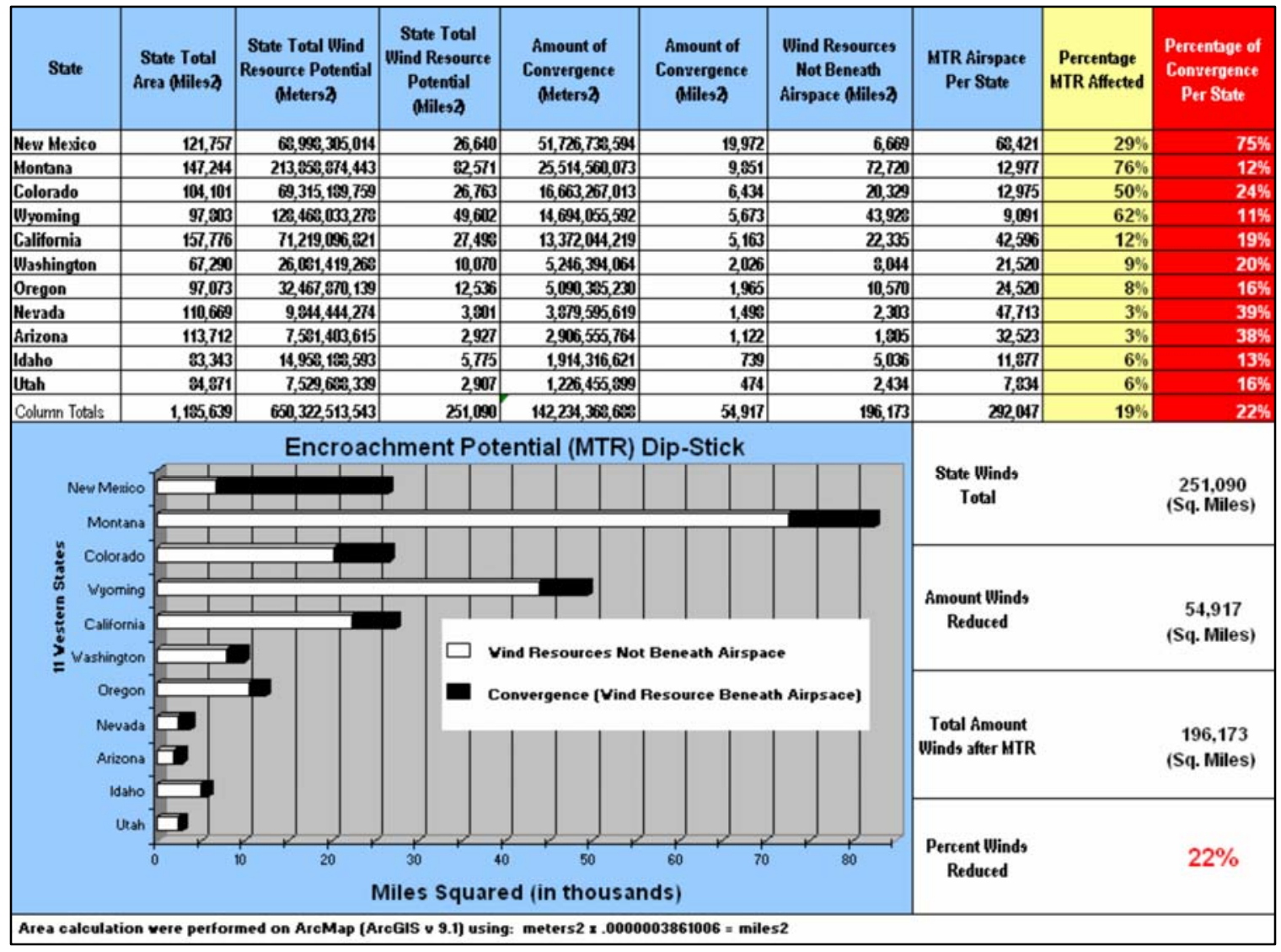

Figure 3-4. Military Training Route and Wind Model Convergence Data.

In an attempt to quantify the geospatial relationship of the military airspace model, the wind turbine vertical obstruction zone model, and the wind resource model (i.e., the inherent effects each variable has on each other based on the their purpose and spatial nature, coupled with the amount of convergence), multivariate analysis was performed 
under the following assumptions and conditions (respectively): First, while it is physically possible to make changes to airspace, this project assumes that wind energy development would not achieve the necessary momentum to effect changes to military airspace. Second, the wind turbine vertical obstruction zone accurately characterizes the vertical characteristic of the wind development potential.

The data reflected in Figure 3-4 and Figure 3-5 indicate that military training route and its spatial dispersion across the study area is experiencing a greater amount of convergence with the wind resource model in comparison to the amount of convergence between special use airspace and the wind resource model. This fact is observable when comparing the amount of white to the amount of black in the horizontal bar-graphs on display in Figures 3-4 and 3-5. Reading the bar is like reading an automobile's oil dipstick. Analogous to the amount of oil on the dip-stick, the amount of black on the bar equates to more convergence in comparison to the length of the white bar (airspace not convergent with the wind resources model). The white and black portions, together, equate to the total amount of wind resources within that state boundary.

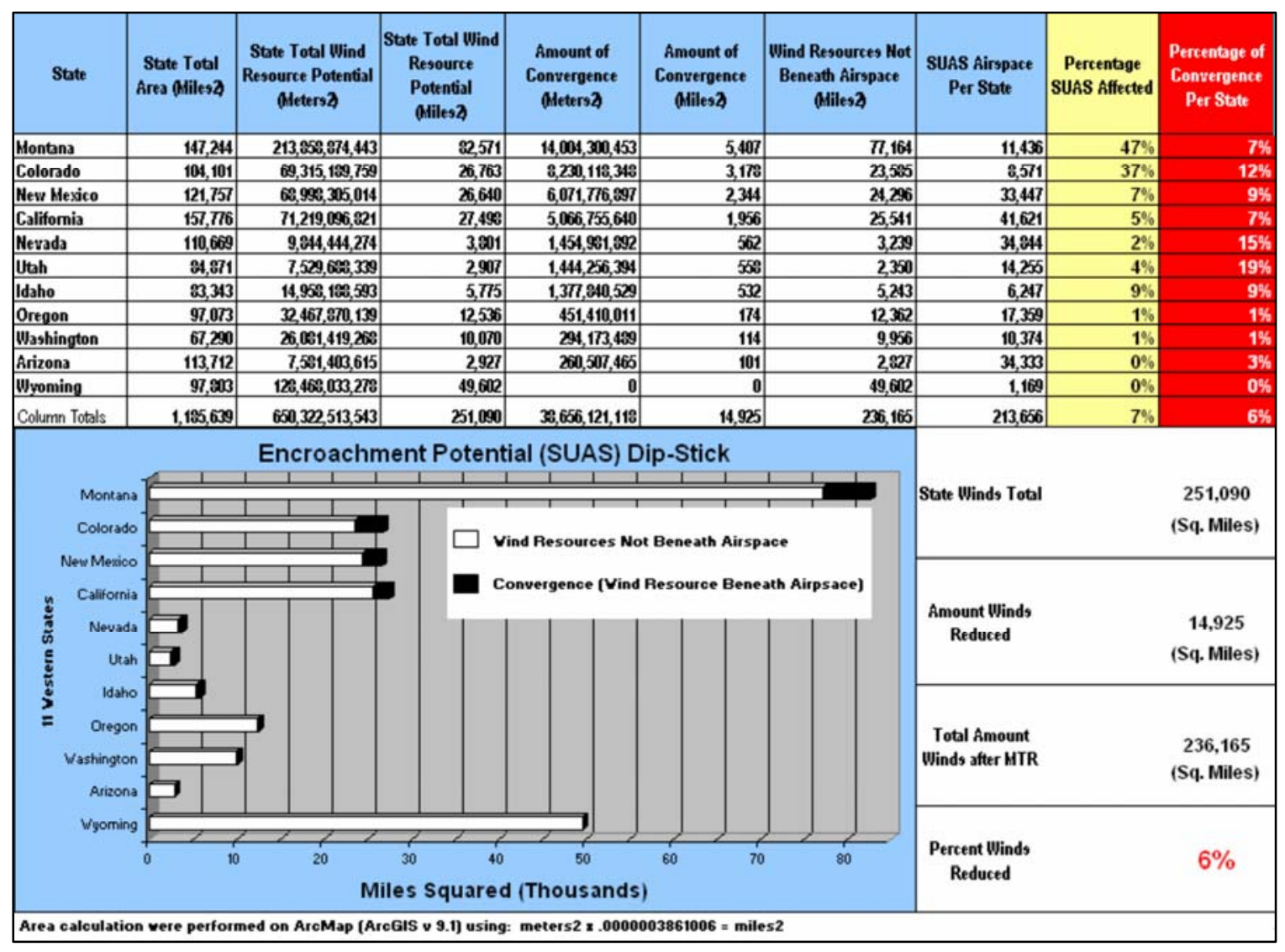

Figure 3-5. Special Use AirSpace and Wind Model Convergence Data.

Most relevant to the client's concerns is how Nevada demonstrates one of the highest amounts of convergence in both figures (i.e., in terms of percentage found in the "Percentage of Convergence Per State" column). This observation is also demonstrated in special use airspace, Figure 3-5. Most relevant to military echelons higher than the 
client, New Mexico, Nevada and Arizona are the top three states with the highest amounts of convergence.

The percentage of affected airspace per state is illustrated in the yellow columns in Figures 3-4 and 3-5. This data was provided for the sake of completeness and to preempt the notion of analytic bias. The difference in percentages of affected airspace per state (yellow column) in comparison to affected wind resource model per state (red column) is somewhat incomparable. Repeating the point from section 2.1, the polygons that construct the wind resource model and the potential for wind development are not mutually exclusive. Development potential can also exist in the vicinity of the wind resource model where specific topographic features exist (D. Heimiller, personal communication, October 17, 2005). ${ }^{18}$ This is a common condition since much of these development indicators are above the 7,000 foot elevation and eight degree slope limits. Therefore, it is the development that can occur in the vicinity of the wind resource polygons, and in or beneath military training airspace that is of most concern to encroachment managers. The mere presence of wind resources beneath military airspace suggest an amount of encroachment that can only be assessed through large-scale GIS analysis of that specific location (demonstrated in section 4). Thus, the percentages illustrated in the yellow column portray a level of encroachment threat that cannot be quantified in lieu of additional analysis. Whereas, the percentage of convergence per state illustrated in the red column reduces the wind development potential in each state, based on the assumption that development requests will be resisted by the DoD. The utility of this measure is that it adjusts the assessment of future development potential to more accurately reflect the wind resource models projection of future development

The bar graph observations illustrated in Figure 3-6 (below), reveal the following: First, covariation of the red and black bars corroborates spatial observations that the majority of convergence is occurring between the wind resource model and military training route airspace, and second, there exists overall considerable convergence between the airspace and wind resource models in Arizona, Nevada, and New Mexico. Therefore, in lieu of programmed mitigating options, either the wind energy or military training airspace have a great amount at stake. A notable observation is the difference in variance between military training route and special use airspace. This difference may indicate a possible mitigating solution. If, in the future, wind energy development in military airspace would be desired or required, covariance indicates that development within special use airspace will have the least effect on military training route geometry.

On the horizontal plain, Figure 3-6 illustrates the amount of convergence, by state. Each bar illustrates the percentage of wind resources that are reduced by special use airspace (e.g., indicated by the white bar) and military training route airspace (e.g., indicated by the black bar) and, finally, an aggregate of both special use and military training route airspace (e.g., indicated by the red bar). Observations from the multivariate plot reveal covariance (i.e., simultaneous and consistent variation) that can be assessed as convergence and correlated to the potential for encroachment upon the multiple airspace aggregates within each state.

\footnotetext{
${ }^{18}$ Donna Heimiller, a GIS analyst at the National Renewable Energy Laboratory, helped create the wind model.
} 


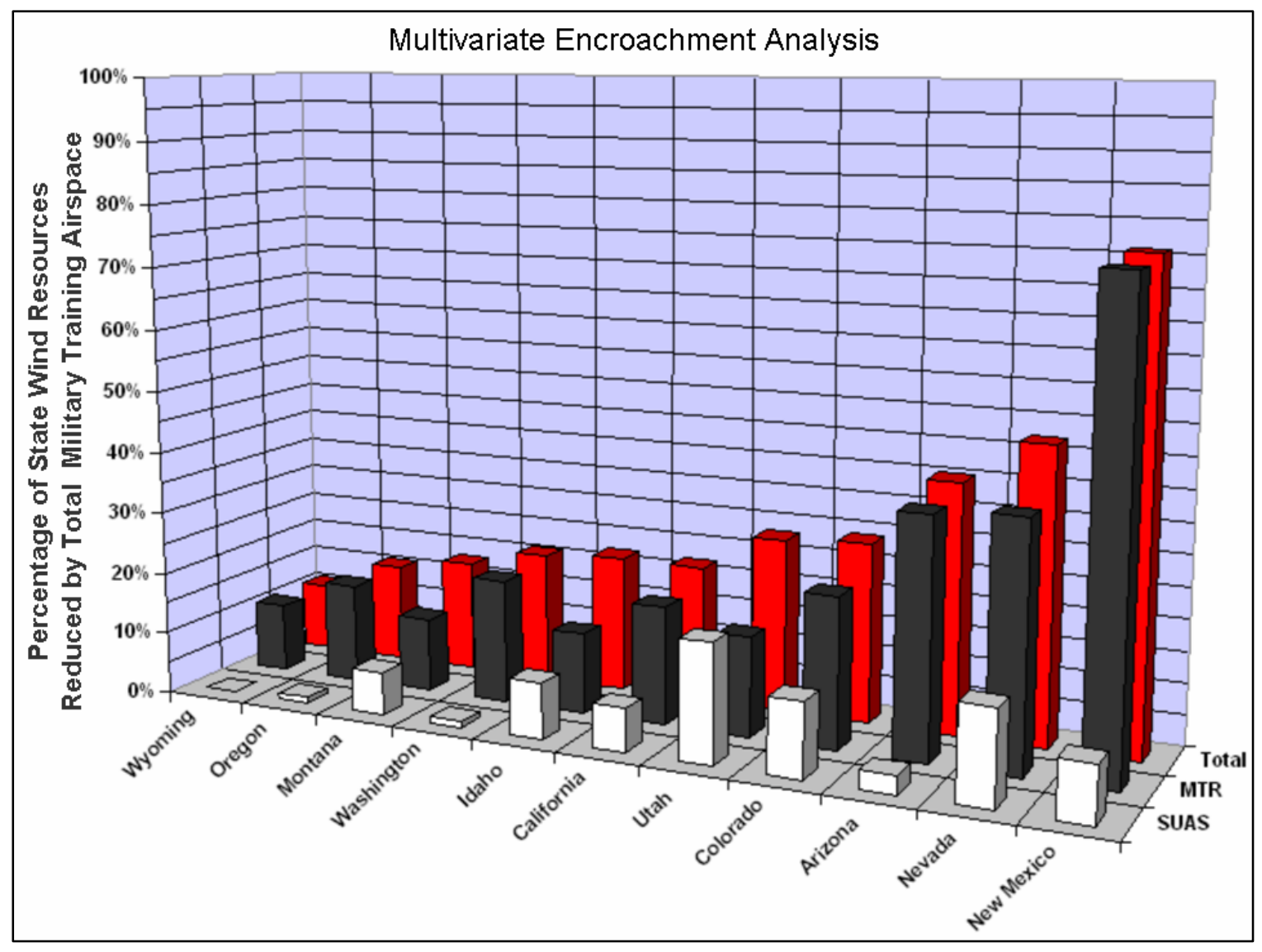

Figure 3-6. Intervening Aggregate, Multivariate Analysis.

There are four possible observable scenarios. First, the two variables do not vary together at all. Second, the two variables generally increase or decrease simultaneously. Third, there exists a perfect correlation. And finally, as one variable increase, the other decreases (Mitchell, 2005). The second and third scenarios represent correlation observed through covariance, while the fourth scenario indicates the potential for correlation through reverse covariance (Balding, 2002). Covariance between the red and black/white lines indicates the potential for increased threat of encroachment, whereas, negative covariance indicates a decrease in the threat of encroachment.

The political boundaries of the study area (i.e., Montana, Wyoming, Colorado, New Mexico, Arizona, Utah, Idaho, Washington, Oregon, Nevada, and California), are geospatial entities that have no biased spatial effect on the dispersion and concentration of wind resources and training airspace (Balding, 2002). State boundaries are simply, an assertion of an intervening aggregate (i.e., an inevitable political limitation to wind development that may vary between states and the 


\section{desires of their voting populations). They facilitate valid, unbiased observations of encroachment potential (Balding, 2002).}

The red bar in Figure 3-6 marks the percentage of variation as the wind resource model is reduced by military airspace within each state (i.e., the amount of convergence between wind resource model and military airspace). The black and white bars mark the percentage of variation as the wind resource model is reduced, first, by the segregated military training route features (i.e., the amount of convergence between wind resource model and military training route airspace, specifically), and then, by the segregated special use airspace vector (i.e., the amount of convergence between wind resource model and special use airspace, specifically). Since the sum of the white and black bars is equal to the red bars, it is logical to assume that it is the potential of covariance across the entire study area, and therefore, the utility of this test is to measure the degree of covariance between the two types of airspace. Overall, a pattern of covariance is observed between the black and red lines, albeit in varying degrees commensurate to observation scenarios two and three. Only the Idaho model demonstrates a reverse or negative covariate pattern, as explained above in scenario four.

Figure 3-6 demonstrates observable linkage between the relevant geospatial phenomena and their effects. The linkage can be spatially characterized as converging and overlapping geometry. As a result, the effect of overlapping wind resource model and military training route geometry could translate into a mean reduction of wind resource potential by 22 percent. Whereas, overlapping special use airspace geometry and the effect on the wind resource model is significantly less at six percent (Balding, 2002). These observations translate into an increased level of encroachment on military training route, even greater than special use airspace in every state, with the exception of Utah, and even more so in New Mexico, and almost at an equivalent level in Idaho and Montana.

\subsubsection{Encroachment Damage Control}

The military training route vectors used in this analysis have already been disaggregated to only those vectors with a minimum altitude of 600 feet $(183 \mathrm{~m})$ or less. In lieu of relevant mitigating courses of action, data from this analysis suggests that a possible mitigating option for adjudicating the requests for site development within military airspace exists within airspace having a minimum altitude of greater than 600 feet $(183 \mathrm{~m})$. Short of stating the obvious, the caveat to adjudicating lands beneath airspace having a minimum altitude of greater than 600 feet $(183 \mathrm{~m})$ is that future wind turbine technology advancements will likely result in eventual encroachment.

Another observation is related to damage control and there are two schools of thought on this topic based on the observed level and dispersion of convergence. First, airspace managers could potentially have more success avoiding encroachment that negatively impacted the military's training mission if wind energy development were allowed on land beneath special use airspace. This fact is made evident by the lower percentage of convergence under special use airspace in comparison to beneath military training route. The second perspective suggests that the amount of damage to the military aviation training mission would be lessened if site development adjudication were limited to lands within military training route, hand selecting lands based on risk management principles 
and minimizing the impact on the military's aviation training mission. This is based simply on the demonstrated observation that the impact on military training route would be less because the amount of convergence is more, giving the adjudicating authorities more options related to location as well as increased risk management opportunity. Finally, the same damage control principles discussed in the second scenario could also apply to an special use airspace scenario, but only with a smaller margin for error. This is based simply on the demonstrated observation that the risk of impact on special use airspace would be greater because the amount of convergence is less, giving the adjudicating authority fewer options related to location as well as decreased risk management opportunity. This observation, however, does not rule out the placement of wind farms on lands within special use airspace, it is simply pointing out the covariation in the amount of convergence with the amount of risk related to right of way adjudication.

These observations are based solely on the amount of convergence demonstrated between military training route and the wind resource model in contrast to the amount of convergence demonstrated between special use airspace and the wind resource model. It is important to note that it is the opinion of airspace managers that the likely scenario is that the DoD will likely provide more resistance to development beneath military training route airspace than development requests beneath special use airspace (S. Ryder, personal communication, October 31, 2006).

\subsection{Topography and the Law of Diminishing Returns.}

As discussed in the data immersion and vector conversion phase of this analysis, experts from the NREL and the NWTC developed screening criteria (US DOI BLM, 2003). The relevant economic and topographic criteria that were formulated and subsequently adopted by this project are: paved road access within 50 miles $(80 \mathrm{~km})$ of the development site, transmission access within 25 miles $(40 \mathrm{~km})$ of the development site, a preferred elevation range of 3,000 to 4,500 feet (914 to $1372 \mathrm{~m}$ ), but not exceeding 7,000 feet MSL $(2,133 \mathrm{~m})$, and a grade of $14 \%$ (i.e., eight degrees) in the area leading into the development site (US DOI BLM, 2003).

The distances of the development site from paved roads and electric power transmission are both economically driven by the costs associated with getting the site developed and getting the electricity to the transmission grid. The prevailing economic principle presiding over the 25 mile $(40 \mathrm{~km})$ distance from the electric power transmission vector is the law of diminishing returns, in consideration of the electric power generation potential of a wind farm (Spillman and Lang, 1924).

Figure 3-7 (below) illustrates a 25 mile $(40 \mathrm{~km})$ distance of the existing electric transmission grid within the study area. ${ }^{19}$ The regions within the study area color-coded black (i.e., blacked out) are regions beyond the 25 mile $(40 \mathrm{~km})$ distance and, therefore, not likely developable in terms of an acceptable profit margin. The green wind resource potential aggregate is reduced approximately by $10 \%$, leaving approximately $90 \%$ of the wind model within the 25 mile $(40 \mathrm{~km})$ distance from existing transmission lines.

\footnotetext{
${ }^{19}$ Analysis was based on electric grid spatial data produced by Energy Velocity.
} 
The economics related to the paved road aggregate are related to moving the massive amounts of equipment associated with site development from the production facilities into the development area, and also the costs associated with building roads leading to the development site. The slope of the topography also comes into play at this point.

Transporters of heavy equipment can haul heavy loads on grades up to $14 \%$, or 8 degrees (Vestas, 2004). As the area leading to the site exceeds 8 degrees, the access road would require topographic-skirting at a lower, more acceptable grade, creating switch-backs, and essentially adding more road construction overhead costs to site development.

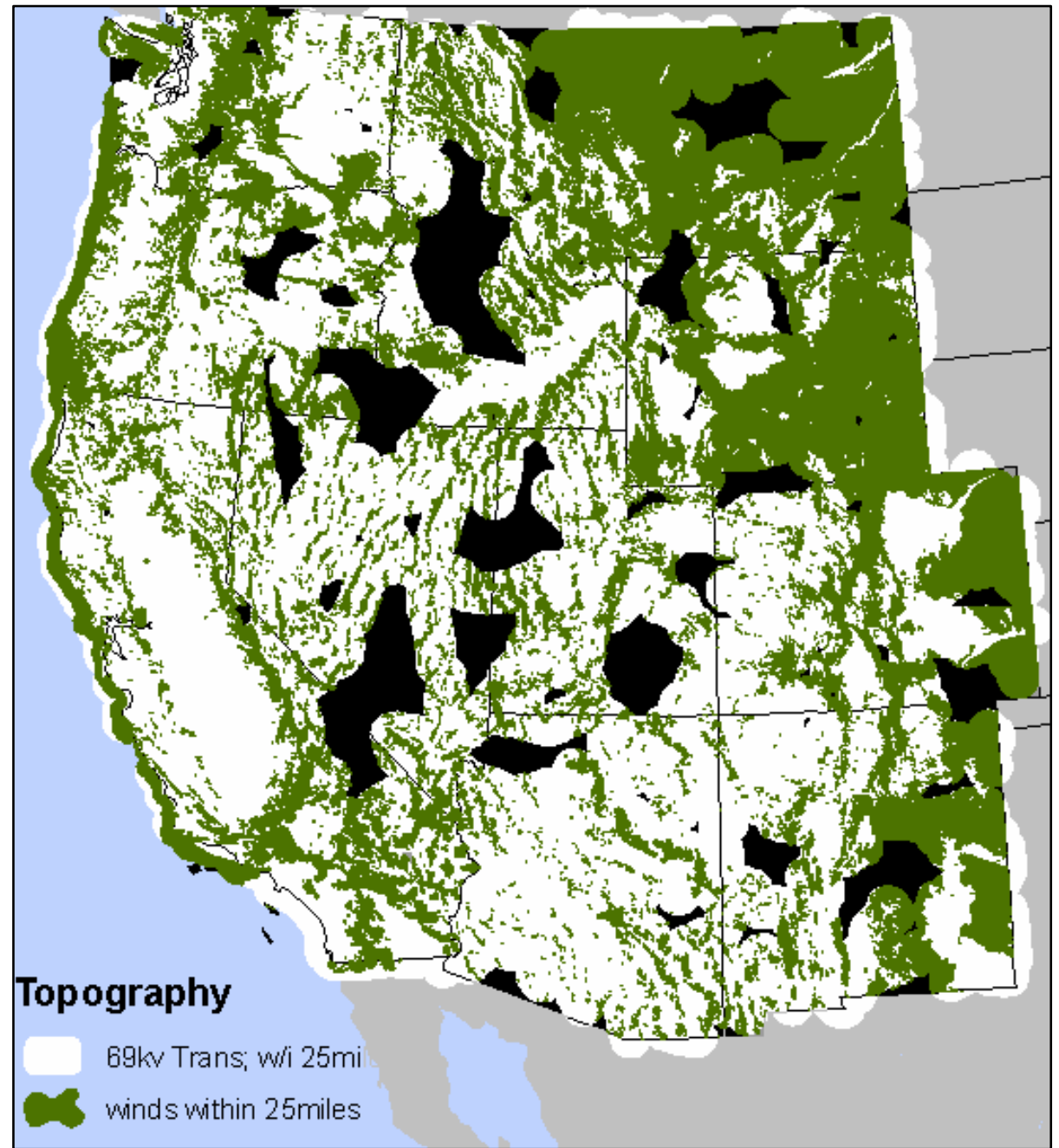

Figure 3-7. Wind Resources Within 25 Miles of Electric Transmission Grid.

Geospatial analysis determined that the study area is not affected by the 50 miles $(80 \mathrm{Km})$ paved road requirement. This observation is not conclusive, however. A closer, sitespecific analysis is required to determine if distances within the 50 miles $(80 \mathrm{Km})$ range, when compounded by slope exceeding $14 \%$ would further reduce the wind resource aggregate. 
Figure 3-8 (below) illustrates the 7,000 feet $(2,133 \mathrm{~m})$ elevation requirement required for a wind turbine's ability to efficiently convert wind energy into blade rotation. Visualized geographically, the 7,000 feet $(2,133 \mathrm{~m})$ elevation limitation was converted to a vector format and visualized with the 25 mile $(40 \mathrm{~km})$ electric transmission variable. In total, areas depicted in blue and red are regions within the study area that exceed the 7,000 feet $(2,133 \mathrm{~m})$ limitation. The vectors highlighted in red annotate wind resource vectors within the original wind model, above the 7,000 feet $(2,133 \mathrm{~m})$ elevation, further reducing the wind model by another $10 \%$.

In summary, all of the following factors, the 25 mile $(40 \mathrm{~km})$ transmission vector which reflects economic principles of diminished profit, the topography, the 7,000 feet $(2,133 \mathrm{~m})$ elevation aggregate, visualizing geographically wind potential vectors where diminished air density would challenge the efficiency of a wind turbine's ability to generate electricity, combine to reduce the wind potential model by approximately $20 \%$.

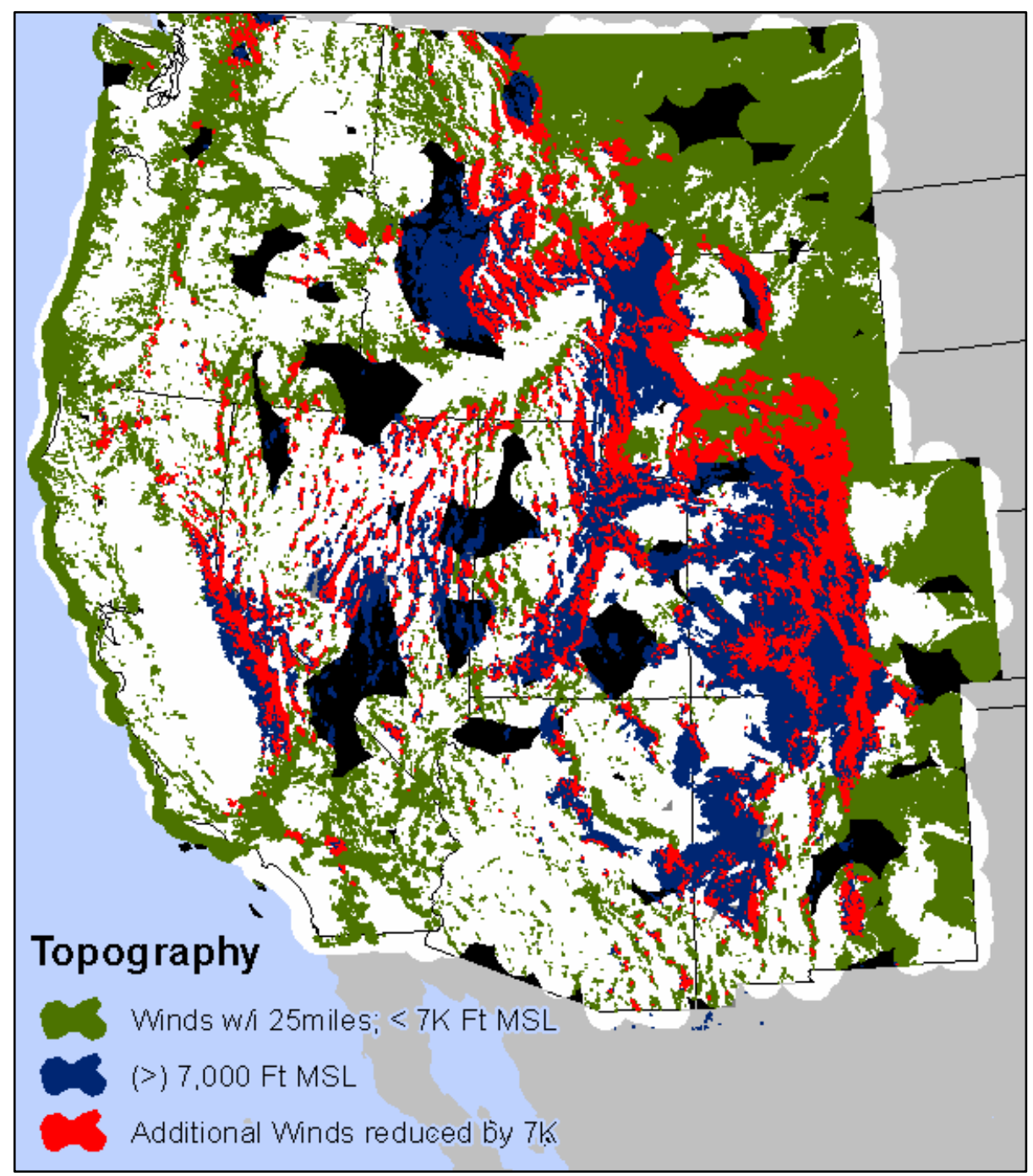

Figure 3-8. Wind Resources Above 7,000 Feet (2,134km) Mean Sea Level. 


\subsection{Findings.}

Through data immersion and after observing the effects of the physical characteristics on each variable (proximity, terrain, orientation, direction and location) as they converge or are dispersed across a geographic landscape, this project geospatially observed and identified the cause-and-effect relationship between the military airspace (i.e., military training route and special use airspace) and the wind resource (i.e., wind power classes three through seven) models. First, the project observed the horizontal relationship of wind resource model and the amount of development potential on lands beneath the airspace model. Second, the project observed that (a) the military airspace and wind resource models are really three dimensional aggregates, each exhibiting horizontal as well as relevant vertical causality, (b) that military airspace has a relevant minimum altitude variable, and (c) for the full potential of wind energy to be realized, wind turbines heights would have to be increased in order to harness wind for electricity, essentially giving wind development height characteristics.

The most significant take-aways are: first, the military airspace, the vertical obstruction zone, and wind resource models are the primary vector models demonstrating the relevant causality to affect the outcome of this project. Second, from a simple geospatial perspective (i.e., excluding politics), New Mexico's, Nevada's, and Arizona's military training route airspace are at greatest risk, respectively, of encroachment, while states with special use airspace most at risk of encroachment are Utah, Nevada, and Colorado, respectively. 


\section{Fallon Range Training Complex Encroachment.}

Periodically, a process known as the Base Realignment and Closure Commission (i.e., BRAC), addresses the military's efficiency and looks for bases around the country that could be closed. One of the factors that influence the BRAC's decision to close a base is "encroachment." Encroachment is the creep of civilian life into the vicinity of the base. Encroachment into the area of a military base weighs against a base's desirability as a military establishment because, by definition, it brings civilian activities and infrastructure closer to the military's working environment, creating hazards and making security more difficult. Therefore, when the Pentagon considers a base for BRAC, they take encroachment into full account. Out of the eight listed base closure criteria, encroachment comes in at number two, listing "the availability and condition of land, facilities and associated airspace" for a base "at both existing and potential" base areas (DoD, 2004).

"The availability and condition of land, facilities and associated airspace (including training areas suitable for maneuver by ground, naval, or air forces throughout a diversity of climate and terrain areas and staging areas for the use of the Armed Forces in homeland defense missions) at both existing and potential receiving locations” (DoD, 2004).”

Encroachment can occur in many ways, some more subtle than others. The convergence described in section 3.4, albeit a common form of encroachment, reads more like intrusion. Multivariate analysis, described in chapter 3, reveals that over $50 \%$ of Nevada's wind development potential lies beneath military airspace, almost $40 \%$ beneath military training routes, and almost $15 \%$ beneath special use airspace. If allowed, wind energy development on these lands would intrude into training airspace geometry, encroaching upward from beneath, violating minimum altitudes, and ultimately, bringing civilians or civilian activities and infrastructure closer to the military's training airspace, creating hazards and making security more difficult.

The following paragraphs will address encroachment from another threat-axis, the perimeter, creeping closer towards the perimeter from external development, along the perimeter of the Fallon Range Training Complex.

The purpose of the following analysis is not to limit wind energy development outside of the FRTC perimeter, but rather to provide airspace managers the predictive insight needed to reduce the threat of unforeseen or unplanned encroachment (i.e., knowing the direction and location from which encroachment will likely occur and knowing where it will likely migrate towards, from a point outside of the FRTC boundary, but eventually migrate into FRTC airspace).

\subsection{Encroachment Areas of Interest (AOI).}

Figure 4-1 reveals 17 areas of interest within five miles of the FRTC boundary that contain the potential for encroachment. For the sake of brevity, the five mile distance presented in Figure 4-1 (i.e., the black semi-transparent band outside of the FRTC perimeter), will be referred to as the encroachment zone. 


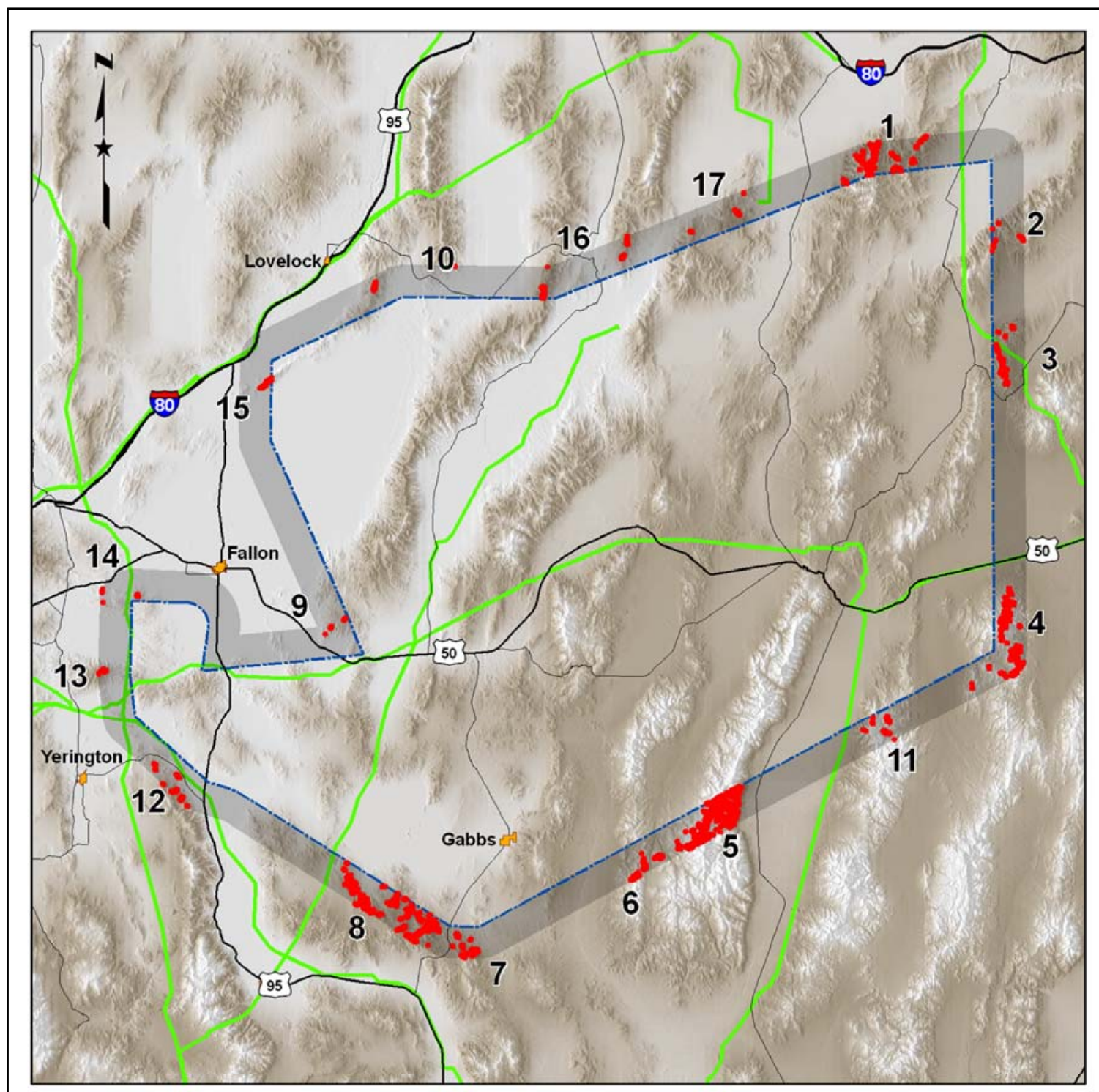

Wind Development Potential

FRTC 5 Mile Encroachment Zone

City Boundaries

- Electric Power Lines

- Primary \& Secondary Paved Roads
FRTC Encroachment Analysis Areas Of Interest (AOI)

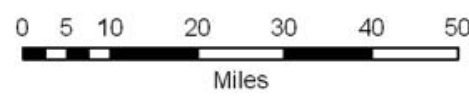

Prepared by: Scott Tabor R
Date: May 18, 2006

Figure 4-1. FRTC Perimeter Encroachment Areas Of Interest. 
The encroachment zone is not a limitation that can be imposed upon wind energy development, but rather an area of analytic interest, focused on the sole effort of identifying the axes and points from which encroachment will likely occur. Because the wind model is only an indicator of development potential in its surrounding area, a larger, five mile distance was chosen to represent the zone in order to capture a larger area around the development potential indicators (i.e., wind power class model vectors).

The wind power class model in Figure 4-1 was captured within five miles of the FRTC perimeter in order to isolate the encroachment threat. Therefore, the threat of potential encroachment is indicated by the spatial presence of the wind model vectors within the encroachment zone. As the graphic indicates, the 17 encroachment scenarios depicted in Figure 4-1 are only indications of encroachment potential. Additional spatial analysis is required in order to validate the threat.

The encroachment zone identified 17 areas of interest, all of which are described in Tables 4-1 and 4-2.

\begin{tabular}{|l|l|}
\hline Area of Interest ONE & $\begin{array}{l}\text { Located at the northern end of the Shoshone } \\
\text { Range near Mill Creek }\end{array}$ \\
\hline Area of Interest TWO & $\begin{array}{l}\text { Located in the Cortez Mountains near Cortez } \\
\text { Nevada }\end{array}$ \\
\hline Area of Interest THREE & $\begin{array}{l}\text { Located on the northern tip of the Simpson Park } \\
\text { and Roberts Mountains, between Nevada } \\
\text { highway 278 (to the east) and highway 306 to } \\
\text { the west the }\end{array}$ \\
\hline Area of Interest FOUR & $\begin{array}{l}\text { Spread over the southern tip of the Toiyabe } \\
\text { National Forest, where the Toiyabe and } \\
\text { Shoshone mountains begin to separate into their } \\
\text { own ranges. }\end{array}$ \\
\hline Area of Interest FIVE and SIX & $\begin{array}{l}\text { Spread over the southern tip of the Toiyabe } \\
\text { National Forest, where the Toiyabe and } \\
\text { Shoshone mountains begin to separate into their } \\
\text { own ranges }\end{array}$ \\
\hline Area of Interest SEVEN and EIGHT & $\begin{array}{l}\text { Located along the Gillis and Gabbs Valley } \\
\text { Ranges, along, Soda Springs Valley, and in the } \\
\text { Excelsior Mountains, starting at Hawthorne and } \\
\text { ending at Mina Nevada }\end{array}$ \\
\hline
\end{tabular}

Table 4-1. Areas of Interest 1 Through 8 


\begin{tabular}{|l|l|}
\hline Area of Interest NINE & $\begin{array}{l}\text { Located near Sand Mountain on the southern foothills } \\
\text { of the Stillwater Range, and area of interest ten (AOI- } \\
10 \text { is located east of Lovelock Nevada, on the } \\
\text { southern tips of the Humbolt and Western Humbolt } \\
\text { mountain ranges }\end{array}$ \\
\hline Area of Interest TEN & $\begin{array}{l}\text { Located east of Lovelock Nevada, on the southern tips } \\
\text { of the Humbolt and Western Humbolt mountain } \\
\text { ranges }\end{array}$ \\
\hline Area of Interest ELEVEN & Located in the Monitor Valley, between AOI's 4 and 5 \\
\hline Area of Interest TWELVE & $\begin{array}{l}\text { Located in the Northern tip of the Wassuk Range, in } \\
\text { the Walker Lake and Walker River Valley's }\end{array}$ \\
\hline Area of Interest THIRTEEN & $\begin{array}{l}\text { Located in the Lahontan State Recreation Area, West } \\
\text { of Fallon. AOI-13 is south of Lahontan Reservoir, and } \\
\text { AOI-14 encompassing the Lahontan Reservoir }\end{array}$ \\
\hline Area of Interest FIFTEEN & $\begin{array}{l}\text { Located in the vicinity of the Humbolt Sink, south of } \\
\text { Lovelock and East of the Interstate 80 and State } \\
\text { Highway 95 junction }\end{array}$ \\
\hline Area of Interest SIXTEEN & $\begin{array}{l}\text { Located between the East and Tobin Ranges, on the } \\
\text { northern tip of the Stillwater Range, on the northern } \\
\text { edge of the FRTC boundary }\end{array}$ \\
\hline Area of Interest SEVENTEEN & $\begin{array}{l}\text { Located between the Tobin Range and Fish Creek } \\
\text { Mountains, also on the northern edge of the FRTC } \\
\text { boundary }\end{array}$ \\
\hline
\end{tabular}

Table 4-2. Area of Interest 9 Through 17

Identified in Chapter Two and characterized in Chapter Three, there are several topographic and socio-economic related spatial phenomena that rank high on the list of relevant spatial features that favor wind energy development. After aggregating these vectors into a spatial model, and once a site is identified as having development potential, site-specific testing known as "micro-siting” occurs (Bailey and McDonald, 1997). This process includes right-of-way authorization to erect meteorological towers that test and assess the wind potential of the specific site (Bailey and McDonald, 1997). Testing and evaluation are conducted at a resolution much higher than the standard wind power class model. Therefore, the goal of site-specific analysis is to locate areas within Nevada that present the most potential for high resolution wind potential testing. 


\subsection{Roads, Electric Transmission, Elevation and Slope.}

As described in the previous analysis, the economic law of diminishing returns (Spillman and Lang, 1924), determined by the costs associated with constructing roads to development sites and the construction of power transmission lines that connect wind farms to already existing electric transmission lines (i.e., the grid), weighs heavily in determining if an area, presenting wind potential, is developable.

All of Nevada's wind resources are within 50 miles $(80 \mathrm{~km})$ of a paved road, therefore slope is the remaining consideration related to road construction into a developable site. Road access to potential sites within the 50 mile distance however, can be marginal or non-existent. Road prerequisites such as: grades $14 \%$ or less, (i.e., converted and rounded to eight degrees), turning radius large enough to accommodate the turning radius of heavy equipment transporters, and a road bed capable of handling the heavy loads that these equipment transporters haul into the site, require uniquely suited roads, or the ability to modify existing roads to achieve these criteria (US DOI BLM, 2005). If roads meeting these criteria do not exist, careful consideration must be given to new road construction and its impact on the wind farm economics (US DOI BLM, 2005).

Although the distance and economic importance associated with this activity in the final assessments is somewhat soft and often subjective, the biggest barrier to wind development, arguably, is the lack of available transmission capacity (US DOI, 2005). Costs for transmitting wind energy to existing lines (i.e., connecting to the grid) consists of the capital cost to build a new line from the wind farm to the grid and a service charge per megawatt-hour to use existing lines. The capital cost of a new line is a linear function of the number of megawatts that the line must be able to carry and the length of the line. Since these lines will likely carry only electricity harnessed by the wind farm, the cost of newly constructed power lines is amortized over the relatively low electricity generating capacity of wind (US DOI, 2005). The maximum linear distance from an existing electric power transmission grid for this project was set by subject matter experts at 25 miles (40km) (US DOI BLM, 2003).

Figure 4-2 demonstrates the Nevada's road network and electric transmission grid around and throughout the FRTC (Global Energy Electric Velocity Energy Map, 2005). Understanding the distance concepts related to the law of diminished returns, as it is applied throughout the FRTC, it is easy to see how the paved roads and electric power line infrastructure are not limiting factors in wind development.

The white and yellow layers (i.e., areas where elevation is greater than 7,000 feet and grades greater than eight degrees, respectively) in Figure 4-2 mask much of the wind resource potential within the encroachment zone. These encroachment AOI's are not rendered unlikely, however. Since the wind model vectors are only indicators of wind development potential, it is the proximity of the wind resources indicators that will have development potential, if these areas have the prerequisite topographic features. 


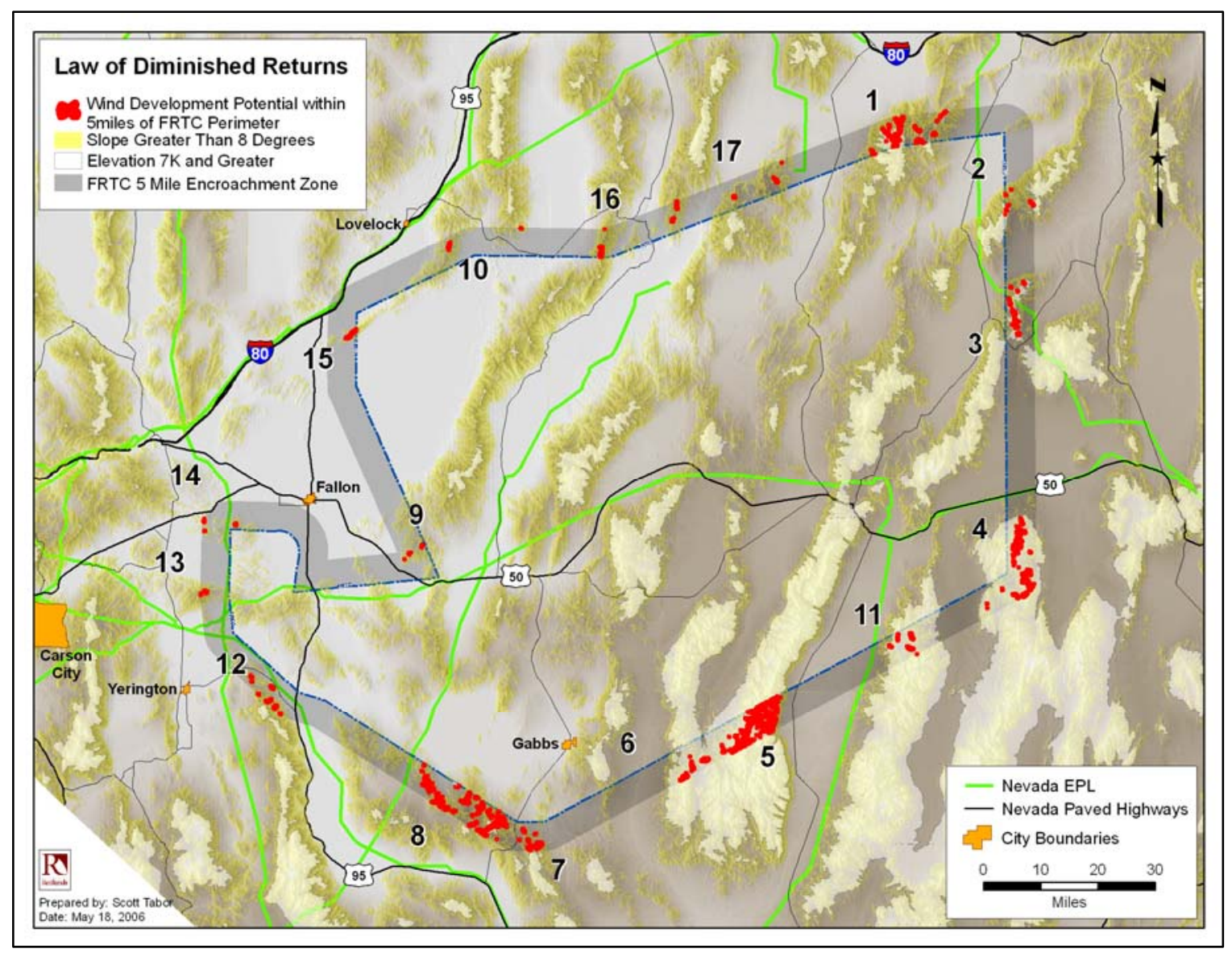

Figure 4-2. Elevation, Slope and the Law of Diminished Returns.

\subsection{Topography: Funnels, Plateaus, and Ridgelines.}

Wind experts describe the following topographic features as more conducive for greater wind potential: valleys and ridgelines, which help funnel local winds to a site oriented in the same direction as the prevailing wind direction; an area with a higher elevation than the surrounding terrain, such as a relatively flat and elevated plateaus; and ridgelines oriented perpendicular to the prevailing wind direction (Bailey and McDonald, 1997). All of these topographic features present conditions for greater wind potential and demonstrate greater economic feasibility (Bailey and McDonald, 1997).

Figure 4-3 represents the prevailing type of funnel-type topography in Nevada. Big Smokey Valley is described as funnel topography with development potential that could facilitate encroachment upon the FRTC. Big Smokey Valley's North-South orientation is only ideal because of the southerly winds that prevail in this area, creating conditions for greater mean wind speed. (Bailey and McDonald, 1997). 


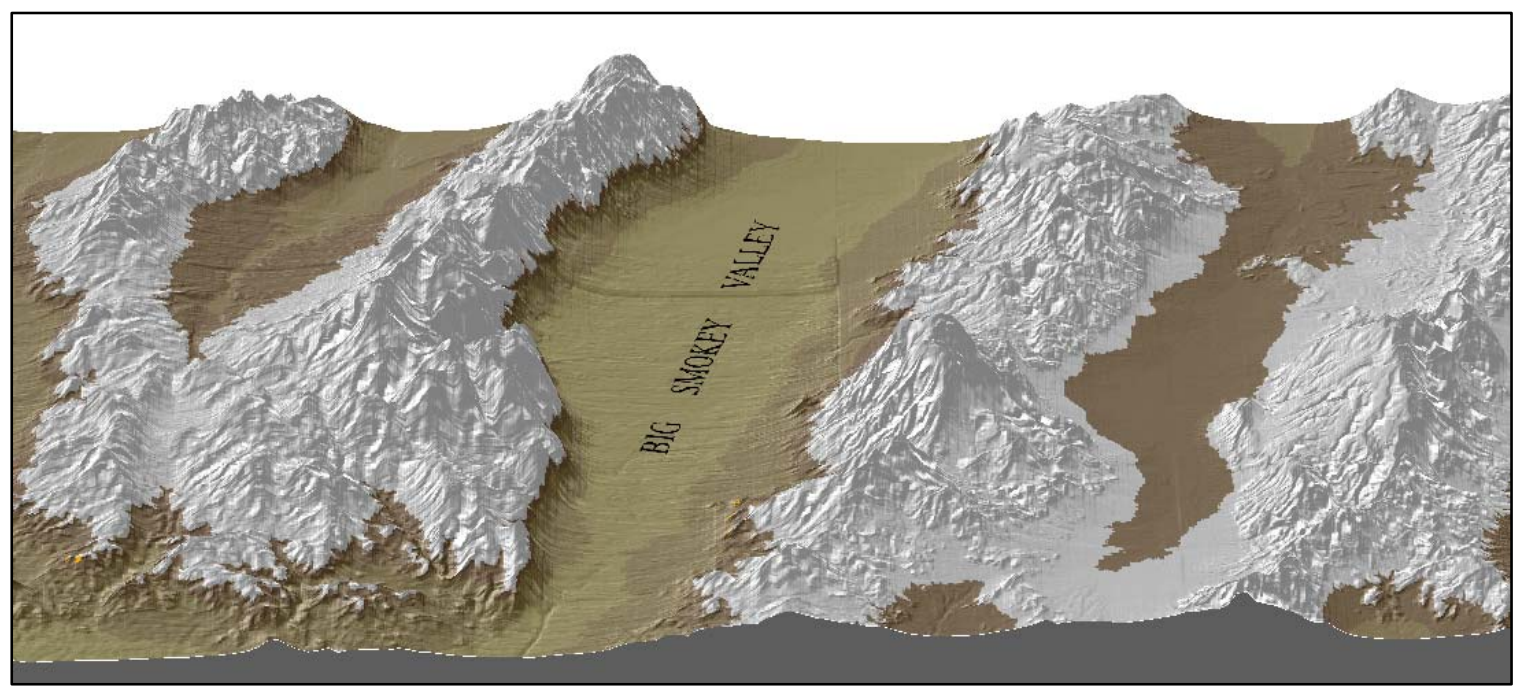

Figure 4-3. Funnel Topography.

Figure 4-4 represents highland plateau topography found in the Hawthorne area. Hawthorne is also an area presenting wind energy development potential because of its elevated terrain and because of the ridgelines presented by the Gillis Range, extending perpendicular to the prevailing wind direction also present desirable development conditions.

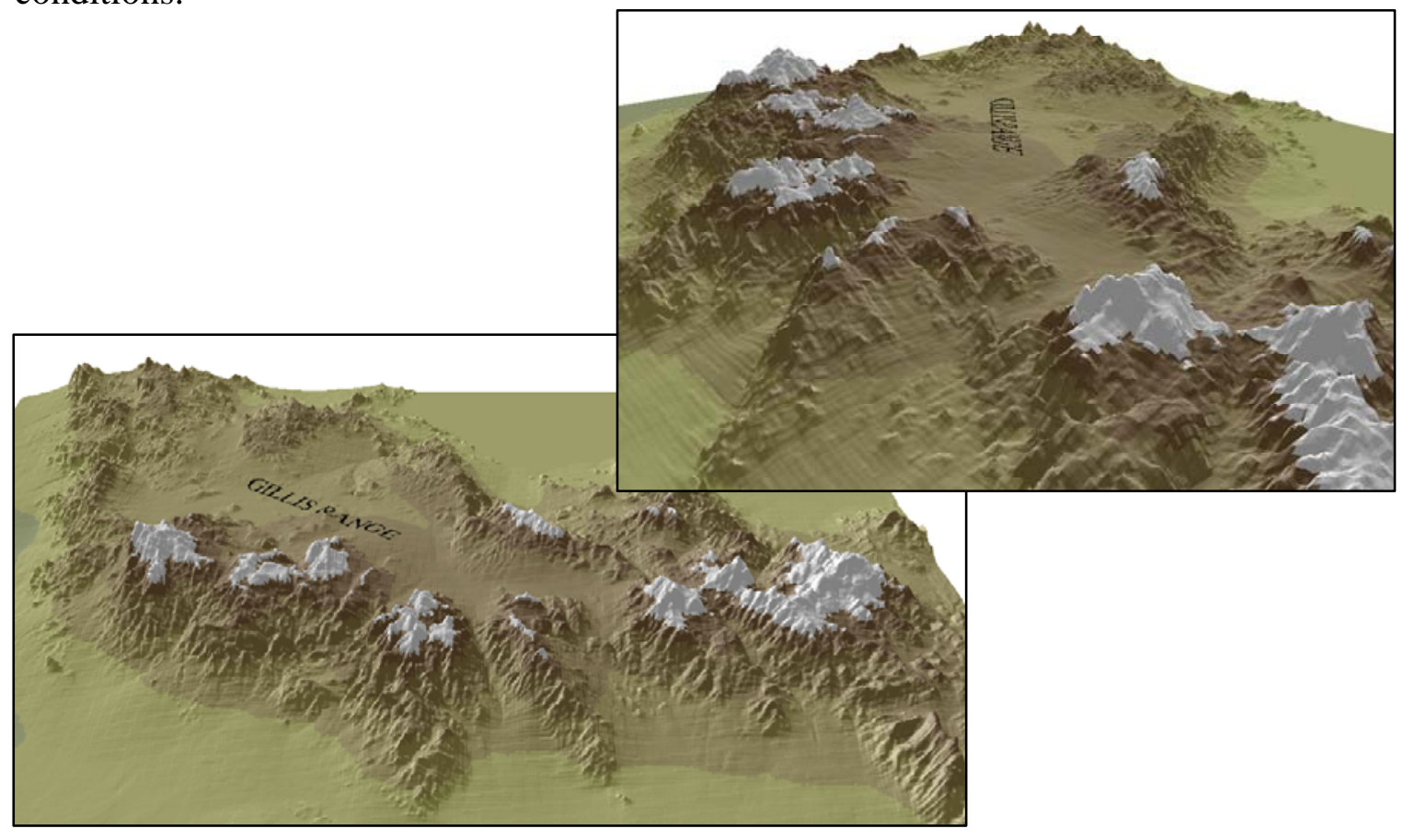

Figure 4-4. Highland Plateau Topography. 


\subsection{Prevailing Winds.}

Equally as important as favorable topographic features within a site are the prevailing wind directions and speeds. Wind direction has a profound effect on the value of favorable topography. For example, a ridgeline is favorable to wind energy development as long as it is oriented perpendicular to wind direction. That same ridgeline, however, when oriented in line with the wind direction may have a funneling effect, creating conditions for even greater mean wind speed (Bailey and McDonald, 1997). Two significantly different topographic features, each rendered relevant or irrelevant to wind energy development (in preceding topographic analysis) by the direction of the wind (Bailey, 2006).

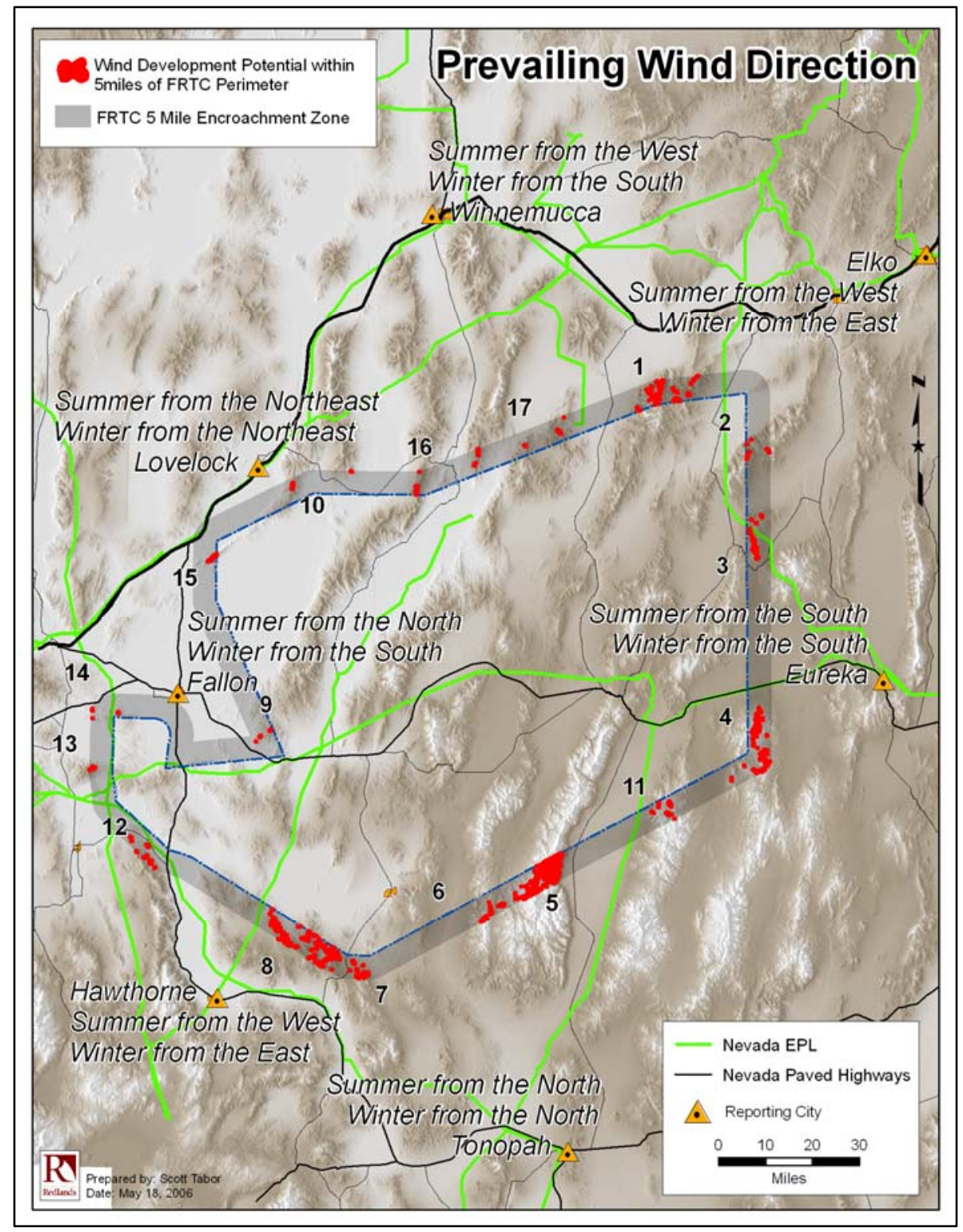

Figure 4-5. Northern Nevada Prevailing Wind Direction. 
In addition to the data obtained through test and evaluation at the site, common sources of wind data include the regional climatic centers, local universities, and airports. On display in Figure 4-5, the Western Regional Climate Center provided tabular data of the prevailing wind direction from 13 wind reporting stations within Nevada (Western Regional Climate Center, 2006). All prevailing winds are named after the direction that the wind blows from (Western Regional Climate Center, 2006). Naming the direction of the prevailing wind direction is based on data taken hourly from 1992 through 2002, and as the prevailing direction chosen is based on the direction with the highest percentage of frequency (Western Regional Climate Center, 2006). The data comes from airports that report the data they collect with wind equipment at a standard height of 10 meters, (Jim Ashby, Western Regional Climate Center personal communication, May 22, 2006).

Additional wind direction data of areas relevant to this project, but not provided in the climate center data base, was obtained through personal communication with the nearest municipal airport administration and operations department.

\subsection{Hawthorne (AOI-7 and AOI-8), Encroachment Analysis Prototype.}

Prototyping topographic analysis techniques before implementing analysis on the other encroachment zones is a procedure designed to produce optimal results while reducing the amount of re-analysis. The following paragraphs present the analytic process, developed for inclusion in programmatic test and evaluation and management practices.

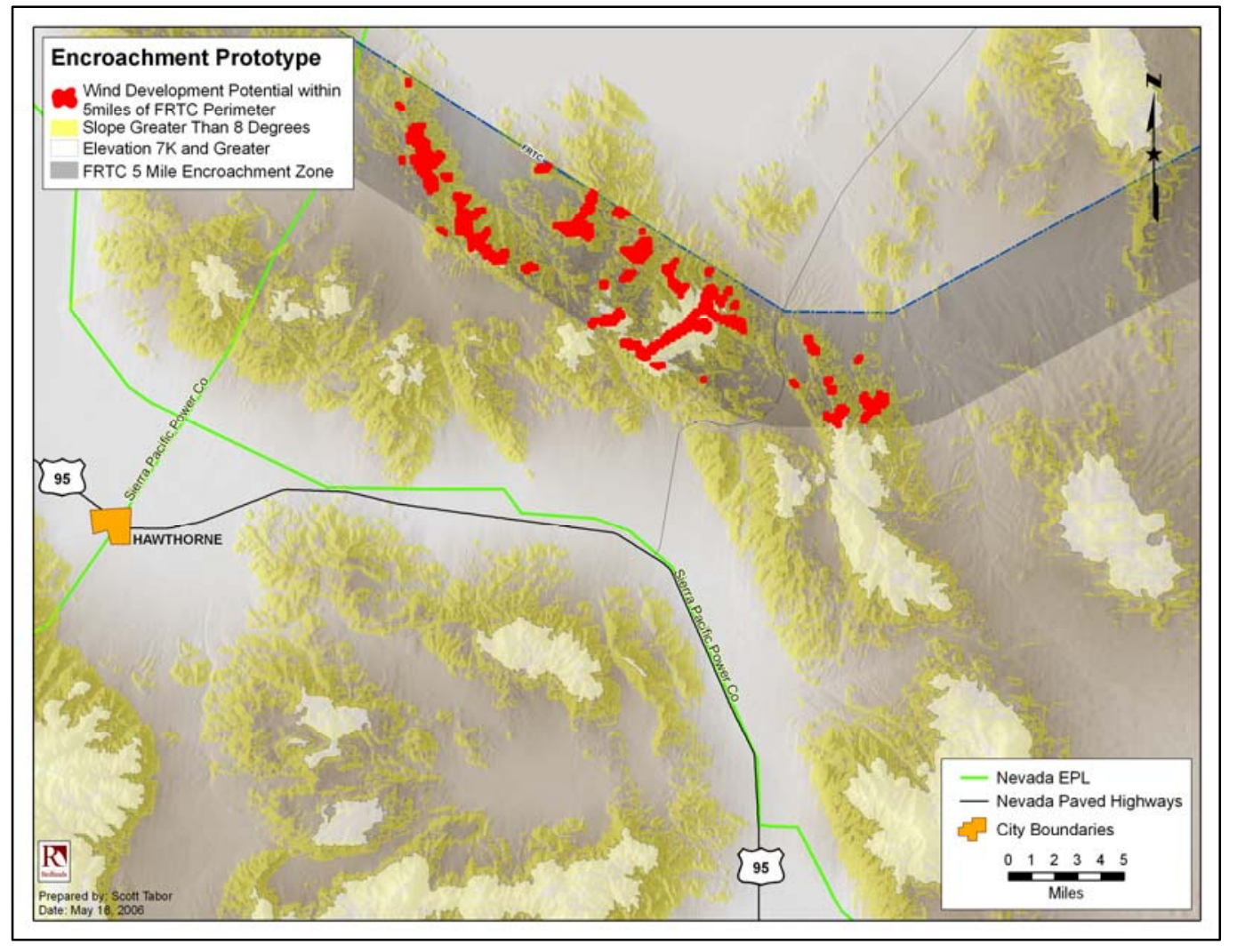

Figure 4-6. Encroachment Analysis Prototype. 
The area adjacent to the southern edge of the Fallon Range Training Complex (i.e., Hawthorne, Nevada) was chosen as the prototype for the site-specific analysis. This area was chosen because it demonstrated all of the screening factors relevant to wind development analysis observable at this thematic resolution.

Figure 4-6 demonstrates an area presenting wind development potential within the fivemile encroachment zone. The Topographic Planning Map (Figure 4-7), is a relief of the Hawthorne and Soda Springs Valley areas. The perspective (bottom) is from the south looking north at the Gillis and Gabbs Valley Ranges. The tallest peak west of the city of Hawthorne is Mount Grant at 11,239 feet. The elevation of Hawthorne is approximately 4200 feet.

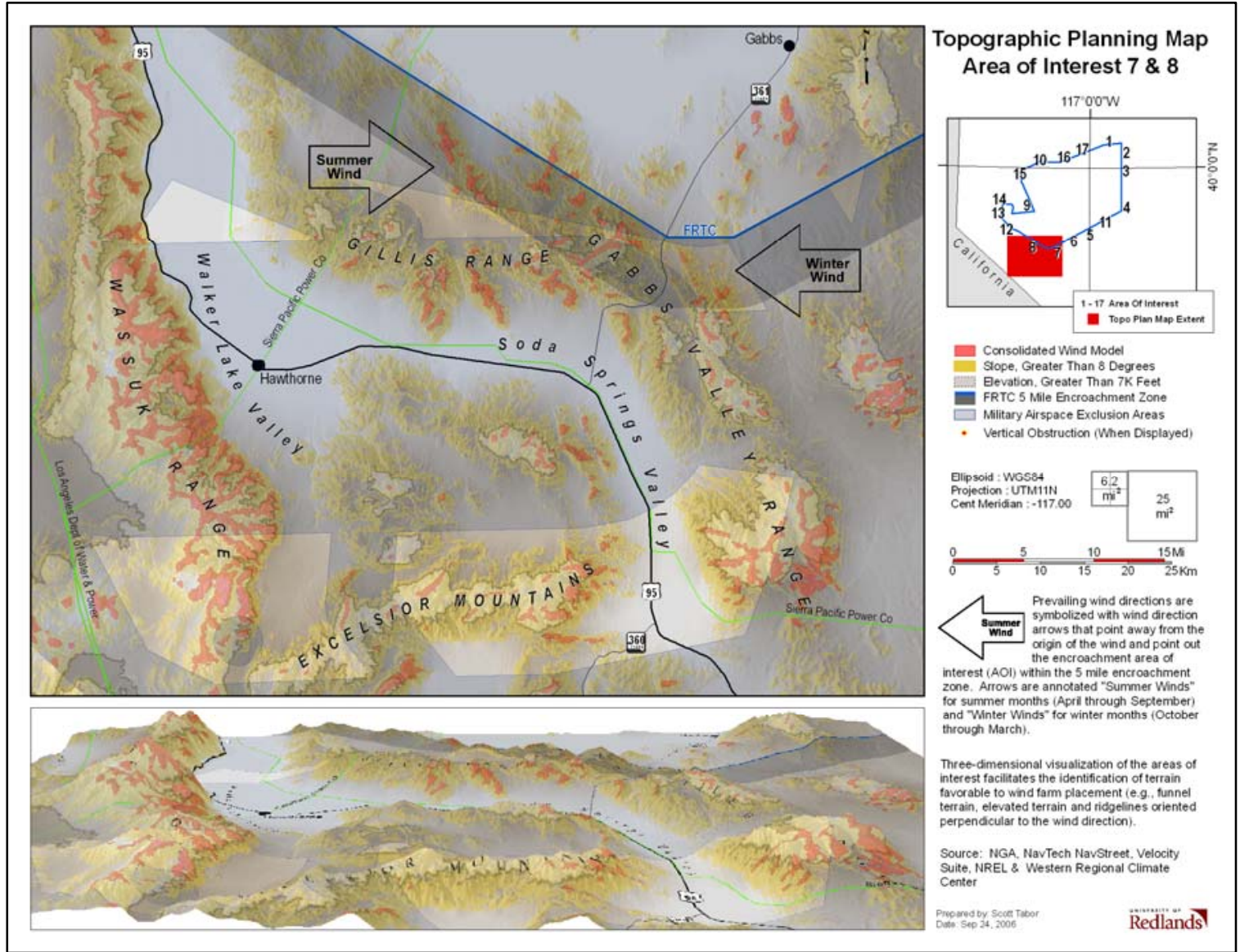

Figure 4-7. Hawthorne Encroachment Planning Map.

The area north of the FRTC five mile encroachment zone, shaded blue, is military training airspace. The area shaded light-red are consolidated polygon vectors of wind power classes 3 through 7 . The wind direction arrows point towards the encroachment points of interest within the 5 mile encroachment zone, also indicating the direction of the prevailing wind at these areas of potential wind energy development. The white areas with medium-gray outline illustrate terrain elevation greater than 7,000 feet and the yellow areas illustrate terrain with a slope greater than eight degrees. The black lines are 
primary and secondary paved roads; green lines depict electric power transmission lines with a capacity of 69 kilovolts or greater. Thus, the Hawthorne encroachment planning map depicts the Hawthorne area with all the relevant wind development screening factors described in section 2, illustrated for analysis.

\subsubsection{Hawthorne Topography.}

A larger scale analysis can shift from small scale in order to locate the topographic features favorable to wind energy development such as: the presence of the topography that would funnel local winds; areas with a elevated terrain, such as a relatively flat plateau; and ridgelines oriented perpendicular to the prevailing wind direction (Bailey and McDonald, 1997).

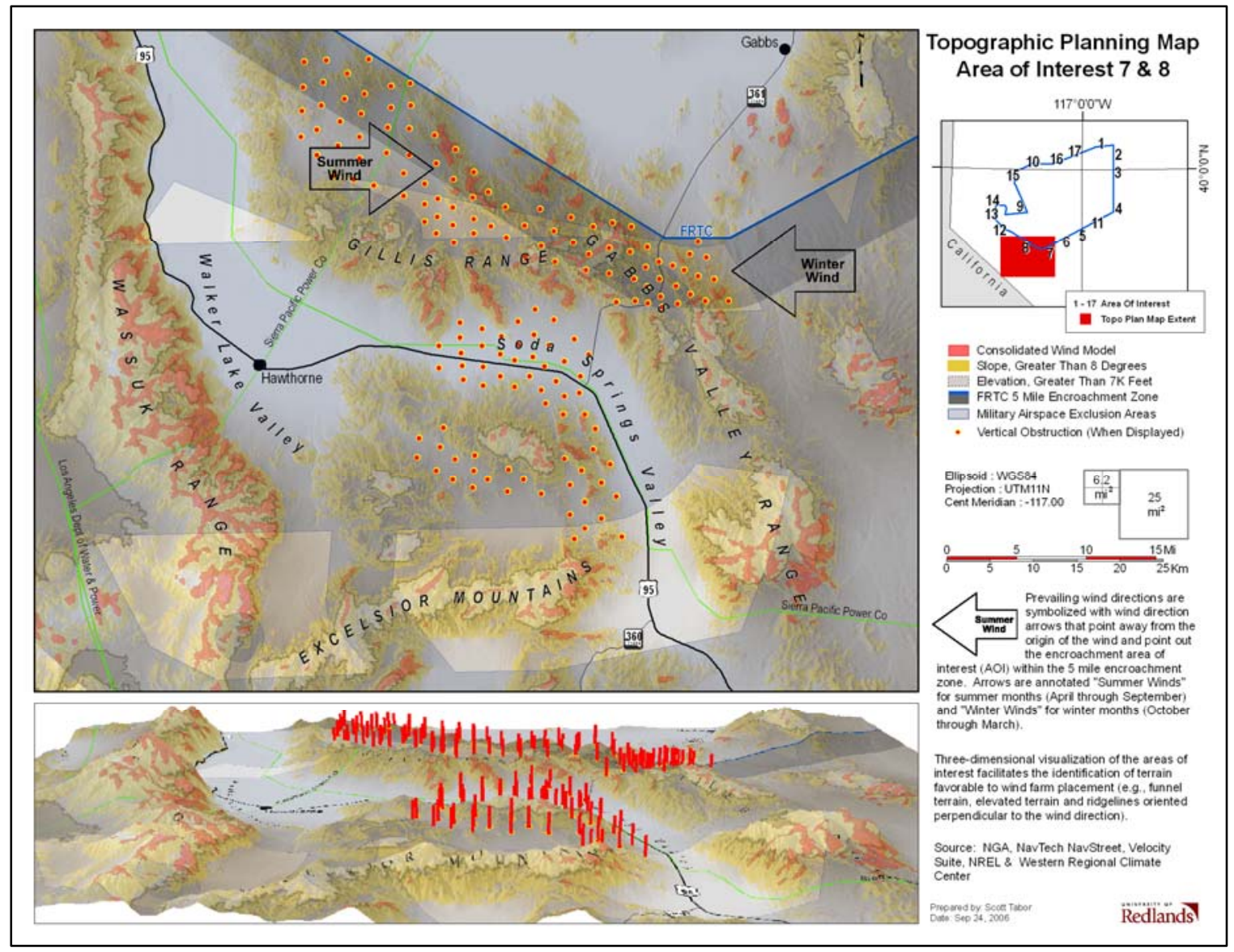

Figure 4-8. Hawthorne Planning Map, Topography.

The bottom portion of the topographic planning map (Figure 4-8) presents the Hawthorne study-site in a perspective format. In this format, the map user can isolate and subsequently identify topographic features of interest described in section 2.4 and 4.3. The red and yellow point features in the main map are vertical obstruction markers that correspond to the red vertical obstructions illustrated in the bottom perspective. The vertical obstruction heights in the lower perspective were extruded in accordance with the 
wind turbine vertical obstruction zone discussed in section 2.3. The northernmost and southernmost clusters of point features indicate elevated topography (i.e., highland plateaus at approximately 6,000 feet, MSL higher than the surrounding terrain) in the Gillis Range and between Soda Springs Valley and Excelsior Mountains. The middle cluster of red and yellow point features lay within the funnel topography (i.e., Soda Springs valley) at approximately 4,500 feet (MSL), oriented in the same direction as the prevailing wind direction: from the east in the winter months and from the west in the summer months (Hawthorne Municipal Airport Administration and Operations, personal communication, November 13, 2005).

\subsubsection{Hawthorne Encroachment Potential.}

The Hawthorne topographic planning map presents the study site and the suitable areas for wind energy development through topographic analysis. Within these areas the potential for wind farm development encompasses approximately 425 square miles (1,101 square kilometers). Of the total development potential, 248 square miles (642 square kilometers) lie beneath military training airspace. Therefore, $58 \%$ of the modeled development potential in the Hawthorne encroachment AOI reflects potential encroachment into military training airspace. More important, there remains 177 square miles (458 square kilometers) of development potential distinct from under military training airspace.

The Hawthorne encroachment analysis model, formulated on AOI-7 and AOI-8 encroachment scenarios, will be applied to all 17 areas of interest in preceding paragraphs. This geospatial analysis approach presents a logical and analytical model based on relevant spatial factors provided by wind development experts.

\subsection{Area of Interest ONE (Reese River Valley) and TWO (Cortez Mountains).}

Area of interest one (AOI-1) and two (AOI-2) are located at the northern end of the Shoshone Range and in the Cortez Mountains, south of US 80, in the northeast corner of the FRTC. The prevailing wind direction is estimated using the nearest reporting climate station in Elko Nevada located approximately 22 miles $(35 \mathrm{~km})$ east of Carlin reporting from the east in the winter months and from the west in the summer months). Illustrated in Figure 4-9 are the paved roads (black line) and electric power line (green line) dissecting the AOI. The wind direction arrows point towards the two encroachment points of interest within the 5 mile encroachment zone, indicating the directions of the prevailing wind at these areas of potential wind energy development.

\subsubsection{Reese River Valley/ Cortez Mountains Topography.}

In the main view of Figure 4-9, the Shoshone Range, oriented north-northeast, lies to the west within the map extent; and the Cortez Mountains, also oriented north-northeast, lie to the east within the map extent, creating a topographic funnel. The most prevalent topographic features, posing most of the development potential, are the ridgelines below 7,000 feet $(2,134 \mathrm{~m})$, followed by the elevated terrain and ridgelines of the Dry Hills and the northern foothills of the Cortez Mountains. 


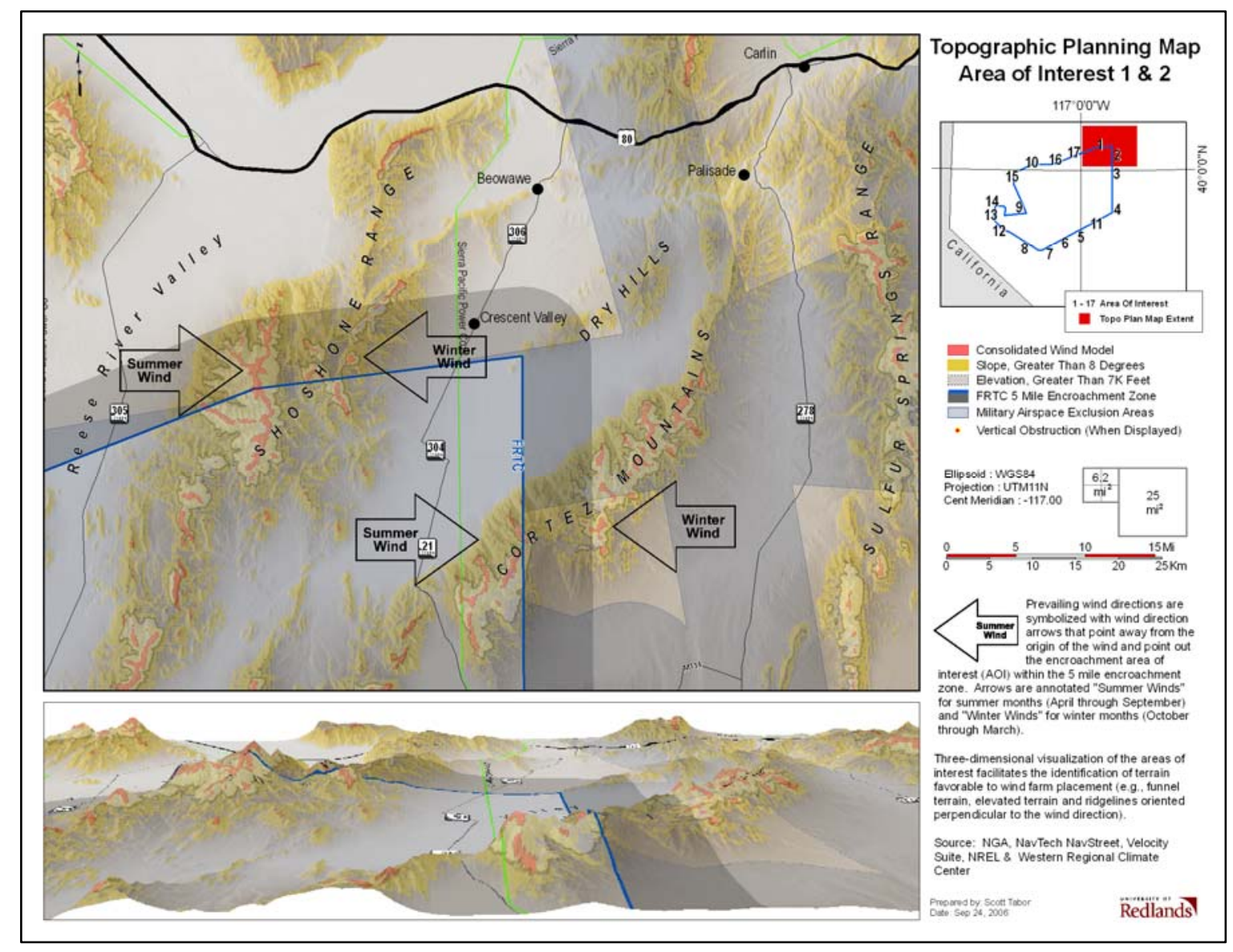

Figure 4-9. AOI-1 and AOI-2 Topographic Planning Map.

\subsubsection{Reese River Valley/ Cortez Mountains Encroachment Potential.}

The Reese River Valley and Cortez Mountains topographic planning map (i.e., figure 49), presents AOI-1 and AOI-2 in a perspective view format. In this format, analysis can help isolate and subsequently identify topographic features of interest (Bailey and McDonald, 1997). Figure 4-10 illustrates the placement of potential wind turbine locations (i.e., red and yellow point symbols in the main map and extruded as red vertical objects in the perspective view), thus, reflecting wind turbine placement analysis. The northeastern cluster of red and yellow points (the northern foothills of the Cortez Mountains) and northwestern cluster of red and yellow points (the northern foothills of the Shoshone Range) are on elevated terrain and ridgelines at altitudes less than 7,000 feet $(2,134 \mathrm{~m})$, with the ridgelines oriented perpendicular to the prevailing wind direction (Western Regional Climate Center, 2006). The cluster of potential turbines in the valley created by the Dry Hills and Cortez Mountains lay within funnel topography, generally oriented in the same direction as the prevailing wind direction: east in the winter months and west in the summer months (Western Regional Climate Center, 2006). The area around Crescent Valley was not considered because the wind would likely be screened by 
the Shoshone Range in the summer months and the assorted elevated terrain to the east in the winter months.

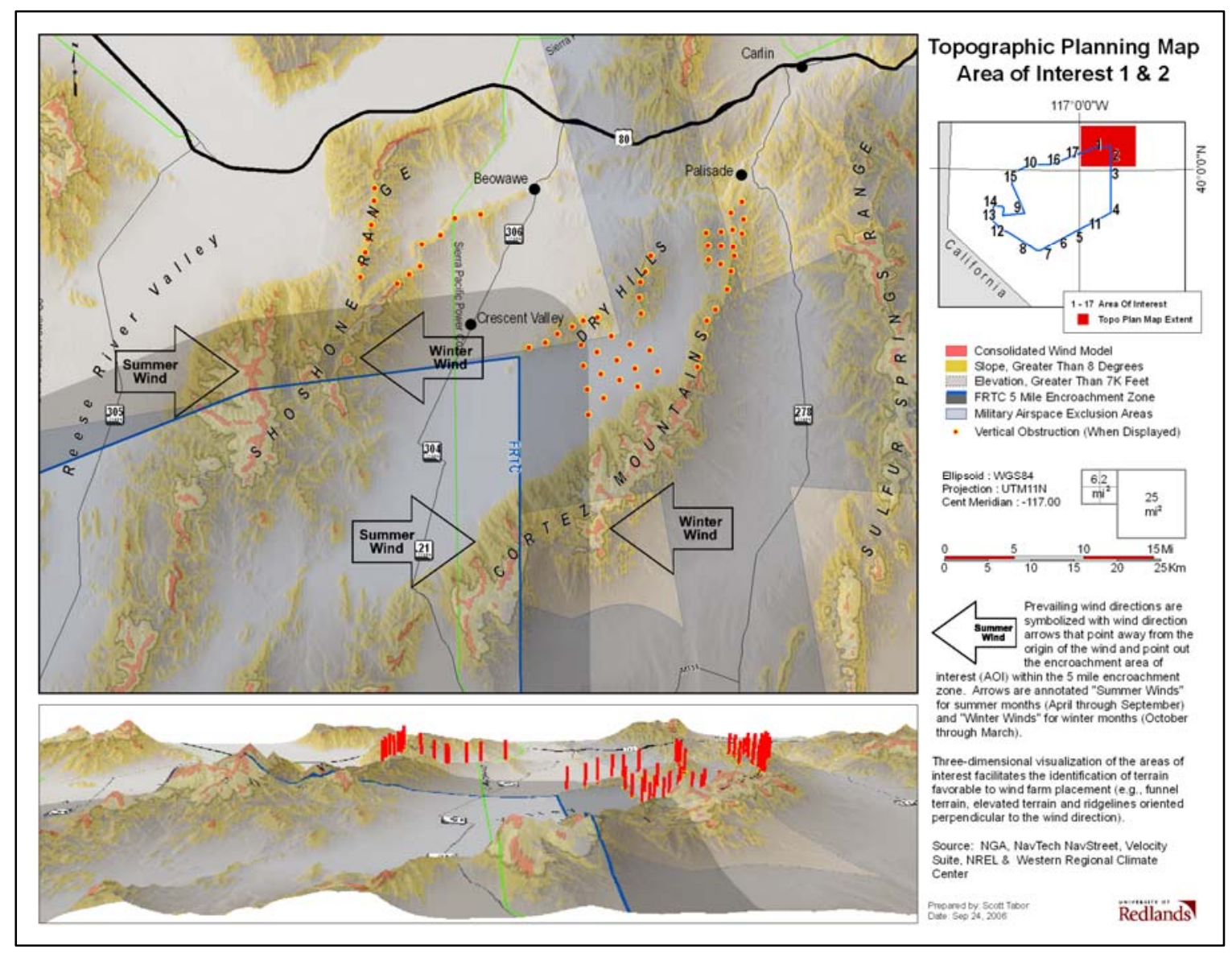

Figure 4-10. AOI-1 and AOI-2, Encroachment Potential.

The Reese River Valley and Cortez Mountains topographic planning map presents the study site and the two areas of interest, identified through topographic analysis, in accordance with previously described screening criteria. The potential for wind farm development encompasses approximately 76 square miles (197 square kilometers). Of the total development potential, 59 square miles (153 square kilometers) lie beneath military training airspace. Therefore, in total, $78 \%$ of the modeled development potential both AOIs reflects encroachment into military training airspace. More important, there remains 17 square miles (44 square kilometers) of development potential distinct from under military training airspace.

\subsection{Simpson Park Mountains, Area of Interest THREE.}

Area of interest three (AOI-3) is at the northern tip of the Simpson Park Mountains, between Nevada Highway 278 (to the east side) and 21 to the west. The prevailing wind direction is estimated using the nearest reporting climate station in Eureka, Nevada 
located 30 miles (48km) southeast of AOI-3, reporting from the south throughout the year (Western Regional Climate Center, 2006).

Visualized geographically on the AOI-3 topographic planning map (see Figure 4-11), paved roads (black line) and electric power line (green line) are evenly dispersed across the AOI. The wind direction arrow points towards the encroachment point of interest within the 5 mile encroachment zone, indicating the direction of the prevailing wind at this area of potential wind energy development.

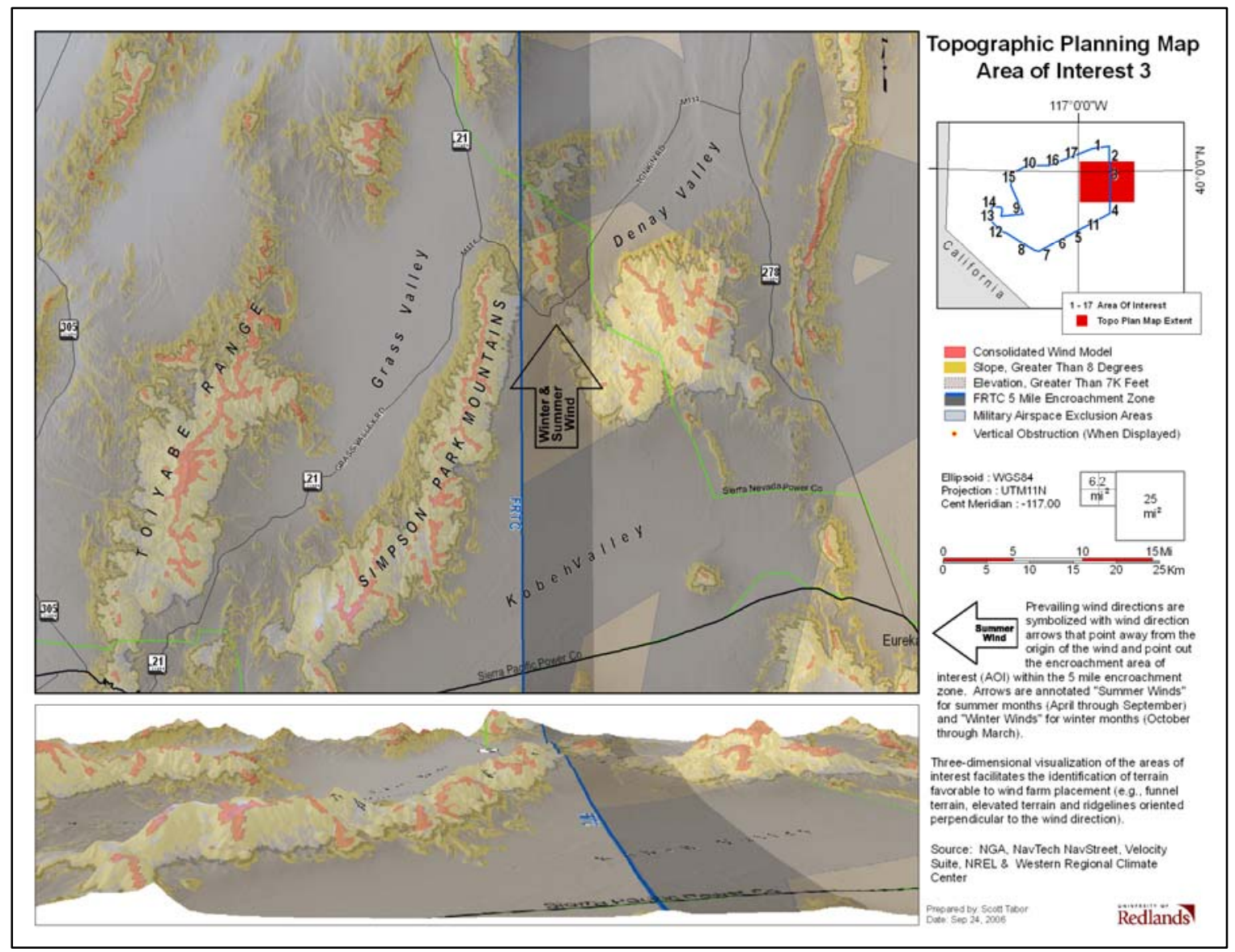

Figure 4-11. AOI-3 Topographic Planning Map.

\subsubsection{Simpson Park Mountains Topography.}

Illustrated in the main map of Figure 4-11, the Simpson Park Mountains are oriented north-south, on the west side of Kobeh Valley, converging with other topography at the northern end of the valley. Since the prevailing wind direction is from the south, the topography forms a very large funnel condensing the wind as it travels north towards the mountain passes where Tonkin Road crosses through the AOI. Thus, Kobeh Valley, 
located on the windward side of the elevated funnel topography creates topographic conditions commensurate to wind farm development. ${ }^{20}$

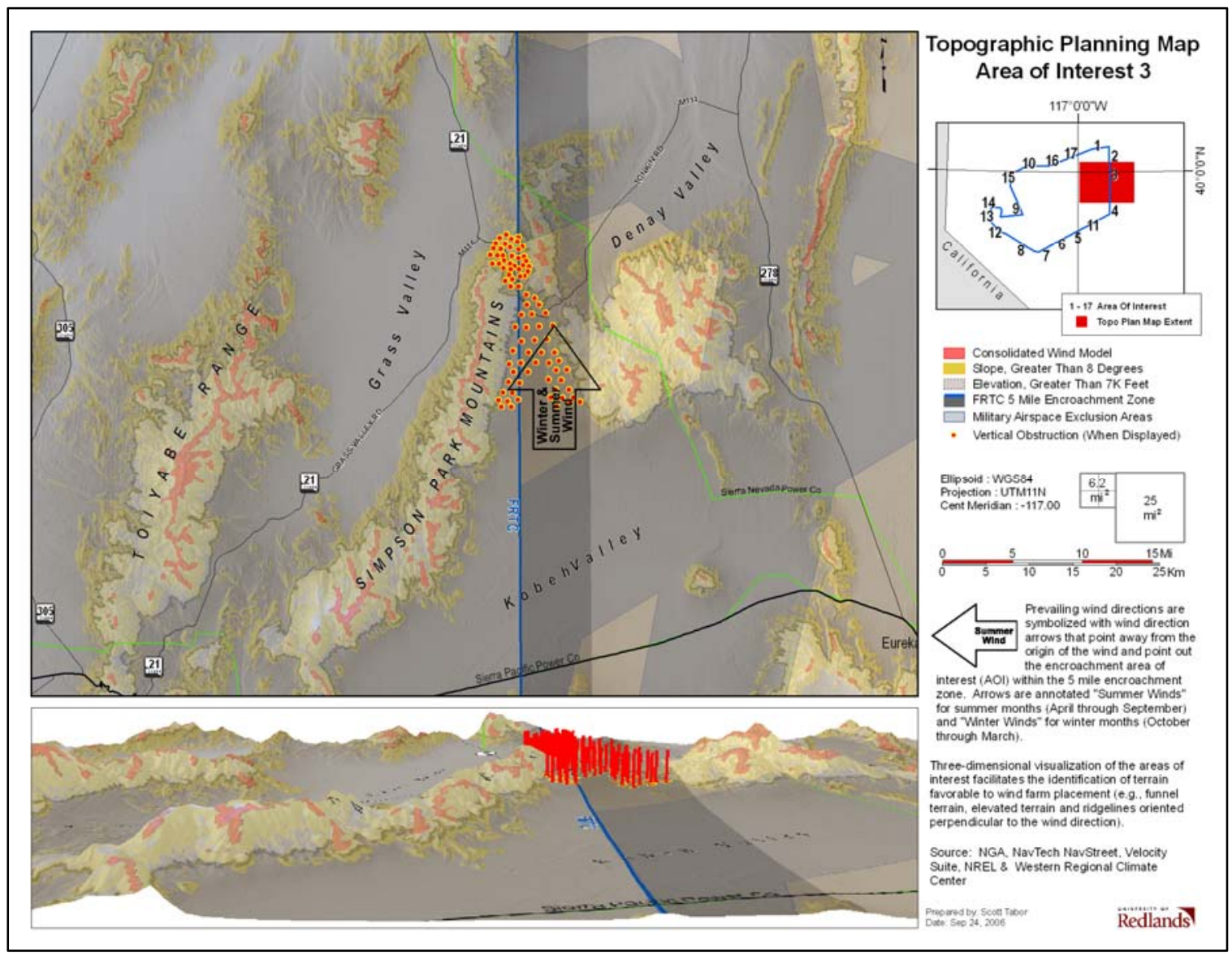

Figure 4-12. AOI-3 Encroachment Potential.

The northern end of Kobeh Valley slowly rises towards the northern end of Simpson Park Mountains creating a very large funnel opening. Inside the funnel, where Tonkin Road cuts through the northern pass, ridgelines running perpendicular to the funnel direction (i.e., perpendicular to the wind direction) create ideal topographic conditions for wind turbine placement. Wind flowing from the south would funnel, intensifying as it travels north through the mountain passes, while the ridgeline would allow developers to place wind turbines at optimal heights.

\subsubsection{Simpson Park Mountains Encroachment Potential.}

Planning maps of the Simpson Park Mountains showing topographic and potential vertical obstructions effectively present the areas of interest, identified through topographic analysis, in comparison with previously described funnel, plateau, and ridgeline screening criteria. Areas with the potential for wind farm development encompass approximately 40 square miles (104 square kilometers), all of which lie

\footnotetext{
${ }^{20}$ Windward refers to the side exposed to the wind.
} 
beneath military training airspace. Therefore, this area of interest presents an encroachment threat of $100 \%$ on the western border of the FRTC.

\subsection{Monitor Valley, Area of Interest FOUR.}

Area of interest four (AOI-4) is located on the northern tip of the Monitor Range with the Monitor Valley immediately to the north, and the Antelope Valley to the east. The prevailing wind direction is estimated using the nearest reporting climate station in Eureka, Nevada located 25miles $(40 \mathrm{~km})$ east of AOI-4, reporting from the south throughout the year (Western Regional Climate Center, 2006). This area of interest is located on the southeast corner of the FRTC.

The wind direction arrows point towards the encroachment points of interest within the 5 mile encroachment zone, indicating the direction of the prevailing wind at this area of potential wind energy development.

\subsubsection{Monitor Valley Topography.}

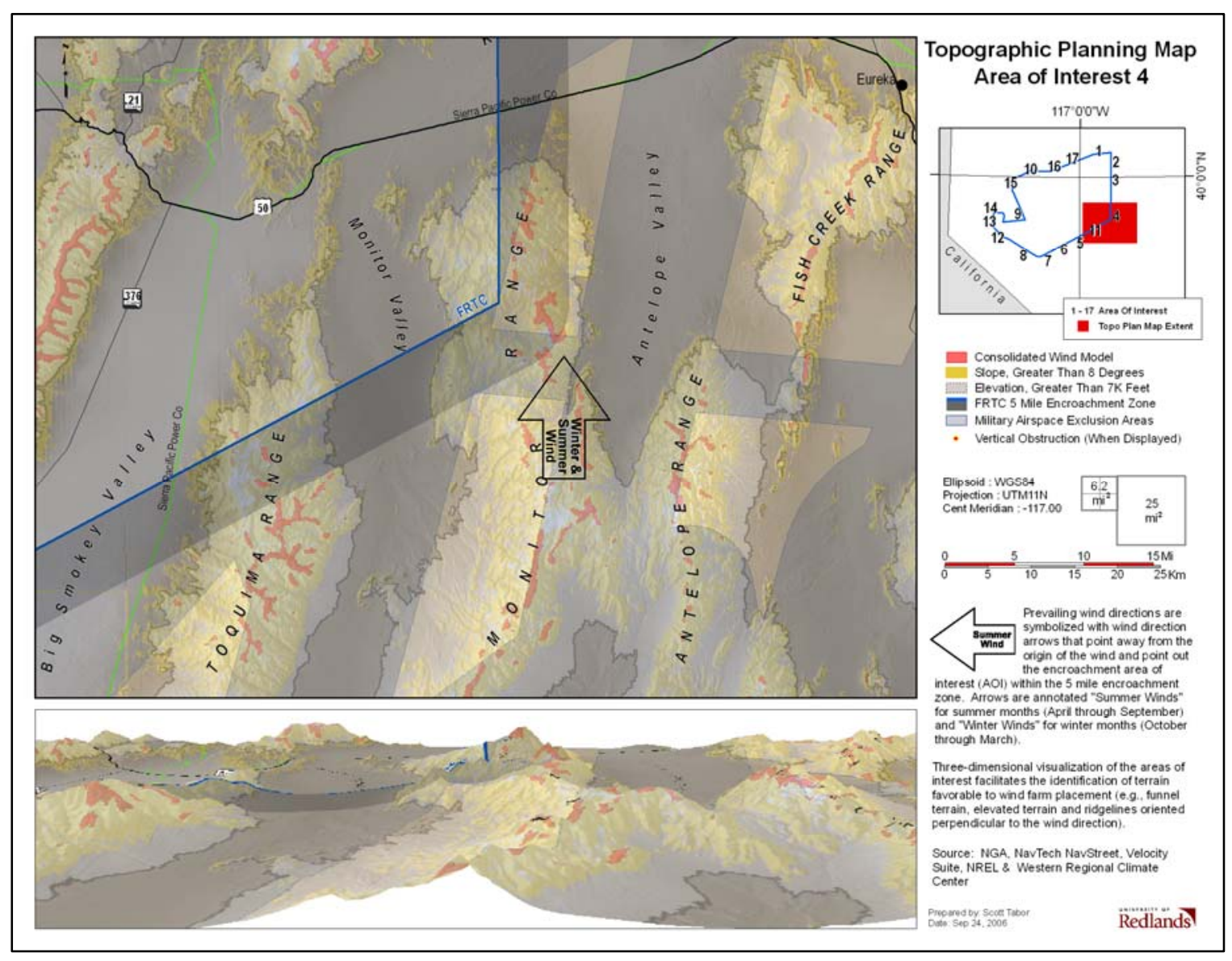

Figure 4-13. AOI-4 Topographic Planning Map. 
Visible in Figure 4-13, Antelope valley lies on the leaward side of the elevated terrain. ${ }^{21}$ The elevated terrain between Antelope and Monitor Ranges block as well as stir the wind rendering it less effective and less desirable for wind energy development.

Monitor Valley, oriented north-south (i.e., in the same direction as the prevailing wind direction), west of the Monitor Range and east of Toquima Range, presents potentially ideal conditions for wind development, presenting a vast funnel configuration that could potentially support a very large wind farm, especially at the narrows south of the FRTC five mile encroachment zone.

\subsubsection{Monitor Valley Encroachment Potential.}

Figure 4-14 illustrates the potential development that could occur in the Monitor Valley. The area indicated by the red vertical obstructions consists of approximately 192 square miles (497 square kilometers) of development potential. All but four square miles (10 square kilometers) reside beneath military airspace, presenting a significant threat (i.e., $97 \%$ ) of encroachment.

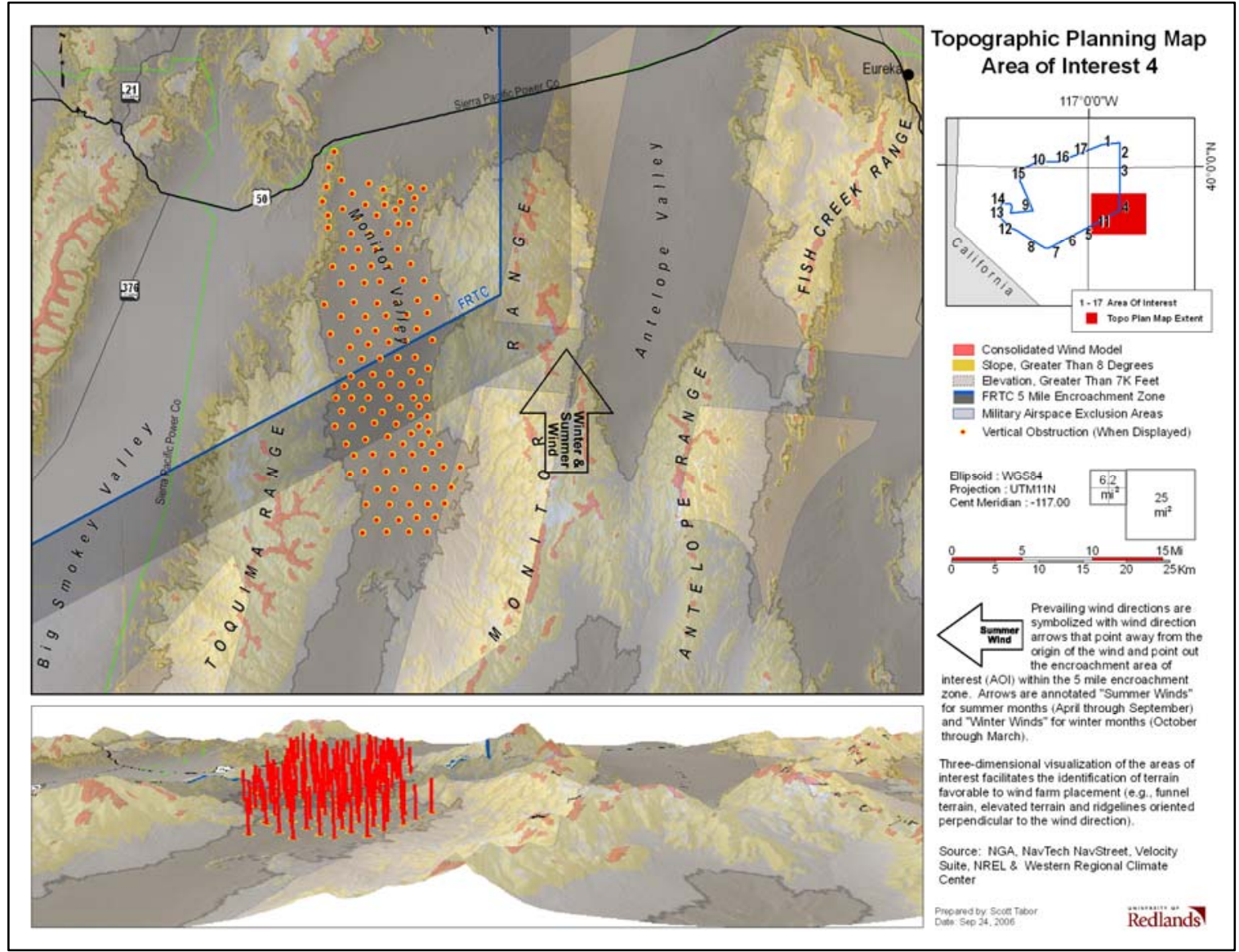

Figure 4-14. AOI-4 Encroachment Potential.

\footnotetext{
${ }^{21}$ Leeward refers to the side away from the wind.
} 


\subsection{Big Smokey and Ione Valley, Area of Interest FIVE, SIX and ELEVEN.}

Areas of interest five, six and eleven (AOI-5, AOI-6 and AOI-11) cover the southern tip of the Toiyabe Range and Shoshone Mountains, where they begin to separate, and the northern end of the Toquima Range, The prevailing wind direction is estimated using the nearest reporting climate station in Tonopah, Nevada located 50 miles $(80 \mathrm{~km})$ south of AOI-5, AOI-6 and AOI-11, reporting from the north throughout the year (Western Regional Climate Center, 2006). These areas of interest are located on the south-central edge of the FRTC. The wind direction arrows point towards the encroachment points of interest within the 5 mile encroachment zone, indicating the direction of the prevailing wind at this area of potential wind energy development.

\subsubsection{Big Smokey and Ione Valley Topography.}

Figure 4-15 illustrates the topographic conditions of these AOIs. Ione Valley is oriented North, bound by the Shoshone Mountains to the east and the Gabbs Valley Range to the west creating a large funnel. Carico Lake Valley is oriented North, on the windward side of the elevated terrain created by the Shoshone Mountains and Toiyabe Range. Big Smokey Valley is also oriented North, bound by the Toiyabe Range to the West and the Toquima mountain range to the East, also creating a large funnel.

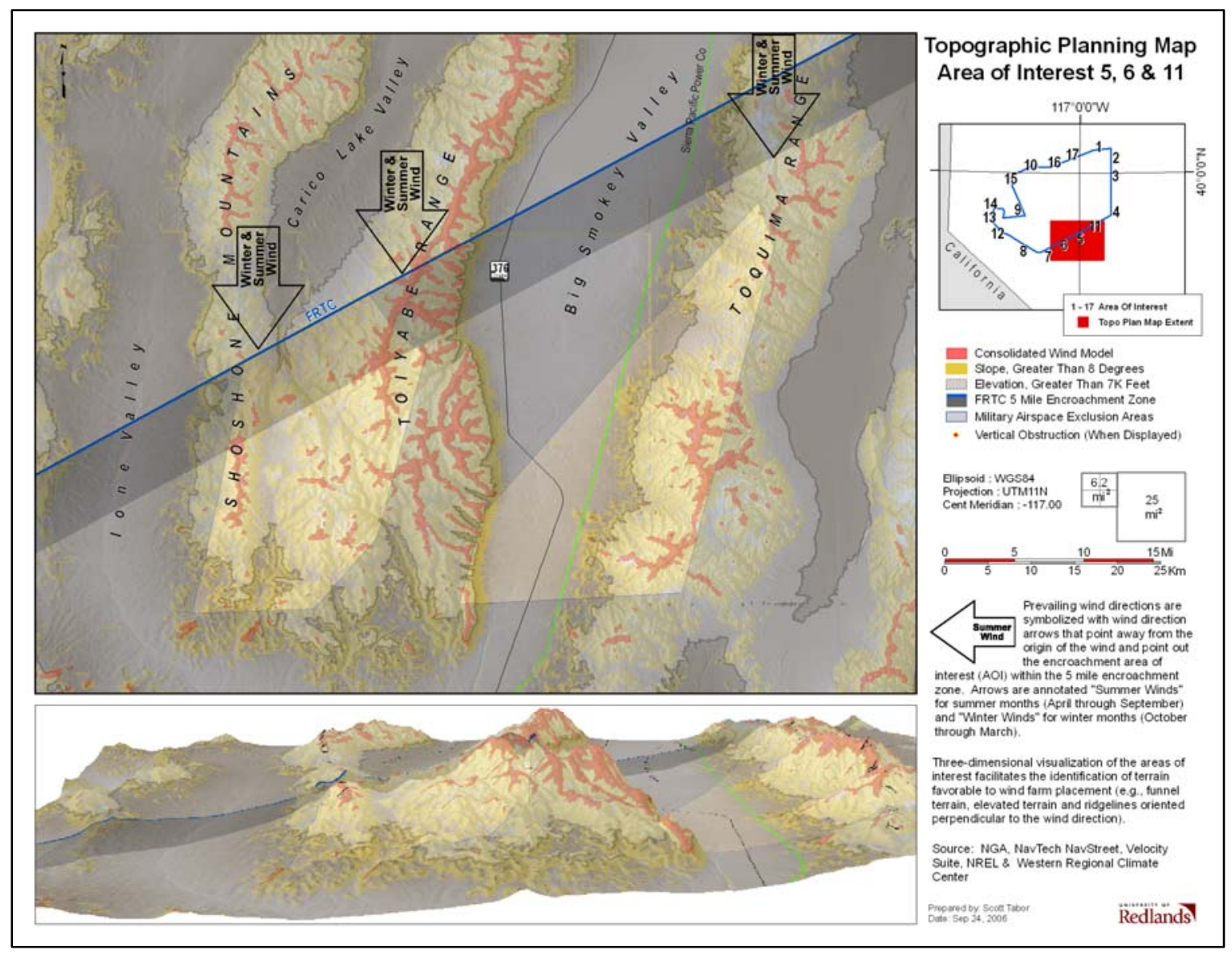

Figure 4-15. AOI-5, AOI-6 and AOI-11 Topographic Planning Map. 
Carico Lake Valley was not analyzed because it is an AOI with development potential that lies beyond the 25 mile $(40 \mathrm{~km})$ electric power grid limitation (discussed in sections 2.4 and 3.5). Big Smokey Valley is approximately 100 miles $(161 \mathrm{~km})$ long with Nevada state route 376 and an electric power transmission line running through the length of the entire valley.

\subsubsection{Big Smokey and Ione Valley Encroachment Potential}

Figure 4-16 illustrates the amount of development that could occur in both the Ione and Big Smokey valleys. The areas indicated by the red and yellow points in the main map and the red vertical obstructions in the perspective view, consists of approximately 680 square miles $(1,094 \mathrm{~km})$ of development potential. All but 160 square miles (414 square kilometers) reside beneath military airspace, presenting a significant threat (i.e., 65\%) of encroachment.

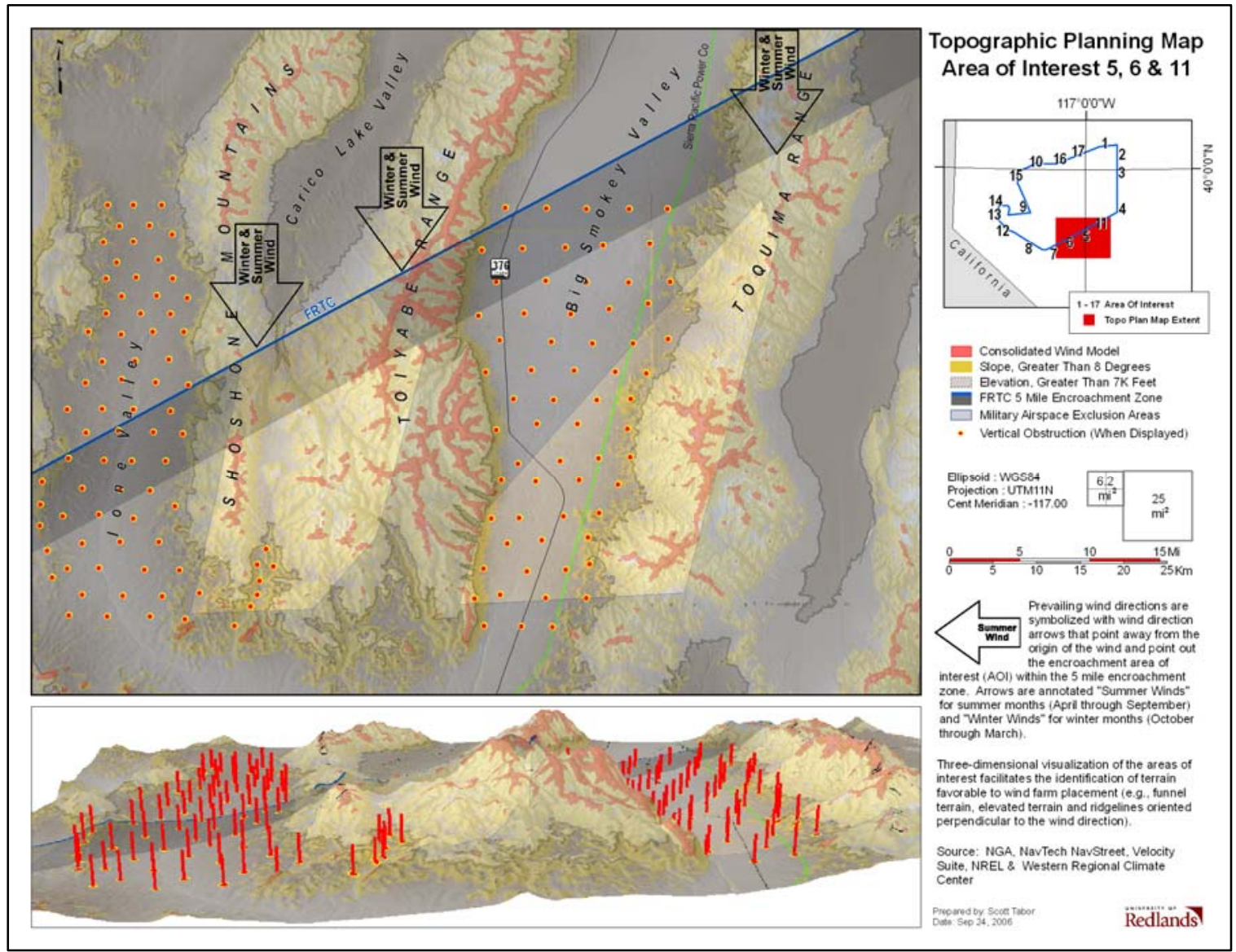

Figure 4-16. AOI-5, AOI-6 and AOI-11 Encroachment Potential.

\subsection{Sand Mountain, Area of Interest NINE.}

Area of interest nine (AOI-9) is located on the southern foothills of the Stillwater Range. The prevailing wind direction is estimated using the nearest reporting climate station in Fallon Naval Air Station, Nevada located 25miles (40km) northwest of AOI-9, reporting 
from the north in the summer months and from the south in the winter months (Western Regional Climate Center, 2006). This area of interest is located on the west-central edge of the FRTC.

The wind direction arrows point towards the encroachment point of interest within the 5 mile encroachment zone, indicating the direction of the prevailing wind at this area of potential wind energy development.

\subsubsection{Sand Mountain Topography.}

Figure 4-17 illustrates the Sand Mountain area of interest. The entire area presents a mixture of topographic features indicative of improved wind performance. The elevated terrain created by the southern foothills of the Stillwater Range, Buenejug and White Throne Mountains comprise approximately $66 \%$ of the western side of this AOI, presenting a significant amount of highland topography. Additionally, the east side of this AOI (southern end of Dixie Valley) presents an undulating funnel, oriented northsouth, all of which provide a considerable amount of area for wind farm production.

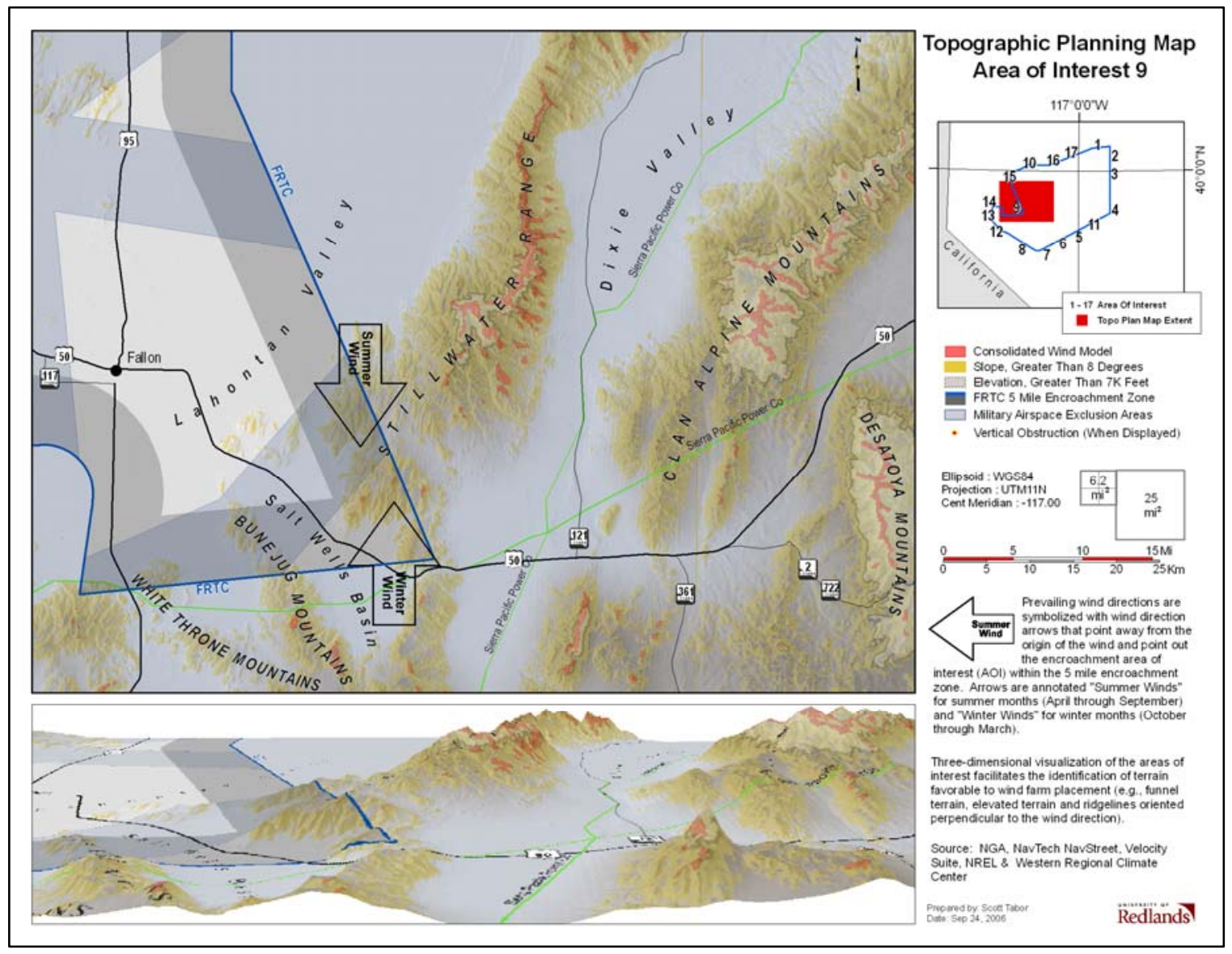

Figure 4-17. AOI-9 Topographic Planning Map. 


\subsubsection{Sand Mountain Encroachment Potential.}

Figure 4-18, (i.e., AOI-9 topographic planning map), illustrates the amount of development that could occur in this area. The area indicated by the red and yellow points in the main map and the red vertical obstructions in the perspective view, consists of approximately 367 square miles (951 square kilometers) of development potential. All but 34 square miles (88 square kilometers) resides beneath military airspace. Approximately $90 \%$ of this area's development potential lies beneath military airspace, thus presenting a significant threat of encroachment.

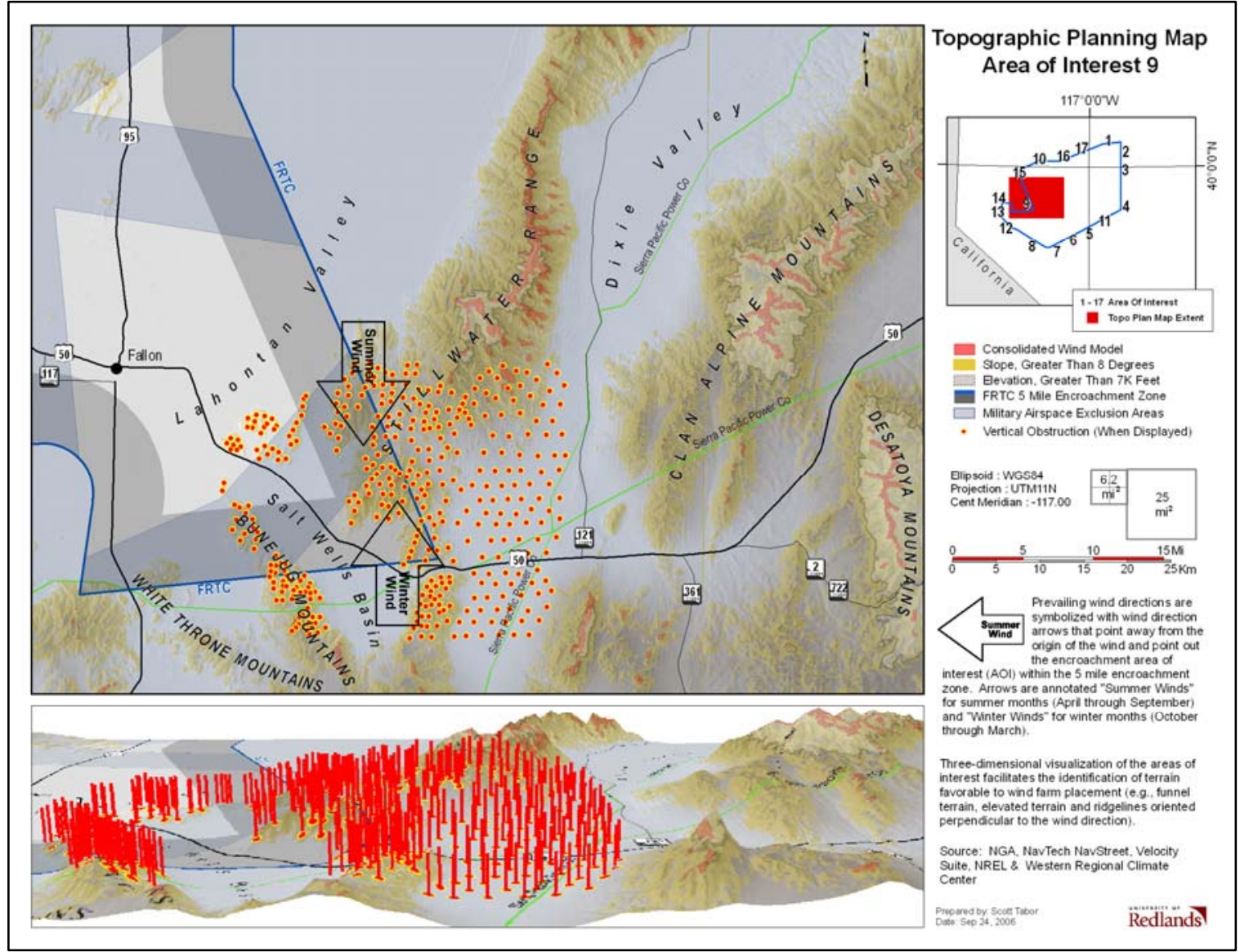

Figure 4-18. AOI-9 Encroachment Potential.

\subsection{Lovelock, Area of Interest TEN and FIFTEEN.}

Areas of interest 10 and 15 (AOI-10 and AOI-15) are located east and southwest of Lovelock, Nevada, both at a distance of approximately 20 miles $(32 \mathrm{~km})$, respectively. The prevailing wind direction is estimated using the nearest reporting climate station in Lovelock Municipal Airport, reporting from the northeast year around (Western Regional Climate Center, 2006). 
The wind direction arrows point towards the encroachment points of interest within the 5 mile encroachment zone, indicating the direction of the prevailing wind at these areas of potential wind energy development.

\subsubsection{Lovelock Topography.}

The prevailing topographic features desired for wind energy development in this AOI are elevated terrain and funnel topography. Since the prevailing wind direction is from the northeast, the wind accommodates the elevated terrain of the southern West Humbolt Range and the perpendicular ridgelines of the southern Humbolt Range. The two valleys, flanked by the Trinity Range, both Humbolt Ranges and the Stillwater Range provides a vast amount of funnel topography.

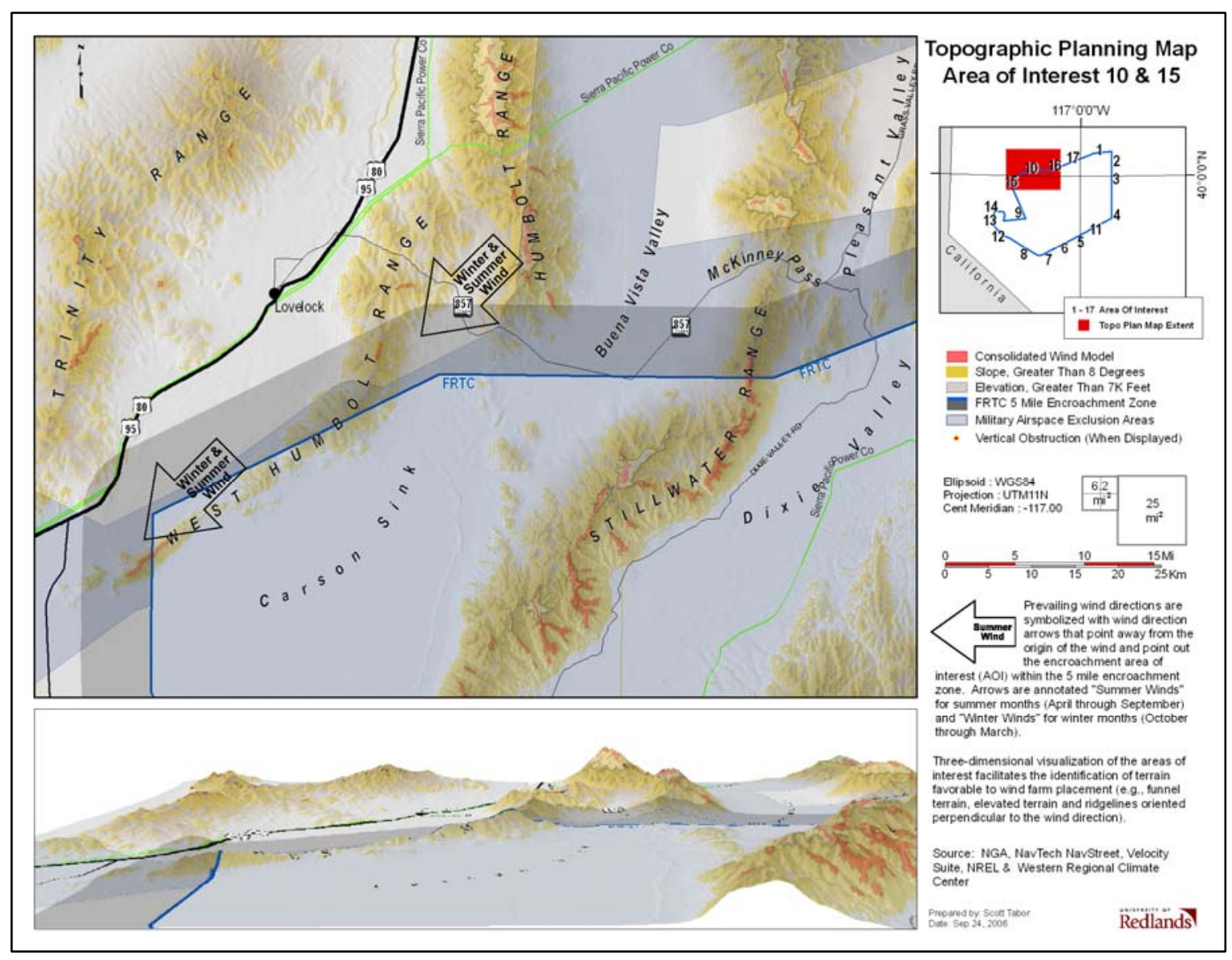

Figure 4-19. AOI-10 and AOI-15 Topographic Planning Map.

\subsubsection{Lovelock Encroachment Potential}

Figure 4-20 illustrates the amount of development that could potentially occur in this area. The area indicated by the red and yellow points in the main map and the red vertical obstructions in the perspective view consist of approximately 612 square miles (1,585 square kilometers) of development potential. Approximately half (i.e., 323 square 
miles, 837 square kilometers) resides beneath military airspace. This results in $47 \%$ of this area's development potential laying beneath military airspace presenting a significant threat of encroachment.

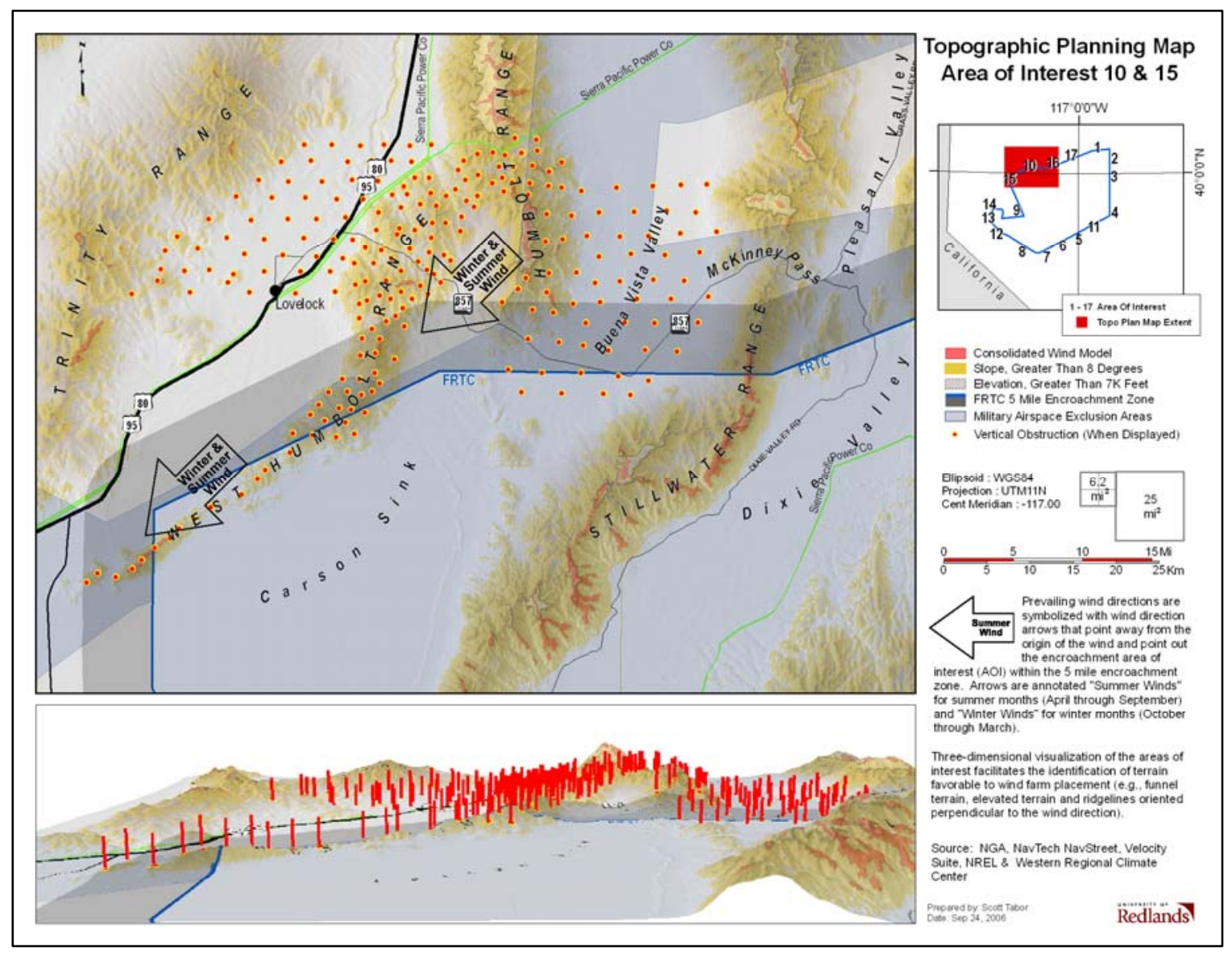

Figure 4-20. AOI-10 and AOI-15 Encroachment Potential.

\subsection{Area of Interest ELEVEN.}

Encroachment analysis for area of interest 11 (AOI-11) was covered in the AOI-5 and AOI-6 chapters.

\subsection{Yerington, Area of Interest TWELVE.}

Area of interest 12 (AOI-12) is located approximately 15 miles (25km) east of Yerington, Nevada. The prevailing wind direction is estimated using the nearest reporting climate station at the Hawthorne Municipal Airport, reporting from the west in the summer months and from the east in the winter months (Western Regional Climate Center, 2006). The wind direction arrows point towards the encroachment point of interest within the 5 mile encroachment zone, indicating the direction of the prevailing wind at this areas of potential wind energy development. 


\subsubsection{Yerington Topography.}

Because the prevailing wind direction is east and west, the dominant topographic features that are conducive to wind energy development, are ridgelines perpendicular to wind direction, located below the 7,000 feet (2,134 m) elevation limitation, as well as, elevated topography such as the foothills extending north from the Wassuk Range, and the northsouth topography of the mountains west of Yerington.

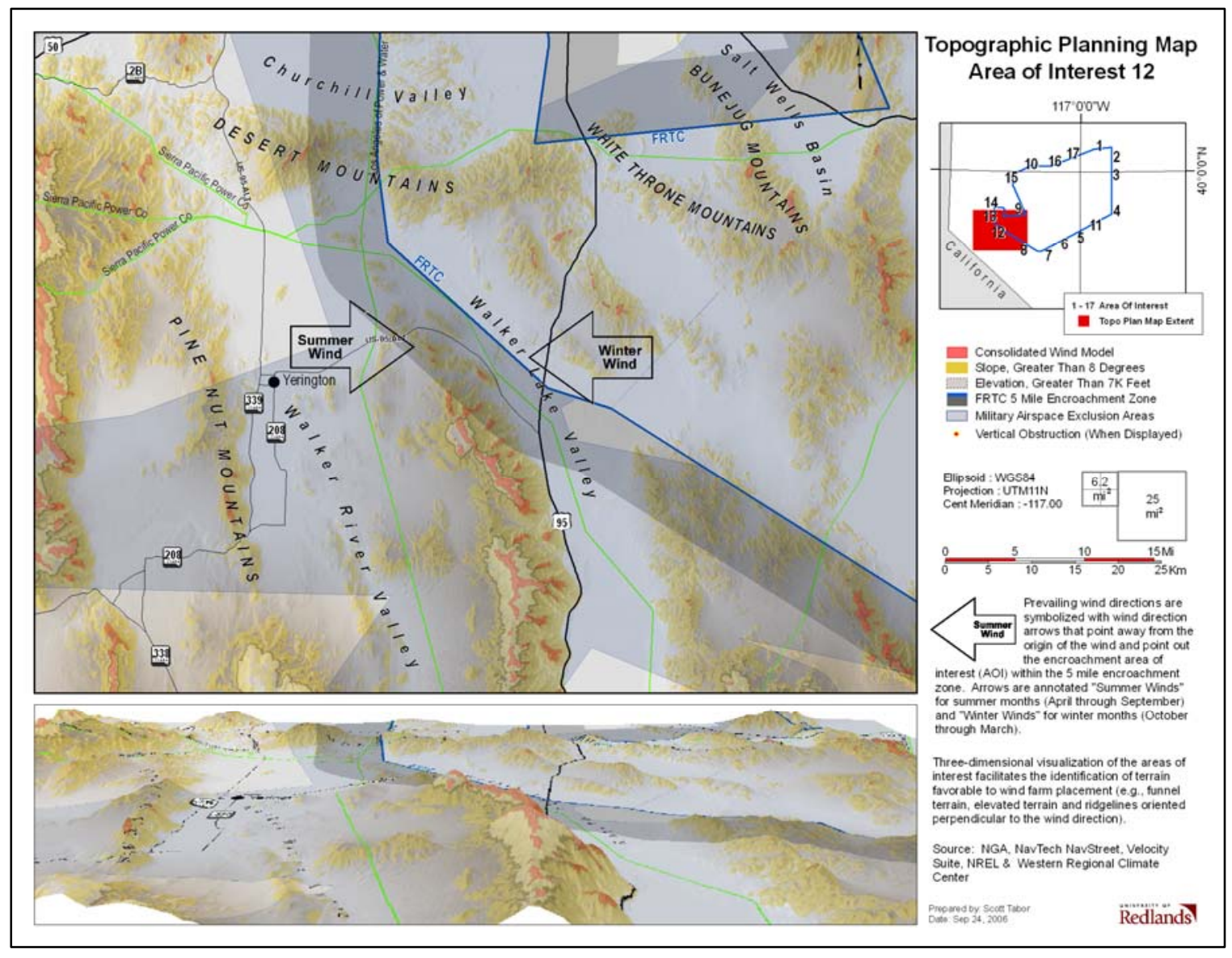

Figure 4-21. AOI-12 Topographic Planning Map.

\subsubsection{Yerington Encroachment Potential.}

Figure 4-23 demonstrates the amount of development that could occur in this area. The area indicated by the red and yellow points in the main map and red vertical obstructions in the perspective view consists of approximately 160 square miles (414 square kilometers) of development potential. Approximately 19\% (i.e., 31 square miles, 80 square kilometers) resides outside of military airspace. Therefore, $81 \%$ of this area's development potential lies beneath military airspace, presenting a significant threat of encroachment. 


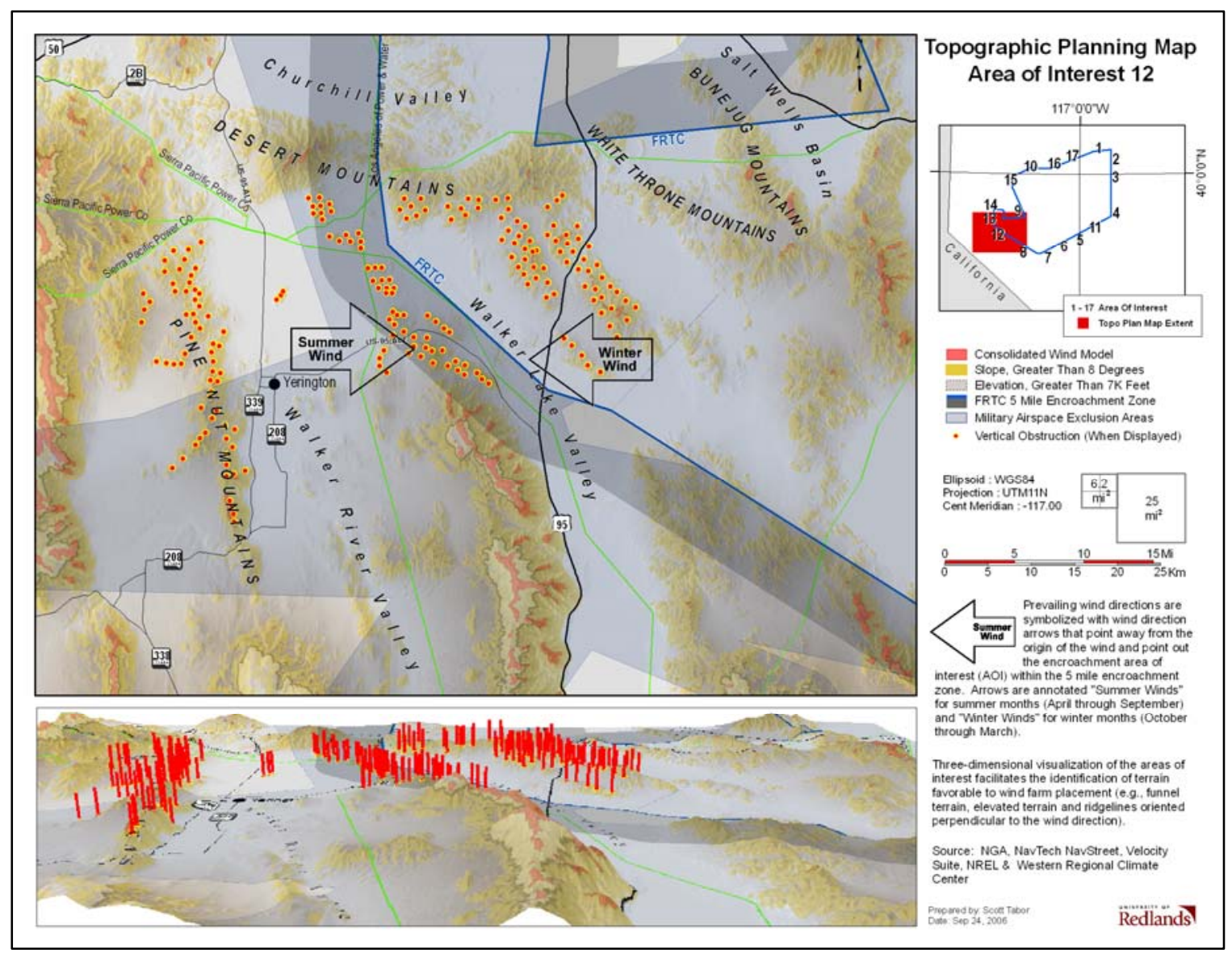

Figure 4-22. AOI-12 Encroachment Potential.

\subsection{Lahontan, Area of Interest THIRTEEN and FOURTEEN.}

Areas of interest 13 and 14 (AOI-13, AOI-14) are located north and south of each other, in the Virginia Range and Desert Mountains, flanking Churchill Valley. The prevailing wind direction is estimated using the nearest reporting climate station at the Fallon Naval Air Station, reporting from the north in the summer months and from the south in the winter months (Western Regional Climate Center, 2006). The wind direction arrows point towards the encroachment point of interest within the 5 mile encroachment zone, indicating the directions of the prevailing wind at this areas of potential wind energy development.

\subsubsection{Lahontan Topography.}

The prevailing desired topography (i.e., topographic features inherent to improved wind speeds and consistency), in this AOI, are elevated terrain. Illustrated in Figure 4-23, in areas like this where the only topography is elevated terrain created by the Virginia Range and Desert, White Throne and Bunejug Mountains, wind direction is not as critical a factor in lieu of ridgelines and funnel topography. 


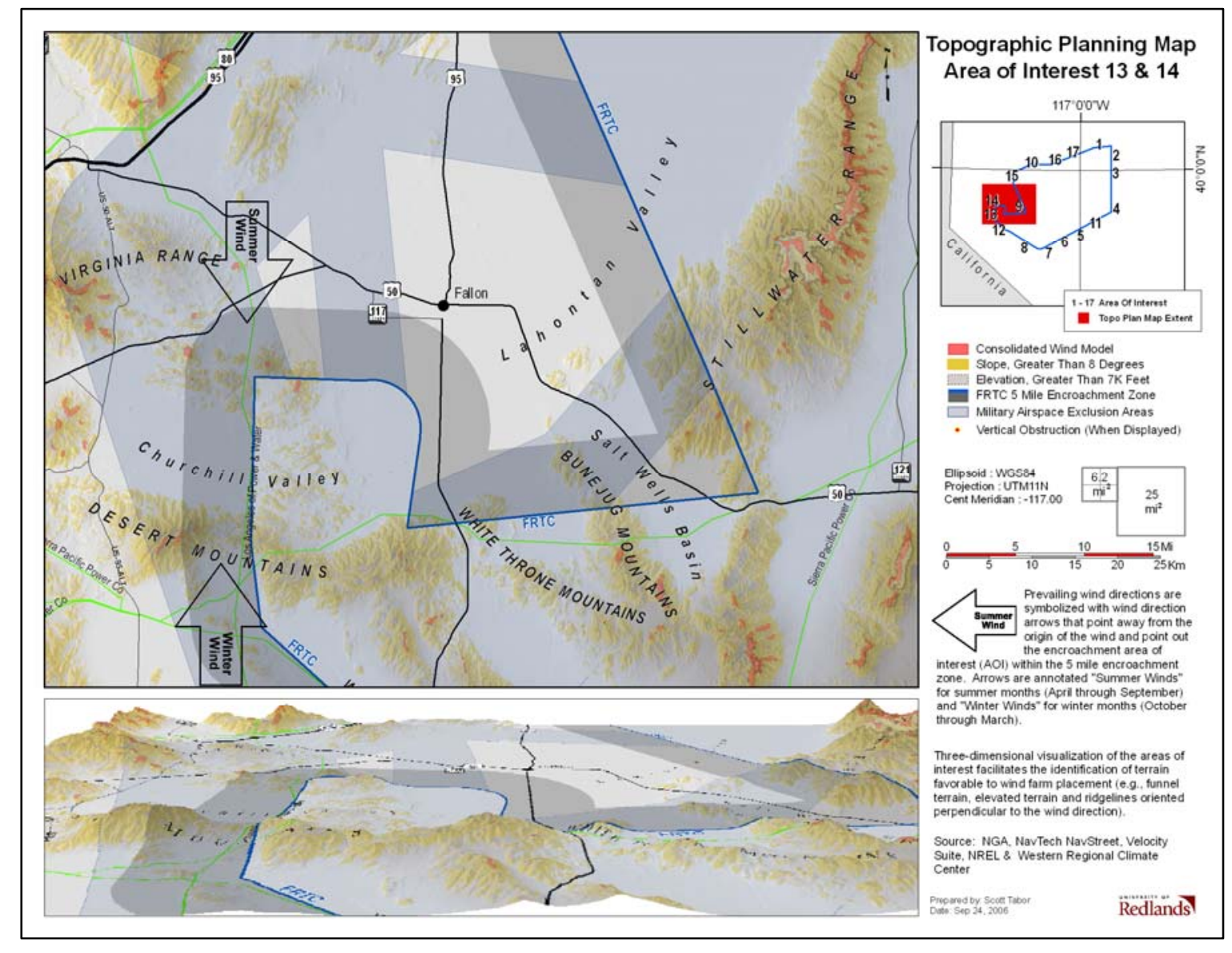

Figure 4-23. AOI-13 and AOI-14 Topographic Planning Map.

\subsubsection{Lahontan Encroachment Potential.}

Figure 4-25 demonstrates the amount of development that could occur in this area. The area indicated by the red and yellow points in the main map and the red vertical obstructions in the perspective view consists of approximately 277 square miles (717 square kilometers) of development potential. Thus, approximately 89\% (i.e., 249 square miles, 645 square kilometers) resides beneath military airspace, presenting a significant threat of encroachment. 


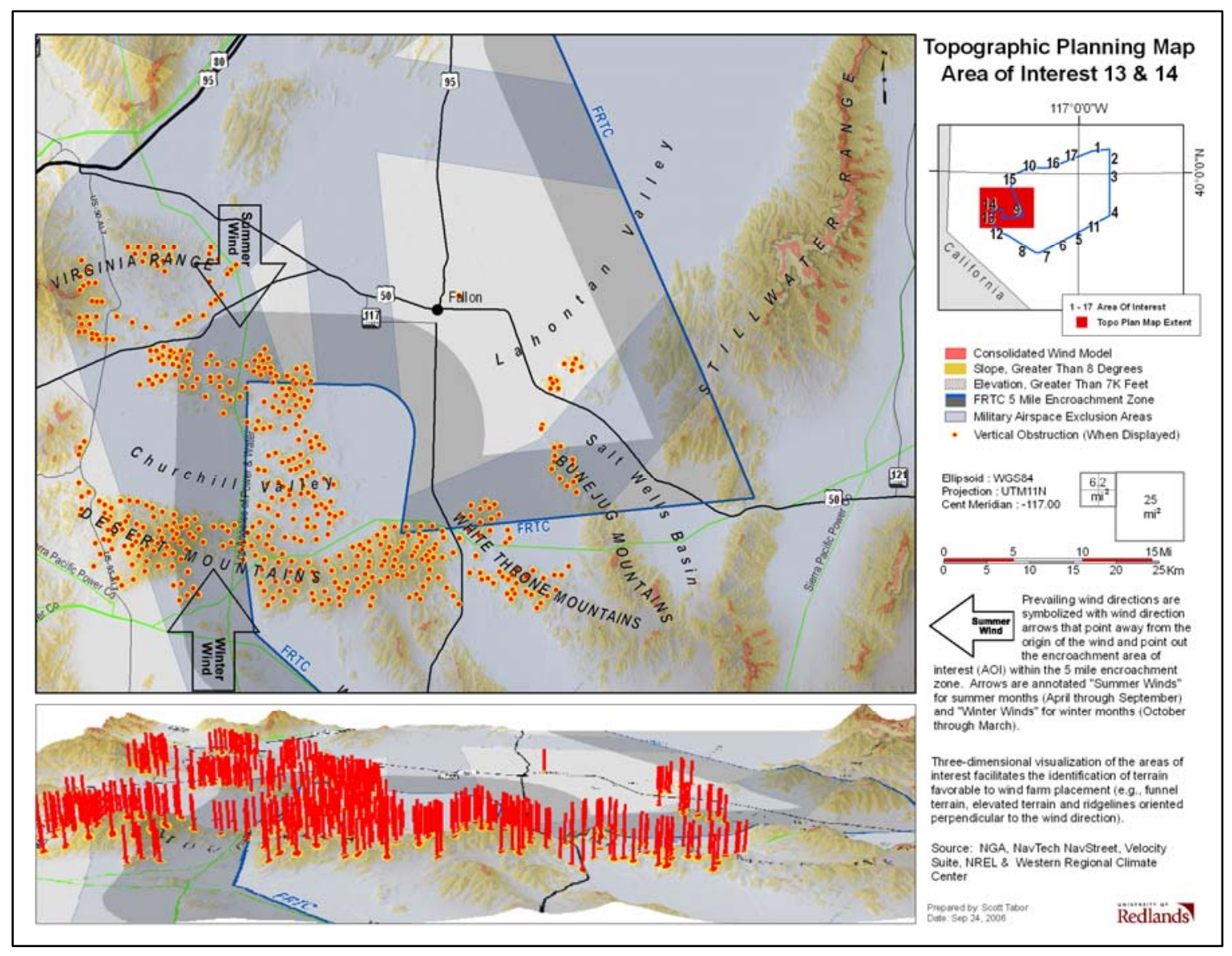

Figure 4-24. AOI-13 and AOI-14 Encroachment Potential.

\subsection{Humbolt Wildlife Area, Area of Interest FIFTEEN.}

Encroachment analysis for area of interest 15 (AOI-15) was covered in the AOI-10 chapter.

\subsection{Tobin Range, Area of Interest SIXTEEN and SEVENTEEN.}

Areas of interest 16 and 17 (AOI-16 and AOI-17) are located on the north-central edge of the FRTC perimeter, in the northern end of the Stillwater Range, south of McKinney Pass, in the southern foothills of the Tobin Range, north of Dixie Valley, and in the northern foothills of the Fish Creek Mountains, between Buffalo and Reese River Valleys. The prevailing wind direction is estimated using the nearest reporting climate station at the Lovelock Municipal Airport, reporting from the northeast, year around (Western Regional Climate Center, 2006). The wind direction arrows point towards the encroachment point of interest within the 5 mile encroachment zone, indicating the directions of the prevailing wind at this areas of potential wind energy development. 


\subsubsection{Tobin Range Topography.}

Demonstrated in figure 4-25, this AOI presents a combination of funnel, ridgeline, and elevated terrain conditions that are conducive to wind energy development. Both the Pleasant and Buffalo valleys present funnel topography, oriented northeast, in the same direction of the prevailing winds. Additional funnel topography exists between the southern foothills of the Tobin Range and the main body of the Tobin Range and the Stillwater Range, southeast of McKinney Pass. Oriented east-west, ridgelines extending into Pleasant Valley from both the Tobin and East Ranges, also present favorable wind turbine placement opportunity. Additionally, the foothills of the Fish Creek Mountains provide elevated terrain conditions that could potentially favor wind energy development.

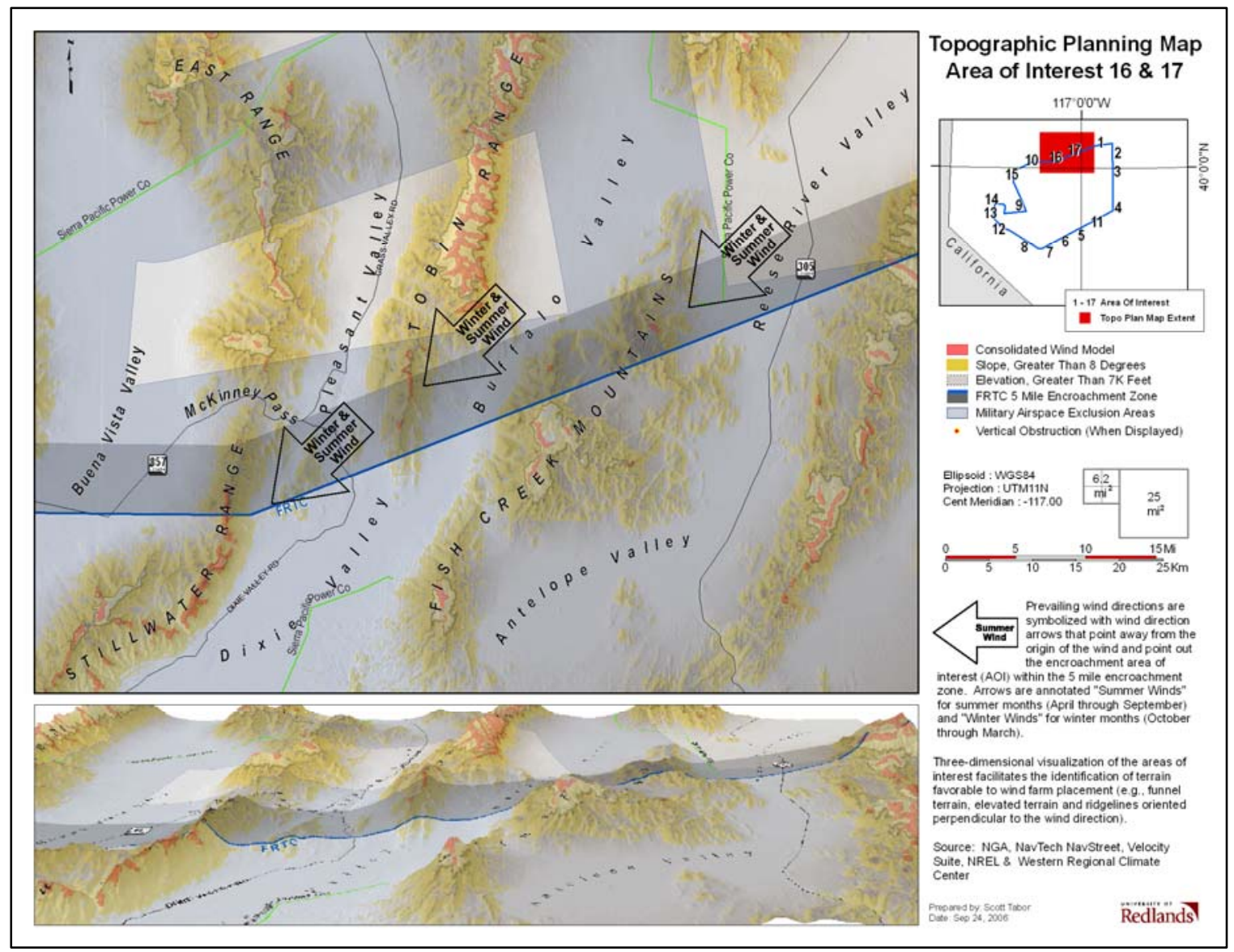

Figure 4-25. AOI-16 and AOI-17 Topographic Planning Map.

\subsubsection{Tobin Range Encroachment Potential.}

Figure 4-27 illustrates the amount of development that could occur in this area. The area indicated by the red and yellow points in the main map and the vertical obstructions in the perspective view consists of approximately 385 square miles (997 square kilometers) 
of development potential. Approximately 78\% (i.e., 302 square miles, 782 square kilometers) resides beneath military airspace, presenting a significant threat of encroachment.

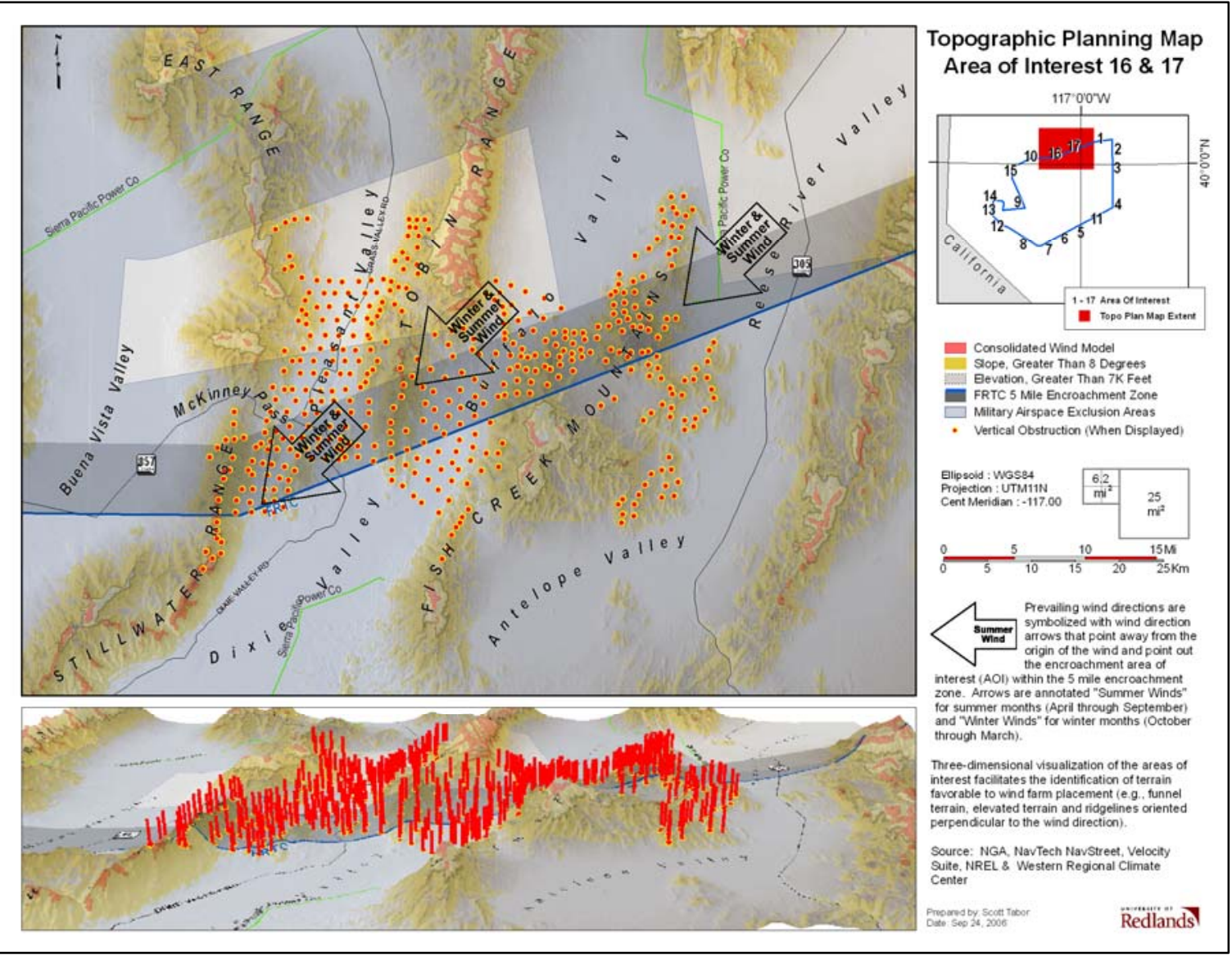

Figure 4-26. AOI-16 and AOI-17 Encroachment Potential.

\subsection{Fallon Range Training Complex Encroachment Findings.}

As a result of wind turbine placement, encroachment into the FRTC would translate into an unplanned and unmanaged change in the airspace's usability, potentially affecting the training mission of the range. The opportunity may arise, however, when development within the FRTC will be desired and thus be planned for in a manner that would minimize any adverse effect to the training mission, in accordance with risk management recommendations discussed in chapter 3.4.1. In that situation, encroachment would not have occurred and it would not be appropriate to include it within the encroachment description.

In the spirit of the DoD definition of encroachment, the greatest risk comes from development outside of the FRTC, along its perimeter. In the preceding sections, encroachment was visualized geographically as development that occurs outside of 
military airspace but eventually grows into military airspace, driven by the momentum of commerce. Geospatial analysis assessed the probability of this type of encroachment as a ratio of development outside of military airspace in relation to the total sum of development that could occur, outside and beneath military airspace.

In order to fully assess the amount of development and encroachment potential, analysis illustrating the development potential in each AOI was quantified by revisualizing it as an area rather than dispersed points. Figure 4-27 illustrates the development potential assessed in AOI 7 and 8 . The area highlighted in red equates to 366 square miles of total development potential beneath military training airspace, while the area highlighted green illustrates the 59 square miles not beneath military training airspace. It is appropriate to emphasize that the potential development assessment is based on an examination of the AOI, by the author, analyzing the 9 spatial phenomena in a 3D format. Thus, the assessments of development and encroachment potential, although rooted in fact, are subjective.

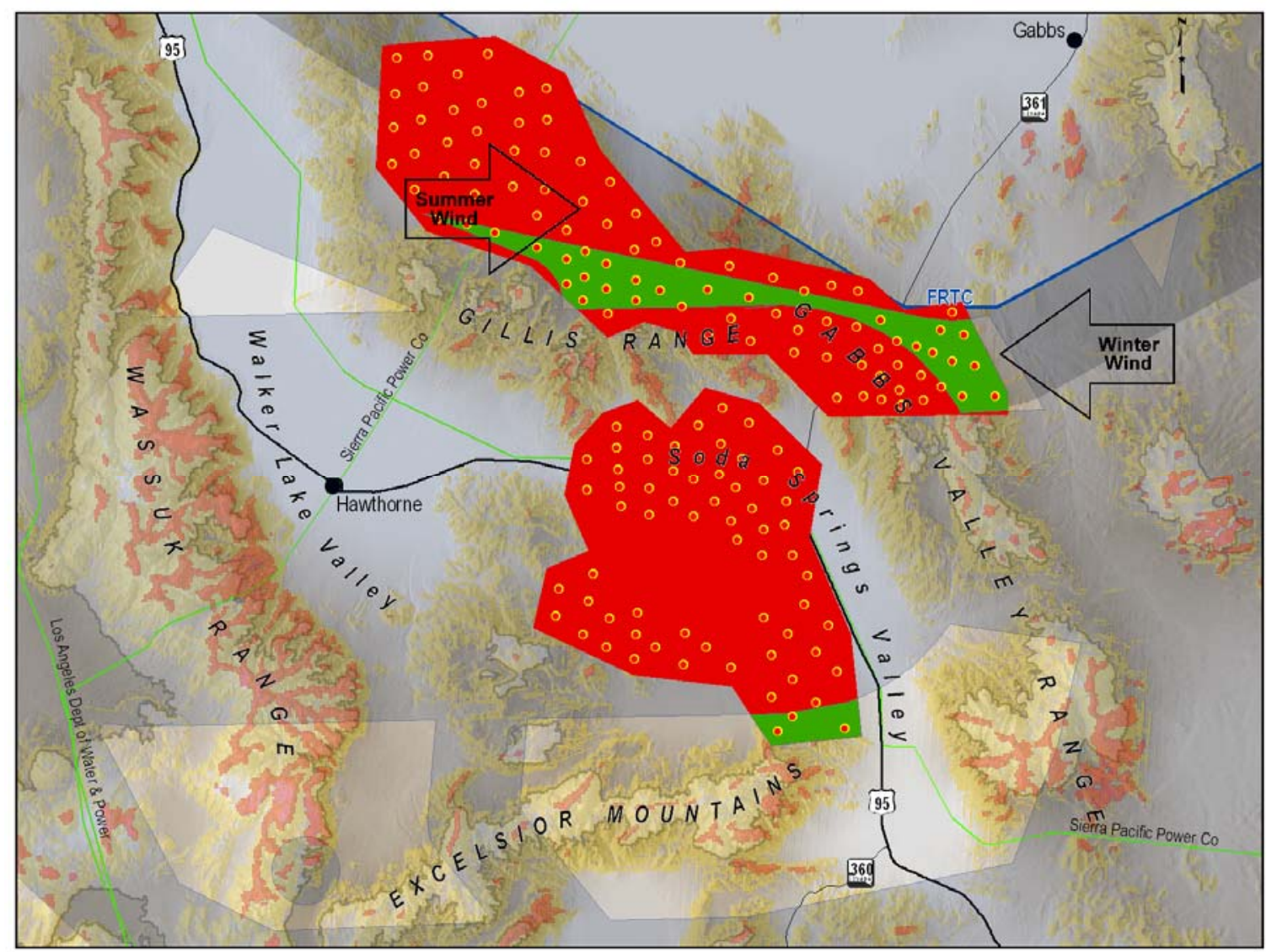

Figure 4-27. Calculating Development and Encroachment Potential

Figure 4-28 quantifies the amount of potential risk to the FRTC from wind energy development related encroachment. The "Percentage of Encroachment" column in Figure 4-28 quantifies the ratio of development potential beneath airspace to the total 
development potential. It is the percentage of encroachment and average encroachment percentage that identifies the level of encroachment risk.

\begin{tabular}{|c|c|c|c|c|}
\hline $\begin{array}{l}\text { Area Of } \\
\text { Interest }\end{array}$ & $\begin{array}{l}\text { Total Development } \\
\text { Potential (Sq Miles) }\end{array}$ & $\begin{array}{c}\text { Part } \\
\text { Beneath } \\
\text { Airspace }\end{array}$ & $\begin{array}{c}\text { Part } \\
\text { Outside } \\
\text { Airspace }\end{array}$ & $\begin{array}{l}\text { Percentage of } \\
\text { Encroachment }\end{array}$ \\
\hline $1 \& 2$ & 76 & 59 & 17 & $78 \%$ \\
\hline 3 & 40 & 40 & 0 & $100 \%$ \\
\hline 4 & 192 & 188 & 4 & $98 \%$ \\
\hline $5 \& 6 \& 11$ & 425 & 366 & 59 & $86 \%$ \\
\hline $7 \& 8$ & 425 & 248 & 248 & $58 \%$ \\
\hline 9 & 367 & 333 & 34 & $91 \%$ \\
\hline $10 \& 15$ & 612 & 323 & 279 & $53 \%$ \\
\hline 12 & 160 & 129 & 31 & $81 \%$ \\
\hline $13 \& 14$ & 277 & 249 & 28 & $90 \%$ \\
\hline $16 \& 17$ & 385 & 302 & 83 & $78 \%$ \\
\hline Totals: & 2959 & 2237 & 783 & $76 \%$ \\
\hline
\end{tabular}

Figure 4-28. Quantification of Encroachment Potential.

Overall, the threat of wind energy related encroachment to the FRTC is high, at $76 \%$. Looking at all the 17 AOIs individually, some pose more risk than others, regardless of whether the AOIs were assessed individually or as a group. 


\section{Techniques, Procedures and Metadata and Conclusions.}

GIS analysis and the sophisticated analytic techniques employed in this project are not always inherently intuitive. Therefore, analytic projects like this one are not complete until the techniques and procedures employed, as well as analytic assessments, are explained clearly and effectively.

As is the case in any scientific endeavor, analysis is pointless if it doesn't enlighten as well as inspire the correct course of action. There is an old saying in the Intelligence business; "If you can't convince your boss to take a specific course of action and, at the end of the day you were right and your boss was wrong, it is still an intelligence failure.” It is an intelligence failure because simply analyzing without qualifying the data and effectively delivering the message to your boss, alone, is unfinished and ineffective intelligence.

The information and findings discussed in this section represent the last step of the fourstep analysis process employed by this project. This step solidifies analysis, adding credibility to the final assessments by demonstrating analytic methods and procedures in order to increase awareness and understanding.

\subsection{Metadata.}

The relevant geospatial phenomena identified in data immersion and validated in the subsequent phases of analysis are as follows:

Digital aeronautic flight information files and the details described within the text of AP$1 \mathrm{~B}$ regarding military training route and special use airspace geometry provided these features additional spatial information to build a complete and accurate military airspace geometry dataset. The final airspace model was used throughout the project in all analysis phases.

The NREL and AWS Truewind datasets produced a wind power density model of polygon features classified into seven power classes. These power class objects represented the potential for wind energy development ranging from poor to excellent and were used to measure the amount of convergence (i.e., spatial overlap) between the wind model and military airspace in order to gauge the amount of encroachment potential in each state. It was also used in conjunction with topography to assess the amount of encroachment potential around the FRTC as well as the location and directions from which encroachment would likely occur.

Information regarding the current heights of wind turbines, coupled with the predictions of future heights, provides a vertical obstruction standard for wind turbines (i.e., the wind turbine vertical obstruction zone). The utility of a standardized wind turbine height is that it facilitates its integration into the GIS analysis model as a consistent metric. Thus, when coupled with the minimum altitudes of military airspace, the wind turbine vertical obstruction zone illustrates the vertical relationship between airspace and wind farms.

Subject matter experts provided information regarding the constraints on wind energy development from excessive slope (i.e., greater than eight degrees) and elevation (i.e., greater than 7,000 feet). The areas eliminated by these variables were determined using Level-1 DTED elevation data. 
Subject matter experts also provided valuable information on the economic limitations, introduced by distance, to roads and electric power lines. This information was visualized geographically using GIS distance and analysis tools (i.e., buffer, clip, and erase), creating spatial models relevant to the economic law of diminishing return and was subsequently factored into the final analysis.

All of the spatial variables discussed above were integrated into analysis of encroachment locations and axes. The wind experts provided spatial information on the topographic conditions (i.e., funnels, ridgelines and elevated terrain), that are favorable to optimal wind farm placement. ArcScene's three dimensional scene visualization capabilities facilitated the study of the topography within each area of interest. Base-maps produced on ArcGIS, reflecting the 9 geospatial phenomena discussed above were draped over an elevation model, visualizing relevant manmade and abstract phenomena in a realistic and natural landscape. Combined with the wind direction information, provided by the Western Regional Climate Center, GIS provided the analytic forum to assess potential encroachment sites, that otherwise, without the aid of GIS, would not have been possible.

The following metadata were created for each of the relevant geospatial phenomena using the current Federal Geospatial Data Committee metadata standards found in FGDC-STD001-1998, titled "Content Standard for Digital Geospatial Metadata. In accordance with FGDC-STD-001-1998 (FGDC), the following compound elements are discussed when information pertaining to that element was available:

\section{Identification Information \\ Spatial Data Quality Information \\ Spatial Reference Information \\ Entity and Attribute Information \\ Distribution Information \\ Metadata Reference Information}

Provided in Appendix C, Metadata contains information on the lineage of the relevant geospatial phenomena used in this project. The origin of much of the data used in this project makes it impractical to assess an absolute horizontal and vertical accuracy (e.g., 90\% CE and LE). ${ }^{22}$ In all cases except the Level-1 DTED dataset, an absolute error estimate did not exist. Therefore, in lieu of absolute error estimates, metadata was provided. The metadata provided in Appendix $\mathrm{C}$ provides the reader and dataset user with the lineage of the datasets and, thus, an estimate of the relative accuracy of the data.

The NGA assessed the absolute accuracy of the Level-1 DTED (U.S. NGA, 2000). The Level-1 DTED is the dataset used to visualize the wind power class model with other relevant geospatial phenomena (i.e., it is the basis for topographic analysis), as well as the dataset used to produce the elevation and slope datasets. The reported horizontal

\footnotetext{
${ }^{22} 90 \%$ absolute accuracy means $90 \%$ of a datasets randomly sampled points lie within a threshold distance from ground truth. Thus, if the dataset consists of 10 points, the distance that the $9^{\text {th }}$ closest point is from truth is the measurement of that datasets absolute accuracy.
} 
accuracy based on the WGS-84 ellipsoid is (</=) 50 meter absolute (90\% Circular Error), and the vertical accuracy based on the EGM-96 GEOID is $(</=) 30$ meter absolute ( $90 \%$ Linear Error) (U.S. NGA, 2000). This means any location selected will have a $90 \%$ chance of falling within 50 meters of its true horizontal position, and 30 meters of its true vertical position. Posts spacing 30 meters or 3 arc seconds (U.S. NGA, 2000).

\subsection{Conclusions.}

This project was a problem solving evolution. The problem, as the client identified it, was based on the unknown end game of wind energy development in Nevada. Thus, the threat of wind farms encroaching upon valuable military training airspace was overly nebulous and required definition. The political sensitivity of this topic demanded a wellestablished and objective analytical process.

This project employed a hybrid of analysis strategies designed to optimize the objectivity and accuracy of analysis findings. The first strategy was to research and identify the relevant geospatial characteristics of wind energy development and military airspace, in order to better understand the physical relationships of these geospatial phenomena. This step involves a rigorous research regimen that leads to the discovery of relevant geospatial elements.

The geospatial elements relevant to this project presented themselves in vector, raster and textual formats and often required conversion (e.g., from a non-GIS textual format into a vector format) in order to accurately place them in the analytic (i.e., geospatial) environment. One example of this type of abstraction is found in the military training route line vectors representing the centerlines of flight corridors. Each of these centerline segments had horizontal (i.e., boundary) and vertical (i.e., minimum altitude) characteristics that were described textually in the digital aeronautic flight information files dataset. These boundary descriptions were relevant to analysis and were subsequently abstracted and integrated into analysis, geographically visualized with other relevant geospatial phenomena.

GIS data management and analysis tools such as the Projection and Transformation tools allowed for the accurate reprojection and registration of both rasters and vectors. There were also analysis tools that allowed for the creation of distance and area-objects; Raster tools that allowed the tailoring of raster datasets like Digital Terrain Elevation Data; Conversion Tools that allowed the conversion and extraction of elevation data into a the proper format, empowering this project with the ability to render all relevant geospatial phenomena, leading to hypotheses.

The second strategy was an exercise in functional and physical observation. Using GIStools and analytic techniques, relevant geospatial phenomena were geographically visualized together into the same spatial environment, and manipulated with the intent to identify physical relationships such as, spatial-convergence (i.e., when phenomena overlap), spatial-concentration, and dispersion of vectors (i.e., the distribution of wind development potential in comparison to military airspace), vector-association, and covariance (i.e., the true maximum potential development scenario adjusted after military training route and special use airspace models, as well as determining which regions possessed the most encroachment threat). 
Geographical visualization is a powerful analytic technique, combining the relevant data as well as visualizing relevant geospatial characteristics (i.e., both two and threedimensional), in order to gain a complete understanding of their physical and functional relationships. GIS Analysis tools such as the clipping, union, buffer and selection tools facilitated the geospatial construction and manipulation of relevant phenomena.

The quantification strategy (i.e., the third strategy) involved a rigorous regimen of vector quantification and comparison, focusing on achieving a complete understanding of the problem and resolving the physical relationships of the relevant phenomena. Using GIS analytic techniques and the application of situational logic, this analytic strategy quantitatively compared data and potential courses of action. GIS tools provided a geometry calculation capability as part of its data calculator within the features attribute table. Vector geometry such as area in square miles as well as linear distance calculation was critical to quantitatively comparing analytic strategies. These and other tools allowed this project to quantify the true and complete causality of the relevant aggregates and the causality of both pre-defined policy and undefined, yet potential, courses of action.

In the fourth strategy, accomplished during the steps preceding analysis and assessment, quantitative comparison techniques were employed to illustrated the wind turbine vertical obstruction zone, quantifying the impact current and future wind turbine technology would have on the stoplight management schema. Most importantly, this project illustrated, through visual and quantitative comparisons, the physical relationships between military training airspace, the wind resource model, and the wind energy communities desire to develop.

The consequences of this project will likely be related to the impact it has on policy development and management decision made by both wind energy developers and military airspace managers. The findings are clear and the following conceptual takeaways should be observed: First, it is likely that wind energy development in the 11 western United States will encroach upon military training airspace if development concerns for military training airspace are ignored. That said, with the additional awareness provided by this project, military airspace manager can now intervene on behalf of military training airspace when desired. Second, in light of the desire to avoid encroachment upon military training airspace, wind energy development still has many areas of potential development within the 11 western United States study region. This project identified many areas between and beneath military training airspace where development can still occur without risk to that airspace. Third, this project argued for a 600 foot vertical obstruction metric. Although this is an argument based on referenced fact, in order to fully assess the potential for encroachment, this standard is recommended for future GIS projects. Fourth, this project identified and communicated the amount of weight the BLM Programmatic Environmental Impact Statement has on wind energy development policy throughout the 11 western United States. Subsequently, the linkage between encroachment avoidance and the BLM Programmatic Environmental Impact Statement is high. Quite likely the most important take-away from this project, especially to the decision maker interested in the BLM environmental impact statement, is that although analysis of the 11 state study area identified a 30 percent level of convergence between the wind resource model and the military training airspace, the 
scale of that analysis did not reveal the location and direction that encroachment would likely occur. A larger scale geospatial analysis effort that addressed specific areas of interest was needed.

The FRTC analysis project demonstrated the scale of geospatial analysis that is necessary to identify likely encroachment location and direction. This observation, alone, presents sufficient argument to integrate this project and additional future large scale analysis of the 11 western state study area into the BLM environmental impact statement. The largescale encroachment analysis prototype proved to be effective at predicting and communicating the threat of encroachment, where encroachment would likely occur and the direction the encroachment would likely advance. Simultaneously, the analysis prototype highlighted areas of potential development in a manner that would minimize its impact on military training airspace. 


\section{References}

Albany Aerial Photo.com. (n.d.). Wind Farms. Wind Farms of Madison County, NY.

Retrieved December 08, 2006 from http://www.albanyaerialphotos.com/ windfarms.htm

Albers, A. and Klug, H. (August, 1999). DEWI Magazine, High Quality Wind Speed Measurements for Site Assessment. Retrieved June 17, 2006 from http://www..dewi.de/dewi_neu/deutsch/themen/magazin/15/02.pdf.

American Wind Energy Association. (n.d.). Foote Creek 3, Wyoming Wind Energy Development. Retrieved March 2006 from http://www.awea.org/Projects/ summaries/ FooteCreek3.pdf.

American Wind Energy Association. (September 1991). Status of Wake and Array Loss Research. Retrieved August 2006 from www.princeton.edu/ globsec/ publications/pdf/4_1cavallo.pdf

Archer, C.L. and Jacobson, M.Z. (2003). Spatial and Temporal Distribution of U.S. Winds and Wind Power at 80 meter Derived From Measurements. Retrieved June 2006 from www.stanford.edu/group/efmh/winds/2002JD002076.pdf

Bailey, B. H. and McDonald, S. L. (1997). Wind Resource Assessment Handbook. New York: AWS Scientific, Inc.

Baily, B.H.. (2006). Wind Energy Manual. Retrieved March 2006 from www.energy. iastate.edu/renewable/wind/wem/wem-01_print.html.

Balding, D.J., et al. (Eds.). (2002). Statistical Rules of Thumb. New York: Wiley and Sons, Inc.

Balthazor R (Photographer). (July 06, 2006). Wind Farm. BetterPhoto.com Second Place Winner. Retrieved December 08, 2006 from http://www.betterphoto.com/gallery /big.asp?photo ID=2349665\&catID=\&style=\&rowNumber=4\&memberID=32439

Collett Transport Ltd. (n.d.). construction. British Wind Energy Association. Retrieved December 08, 2006 from http://www.bwea.com/media/photo/index.html

Digital Aeronautical Flight Information File, v.0601, 19 January to 15 February 2006 [Military Training Routes and Special Use Airspace]. Available from National Geospatial Intelligence Agency website, https://164.214.2.62/products/digitalaero/ index.cfm 
Desert Research Institute (DRI) News. (2003, Spring). Planning for Serious Wind Energy Development in Nevada and the Southwest. Retrieved April 03, 2006, from http://newsletter.dri.edu/2003/spring/windenergy.html

Dorset against Rural Turbines (n.d.). Campaign to protect rural England. Retrieved April 06, 2006, from http://www.dartdorset.org/html/graphics.shtml Energy Velocity

Electric Power Research Institute TR-104398. (1994). Planning Your First Wind Power Project: A Primer for Utilities: Everything you need to know to bring your first wind power plant on- line. Retrieved August 2006 from www.epri.com/ attachments/197564_LessonsLearned062301.pdf.

Federal Geographic Data Committee (FGDC). (n.d.). Content Standards For Digital Geospatial Metadata. Retrieved June 2006 from http://www.fgdc.gov/metadata/ csdgm/index_html

Franke D. I. (Photographer). (n.d.). Xah Lee’s Home Page. Whirl Wheels photo exhibition. Retrieved December 08, 2006 from http://xahlee.org/Whirlwheel_dir/ windturbine.html.

General Electric. (n.d.). 3.6 megawatt Turbine. United States Department of Energy. Wind and Hydro Technologies Program. Retrieved December 08, 2006 from http://www1.eere.energy.gov/windandhydro/wind_how.html

Gipe, Paul. (2000). Testing the Power Curves of Small Wind Turbines. Wind-Works.org. Retrieved March 2006 from http://www.wind-works.org/articles/ PowerCurves.html.

Paul Gipe (Photographer). (n.d.). Wind Farms of the World. Wind-Works.org. Retrieved December 08, 2006 from http://www. wind-works.org/photos/wind_farm.html Haefner S. (Photographer). (n.d.). Meridian01. Kite Aerial Photography. Retrieved December 08, 2006 from http://scotthaefner.com/kap/gallery/image.php?i= meridian01.jpg\&l=Te+Apiti+Wind+Farm

Hiester T. and Pennell W. (1981). The Meteorological Aspects of Siting Large Wind Turbines. (Report No. PNL-2522)., National Technical Information Service. Retrieved June 2006 from http://www.nationalwind.org/publications/ wes/wes04.htm 
Livingston J., and Anderson T. (2004, March 15). Wind Shear, Taller Turbines, and the Effects on Wind Farm Development create a need for Taller MET Towers, Isotruss Structures Incorporated. Retrieved March 8, 2006 from http://www.isotruss.com/PDF/windshearpositiondoc.doc.

Lydersen, K. (2006, June 10). Wind Power Projects Halted. Washington Post. Retrieved December 2006 from http://www.washingtonpost.com/wp -dyn/content/article/2006/06/09/AR2006060901420.html

Mitchell, Andy. (2005). The ESRI Guide to GIS Analysis Volume 2: Spatial Measurements and Statistics. Redlands: ESRI Press

New Zealand Wind Energy Association. (n.d.). Mountain Cloud. Retrieved December 08, 2006 from http://www.windenergy.org.nz/photos/gallery/teapiti/index.html

Npower Renewables (n.d.). novar. British Wind Energy Association. Retrieved December 08, 2006 from http://www.bwea.com/media/photo/index.html

Organization for the Promotion of Energy Technology - OPET Network, (April 2004). Towards multi-MW wind turbines. Retrieved December 2006 from websrv2.tekes.fi/.../Viestinta_ja_aktivointi/Julkaisut/OPET-RES/Technology_ paper1_wind_70404.pdf

Purcell, K. (Photographer). (n.d.). Wind Farm. About.com. Digital Photography Contest Gallery. http://cameras.about.com/od/ digitalphotography contest/ig/March-2006Photo-Gallery/Wind-Farm.htm

PPM Energy. (n.d.). Wind Farm Photo Gallery. Retrieved December 08, 2006 from http://www.ppmenergy.com/pa.html\#co

Sparks, A., and Kidner, D. (1996). A GIS for the environmental impact assessment of wind farms. Proceedings of the ESRI Conference, London England, 2-4 October 1996. Retrieved November 07, 2006, from http://gis.esri.com/library/ userconf/europroc96/WELCOME.HTM

Spillman, W.J. and Lang, E. (1924). The Law of Diminishing Returns. New York: The World Book Company. 
Thresher, B. (May 1998). Regarding tower heights, yes, the trend is to 70-80m tower heights and will likely top off with next generation of turbines reaching $150 \mathrm{~m}$ above ground level (top of rotor blades?). In S. Schwartz (Ed.), Proceedings Onshore Wildlife Interactions With Wind Development: Research Meeting V. (p. 52). Washington D.C.: Resolve Inc.

Tufte, E. R. (Ed.). (November 2004). The Cognitive Style of PowerPoint. Cheshire, CT: Graphics Press LLC, (2003).

Tufte, E. R. (Ed.). (September, 2004). Visual And Statistical Thinking: Displays Of Evidence For Making Decisions. Cheshire, CT: Graphics Press LLC, (2003).

Tyrrell J (Photographer). (n.d.). Wind Farm 18. Artnet.com. Retrieved December 08, 2006 from http://www.artnet.com/Galleries/Exhibitions.asp?gid= 423822194\&cid $=109540$

United States Central Intelligence Agency, Center For The Study of Intelligence. (1999). Psychology of Intelligence Analysis. Retrieved January 20, 2006, from http://www.cia.gov/csi/books/19104/

United States Department of Defense. Flight Information Publication. (2005, March 17). Area Planning Military Training Routes North and South America [AP-1B]. Retrieved March 2005, from https://164.214.2.62/products/digitalaero/index.cfm.

United States Department of Defense. (2004, September). The 8 BRAC criteria to be used by Secretary of Defense (SecDef). Retrieved May2006, from www.dod.mil/news/Feb2004/n02282004_200402281.html

United States Department of Energy, Energy Information Administration. (1997). Financial Statistics of Major U.S. Investor-Owned Electric Utilities 1997. Retrieved March 2006 from http://www.eia.doe.gov/cneaf/electricity/invest/ invest_sum.html

United States Department of Energy, Energy Information Administration. (1998). Transmission Pricing Issues For Electricity Generation From Renewable Resources. Retrieved March 2006 from http://www.eia.doe.gov/cneaf/solar. renewables/rea_issues/transprice_art.pdf

United States Department of Energy, National Renewable Energy Laboratory. (2005, July). Development and Validation of High-Resolution State Wind Resource Maps for the United States (NREL/TP-500-38127). Retrieved January 20, 2006 
from http://www.nrel.gov/docs/fy05osti/38127.pdf

United States Department of Energy, National Renewable Energy Laboratory. (2002,

May). Evaluation of Wind Shear Patterns at Midwest Wind Energy Facilities.

Retrieved March 12, 2006 from http://www.nrel.gov/docs/fy02osti/32492.pdf.

United States Department of Energy, National Renewable Energy Laboratory. (2005).

Small Wind Electric Systems, An Oregon Consumer's Guide. Retrieved March, 2006 from http://www.eere.energy.gov/windandhydro/windpoweringamerica/ pdfs/small_wind/small_wind_or.pdf.

United States Department of Energy. National Renewable Energy Laboratory. (2002).

Towards a Wind Energy Climatology at Advanced Turbine Hub-Heights.

Retrieved March 2006 from http://www.nrel.gov/docs/fy05osti/38109.pdf

United States Department of Energy, National Renewable Energy Laboratory. (1997)

Wind Resource Assessment Handbook Fundamentals for Conducting a Successful

Monitoring Program. Retrieved March, 2006 from http://www.nrel.gov/docs/ legosti/fy97/22223.pdf

United States Department of Interior. (2005, February). Renewable Resources for

America's Future, The United States Department of the Interior. Retrieved

March 19, 2006 from http://www.doi.gov/initiatives/renewable_energy.pdf.

United States Department of Interior Bureau of Land Management. (2003, February).

Assessing The Potential For Renewable Energy On Public Lands. Retrieved

March 12, 2006 from http://www.nrel.gov/docs/fy03osti/33530.pdf.

United States Department of Interior, Bureau of Land Management. (n.d.). BLM Facts.

Retrieved January 20, 2006, from http://www.blm.gov/nhp/facts/

United States Department of Interior, Bureau of Land Management. (2005 June).

Final Programmatic Environmental Impact Statement on Wind Energy

Development on BLM-Administered Lands in the Western United States.

Retrieved January 25, 2006, from http://windeis.anl.gov/documents/ fpeis/index.cfm

United States Department of Interior, Bureau of Land Management. (1999). Nevada,

Selected Heritage Assets in Nevada Under BLM Stewardship As September, 30

1998. Retrieved November 07, 2006, from http://www.blm.gov/nhp/pubs/ rewards/1999/5nv.htm 
United States Department of Transportation, Federal Aviation Administration. (2004, February 19). Order 7610.4K, Special Military Operations. Retrieved March 2006 from http://www.faa.gov/ATpubs/MIL/Foreword/milfwd.html.

United States Department of Transportation, Federal Aviation Administration. (1999, June 21). Order 7450.1, Special Use Airspace Management System. Retrieved March 2006 from http://www.faa.gov/atpubs/SAM/7450.1.html.

United States House of Representatives, House Committee On Armed Services, One Hundred Sixth Congress. (May 24, 1999). National Defense Authorization Act For Fiscal Year 2000. Retrieved January 20, 2006, from http://www. gpoaccess.gov/congress/house/armedservices/index.html

United States National Geospatial-Intelligence Agency. (2000). Performance Specification Digital Terrain Elevation Data (DTED). Retrieved July 2006, from http://www1.gsi.go.jp/geowww/globalmap-gsi/gtopo30/papers/geschd3.html United States National Geospatial-Intelligence Agency. (2006). Digital Aeronautical Flight Information File. Retrieved July 2006, from http://www.nga.mil/portal/ site/nga01/index.jsp?epi-content=GENERIC\&itemID=c918c08a8c6ed010Vgn VCMServer3c02010aRCRD\&beanID=1629630080\&viewID=Article United States Navy. (November 19, 2003). Fallon Range Training Complex Users's Manual. NAS Fallon, Nevada: Naval Strike Air Warfare Center. Naval Strike Air Warfare Center Instruction 3752.1D

Vestas. (n.d.). Blade Factory in Nakskov Denmark. Retrieved December 06, 2006 from http://www.vestas.com/vestas/global/en/Press/Photo_library/

Vestas Wind Systems A/S. (n.d.). Key Aspects in Developing a Wind Power Project. Retrieved March 2006 from http://www.eere.energy.gov/tribalenergy/ guide/pdfs/DevelopingWindPower.pdf

Vestas Wind Systems A/S. (2003, September). New Turbines, V90-2.0MW and V901.8MW. Retrieved November 2005 from http://www.vestas.com/pdf/ publikationer/tidligere_publikationer/theWindow/pdf/Window_no12.pdf Vestas Wind Systems A/S. (2004, June). The Challenge of Turbine Transport Vestas Global. Retrieved March 2006 from http://www.vestas.com/pdf/publikationer/ VestasGlobal/VestasGlobal01.pdf 
Western Regional Climate Center. Historical Climate Information. (n.d.) Average Wind Direction by State. Retrieved March 2006 from, http://www.wrcc.dri.edu/ CLIMATEDATA.html

Wind Atlas Model, (2005). Vector database [Data File]. Boulder, CO: National Renewable Energy Laboratory.

Windustry. (n.d.). Photo Gallery: Construction. Retrieved December 08, 2006 from http://www.windustry.org/windustryphotogallery/Photo\%20Gallery/default.htm 


\section{Appendix A. Topographic Planning Map Series}

\section{A.1. (Prototype) Area of Interest 7 and 8}

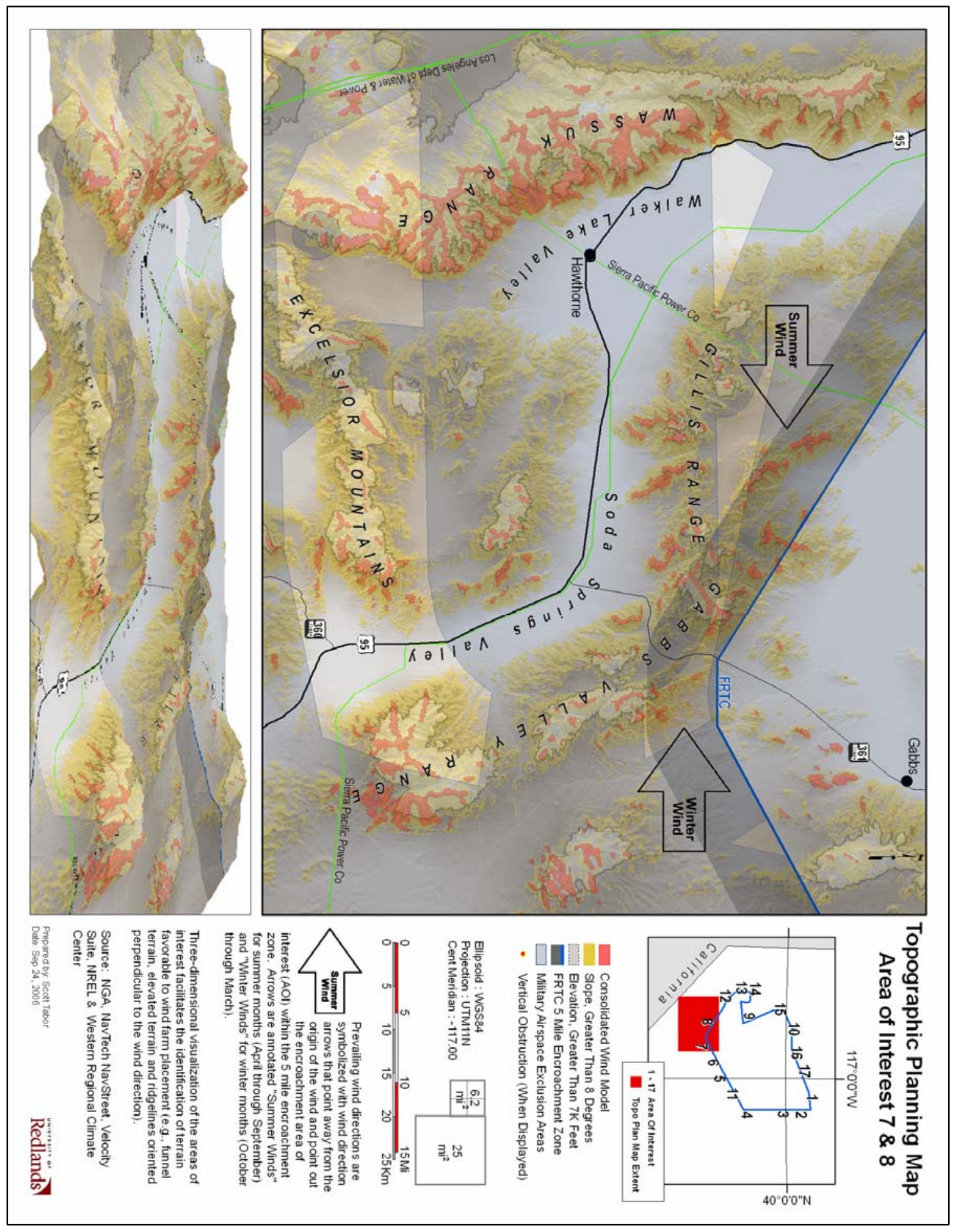




\section{A.2. Area of Interest 1 and 2}

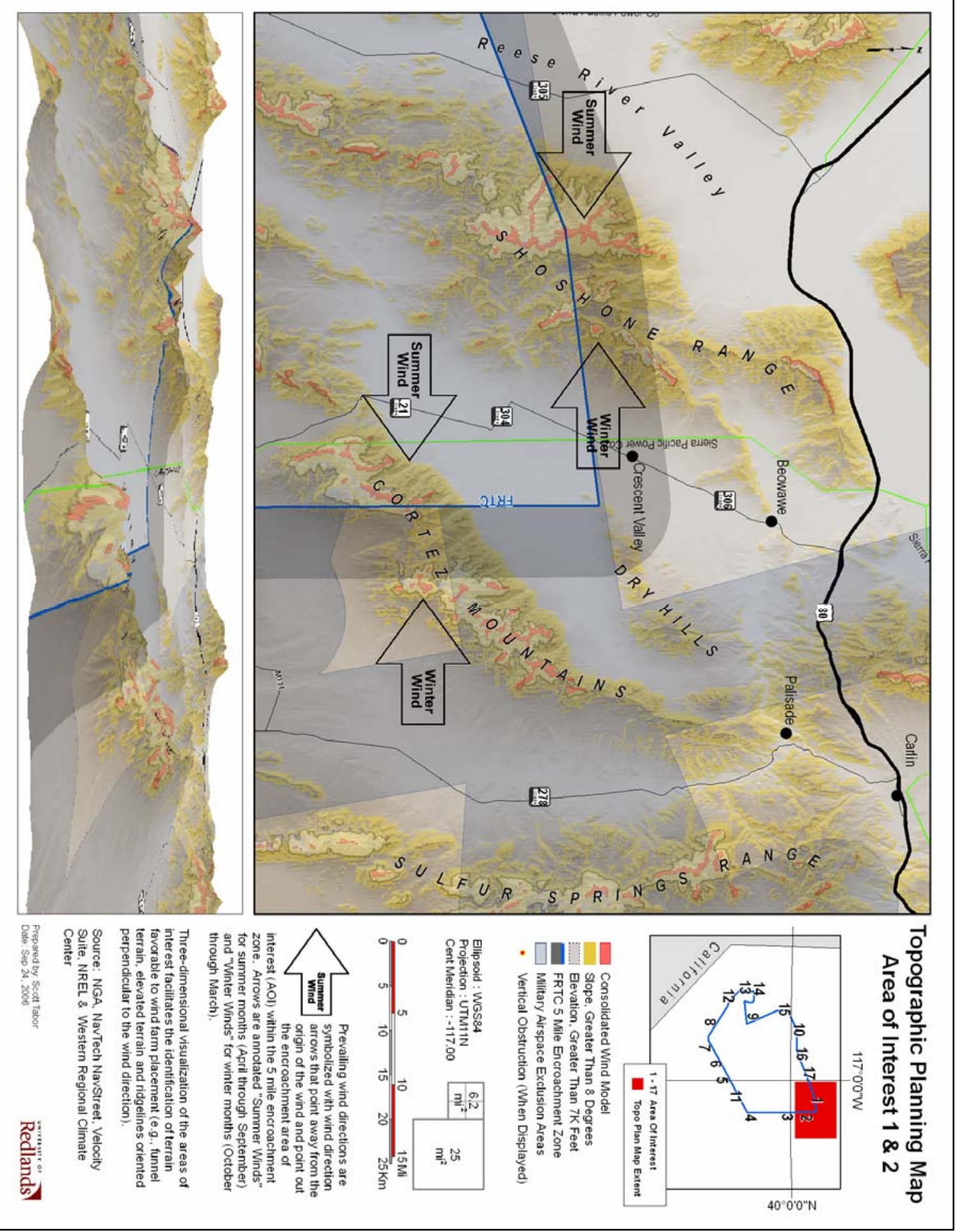




\section{A.3. Area of Interest 3}

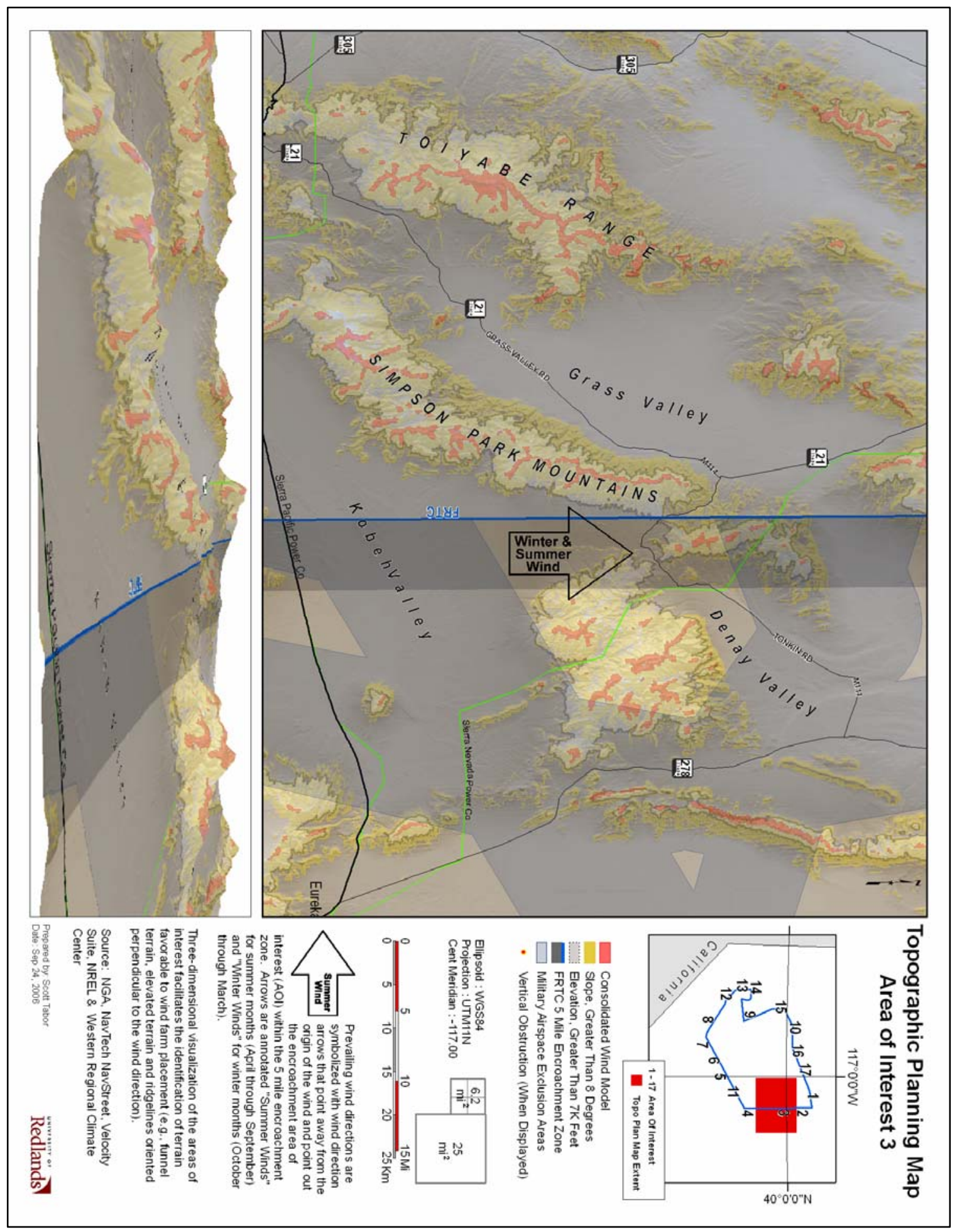




\section{A.4. Area of Interest 4}

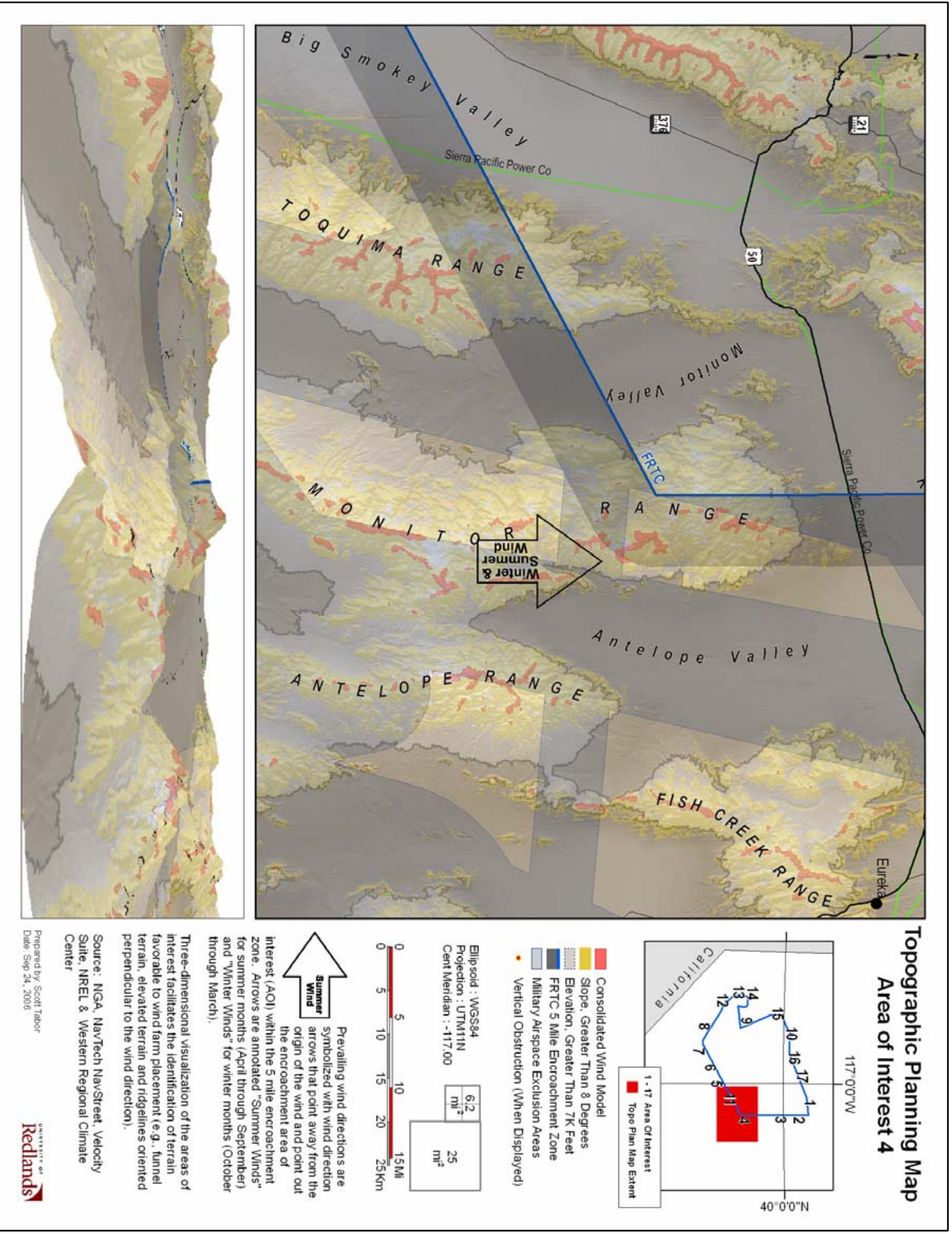




\section{A.5. Area of Interest 5, 6, and 11}

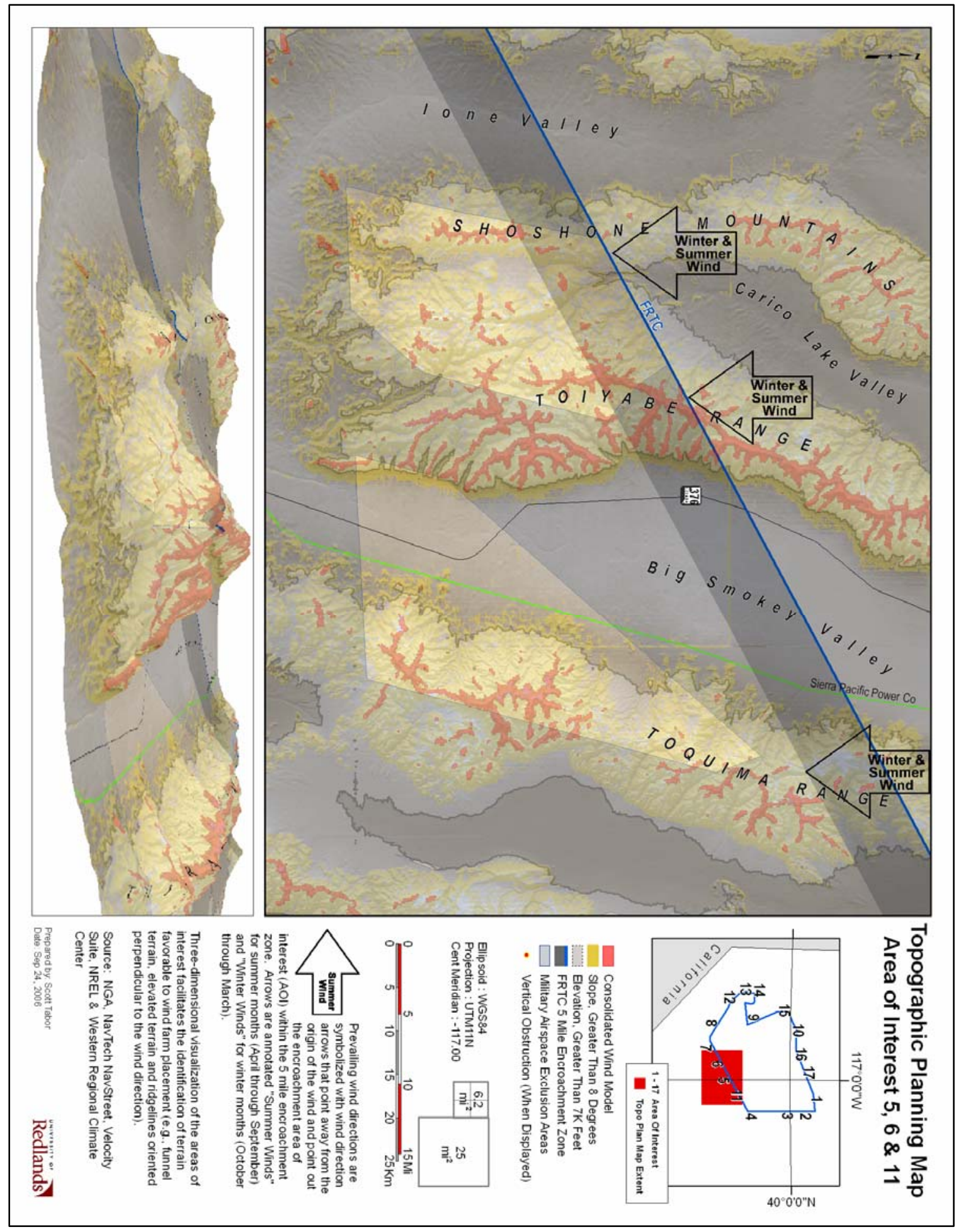




\section{A.6. Area of Interest 9}

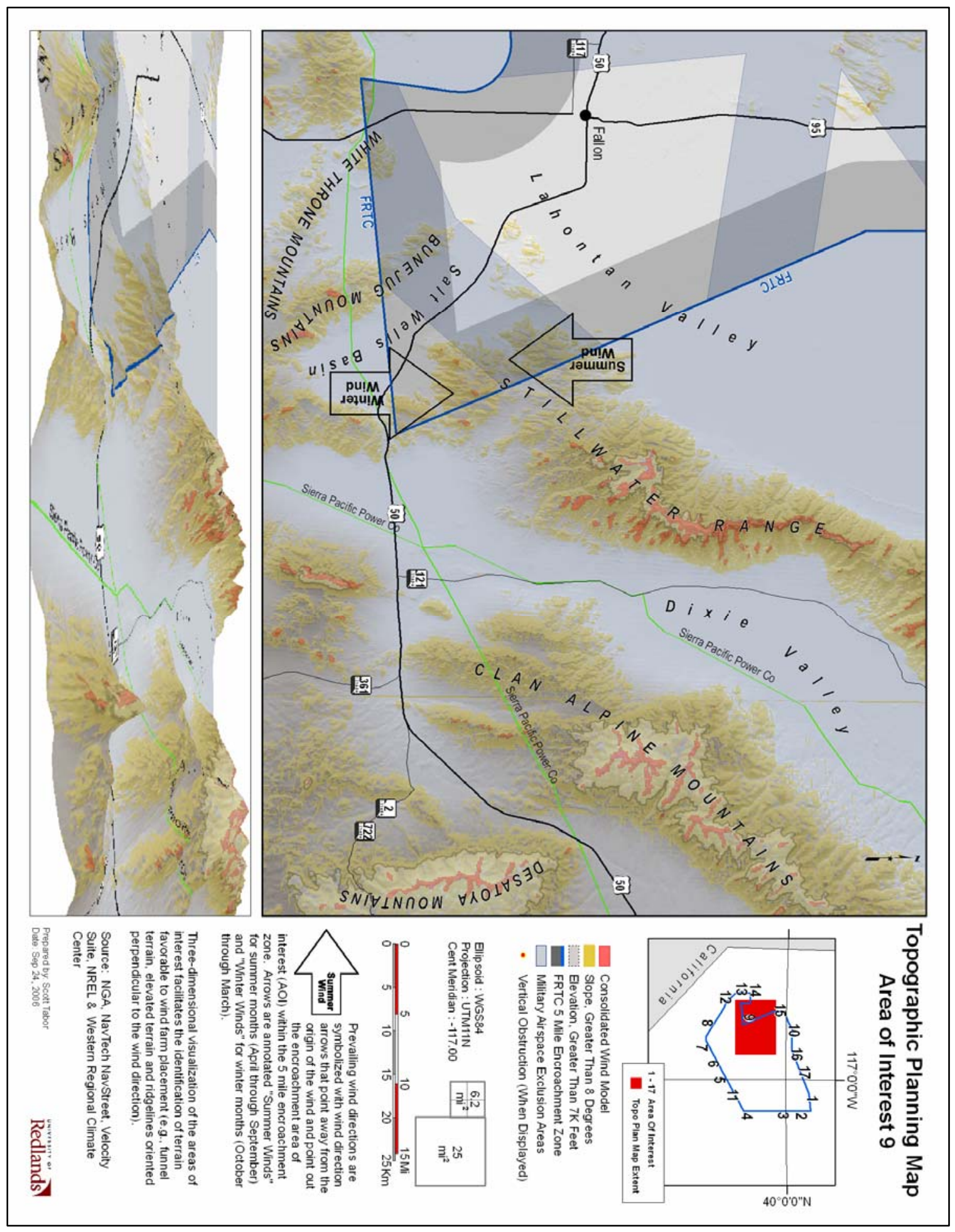




\section{A.7. Area of Interest $\mathbf{1 0}$ and $\mathbf{1 5}$}

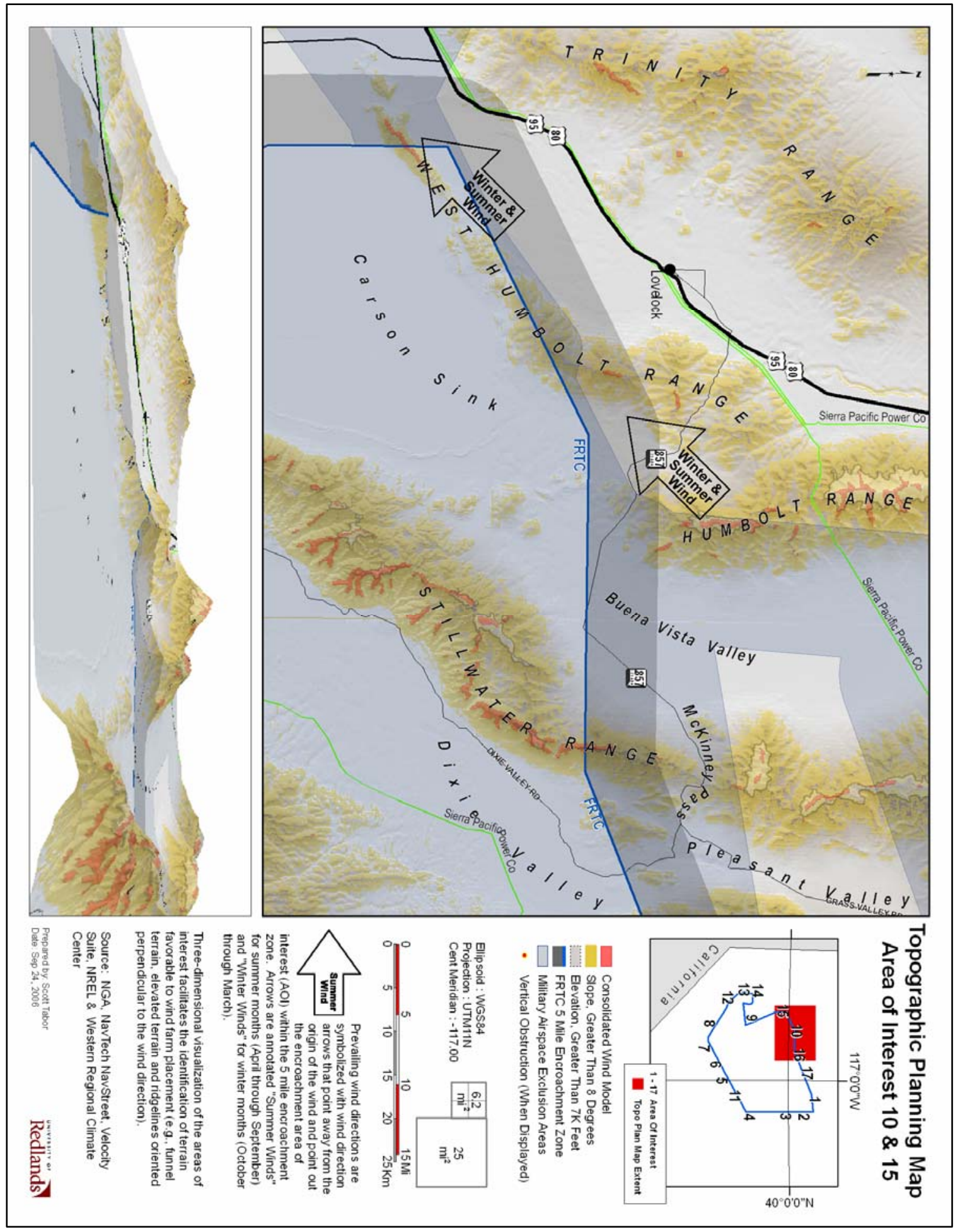




\section{A.8. Area of Interest 12}

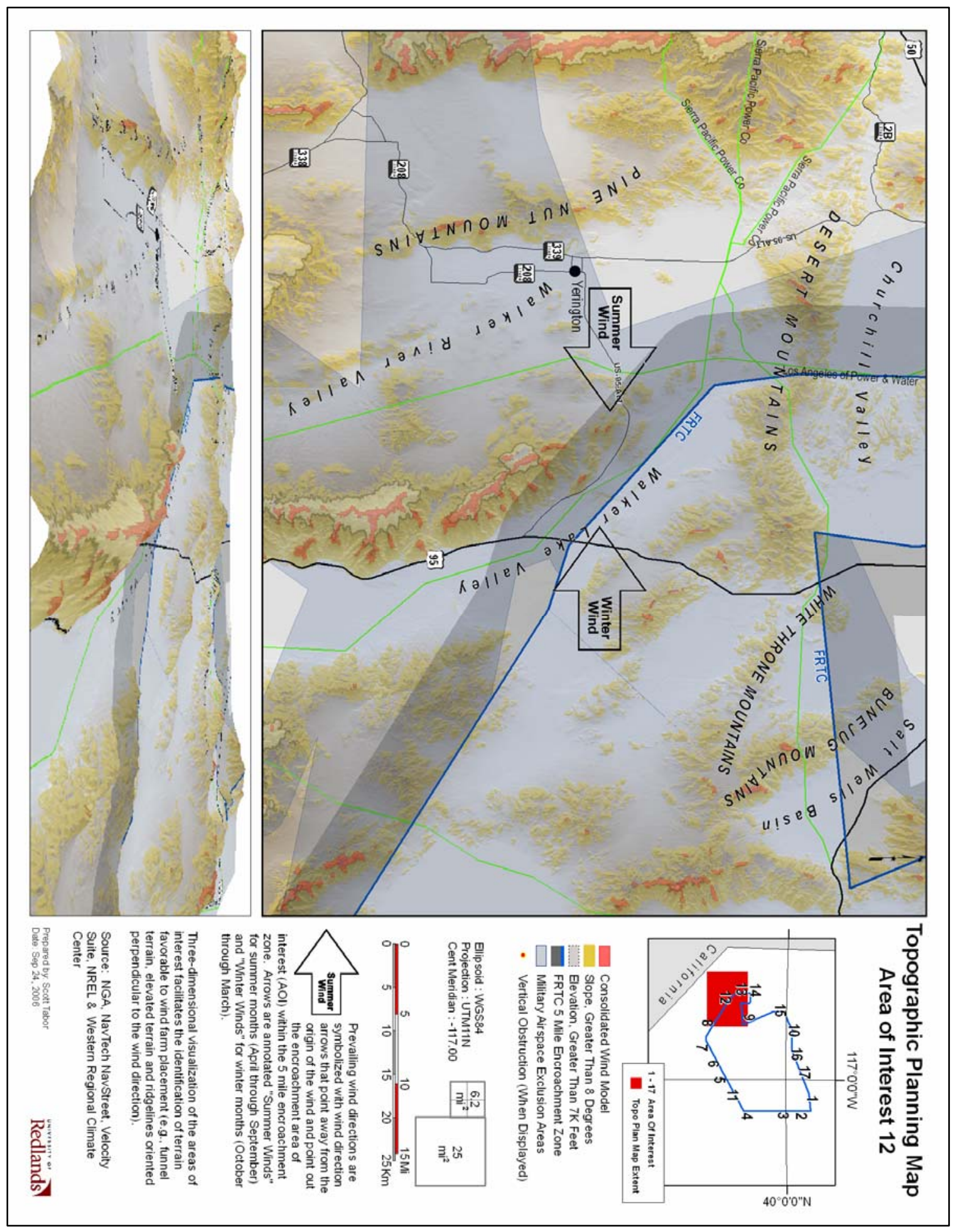




\section{A.9. Area of Interest 13 and 14}

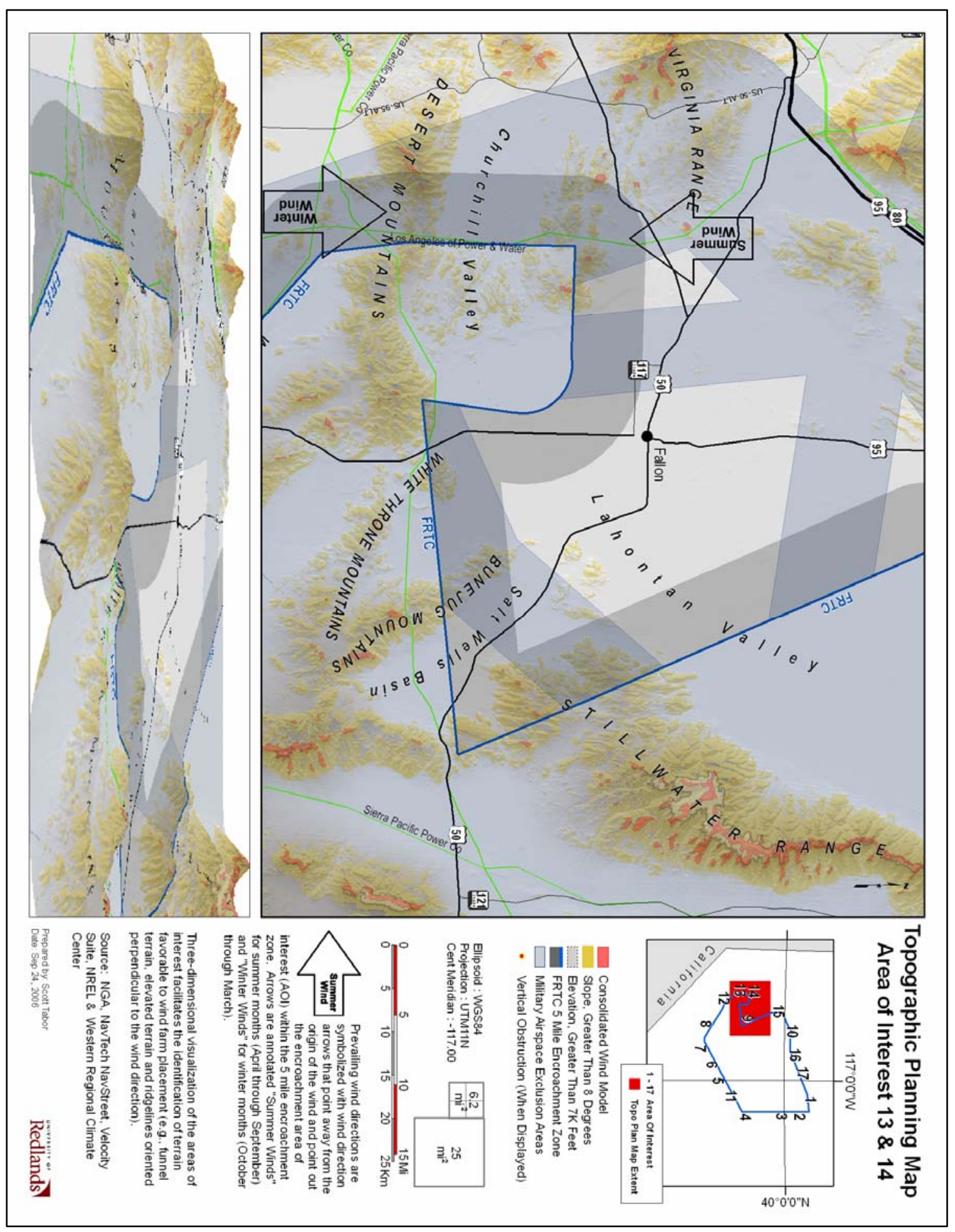




\section{A.10. Area of Interest 16 and 17}

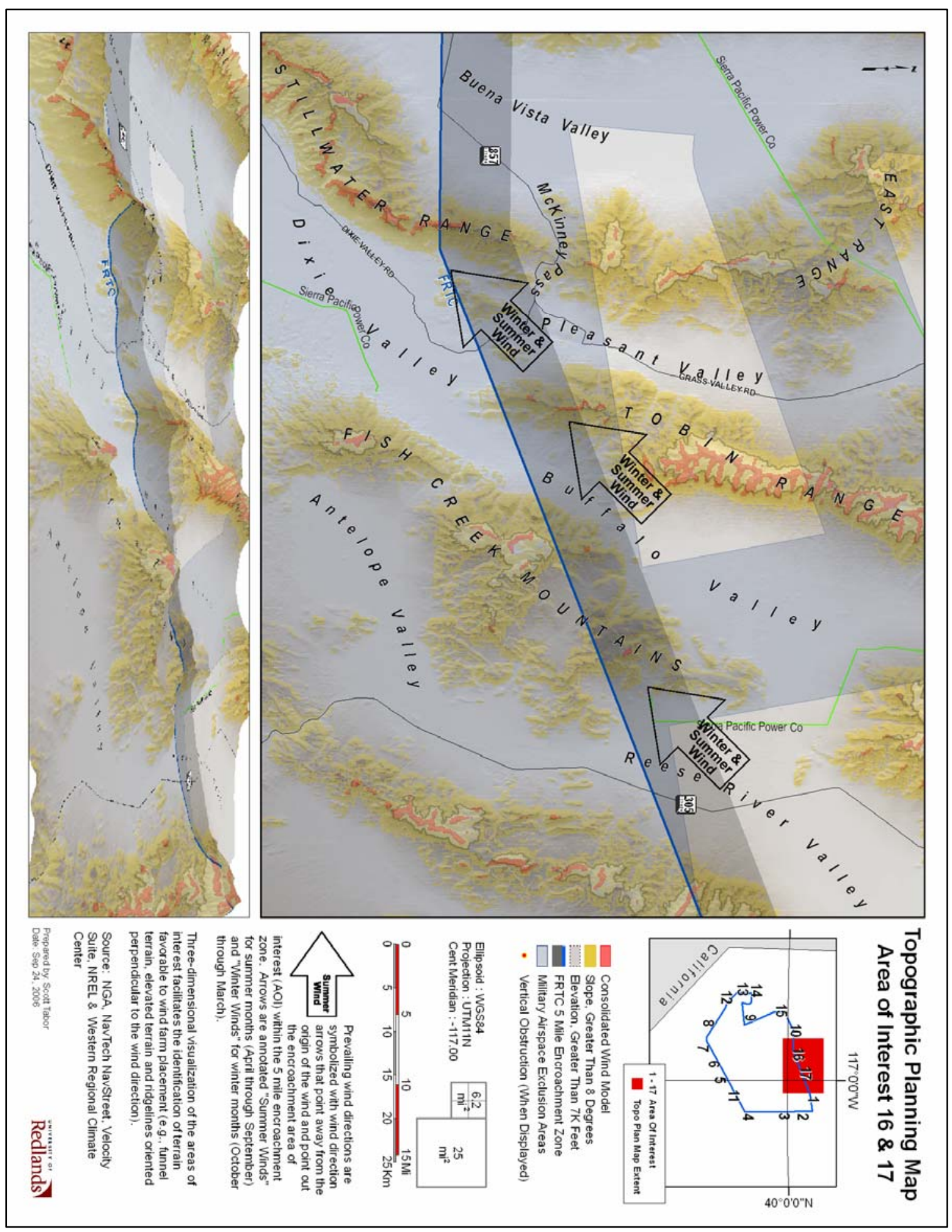


Appendix B. Wind Turbine Photo Tour

B.1. Mountain Cloud (New Zealand Wind Energy Association, n.d.).

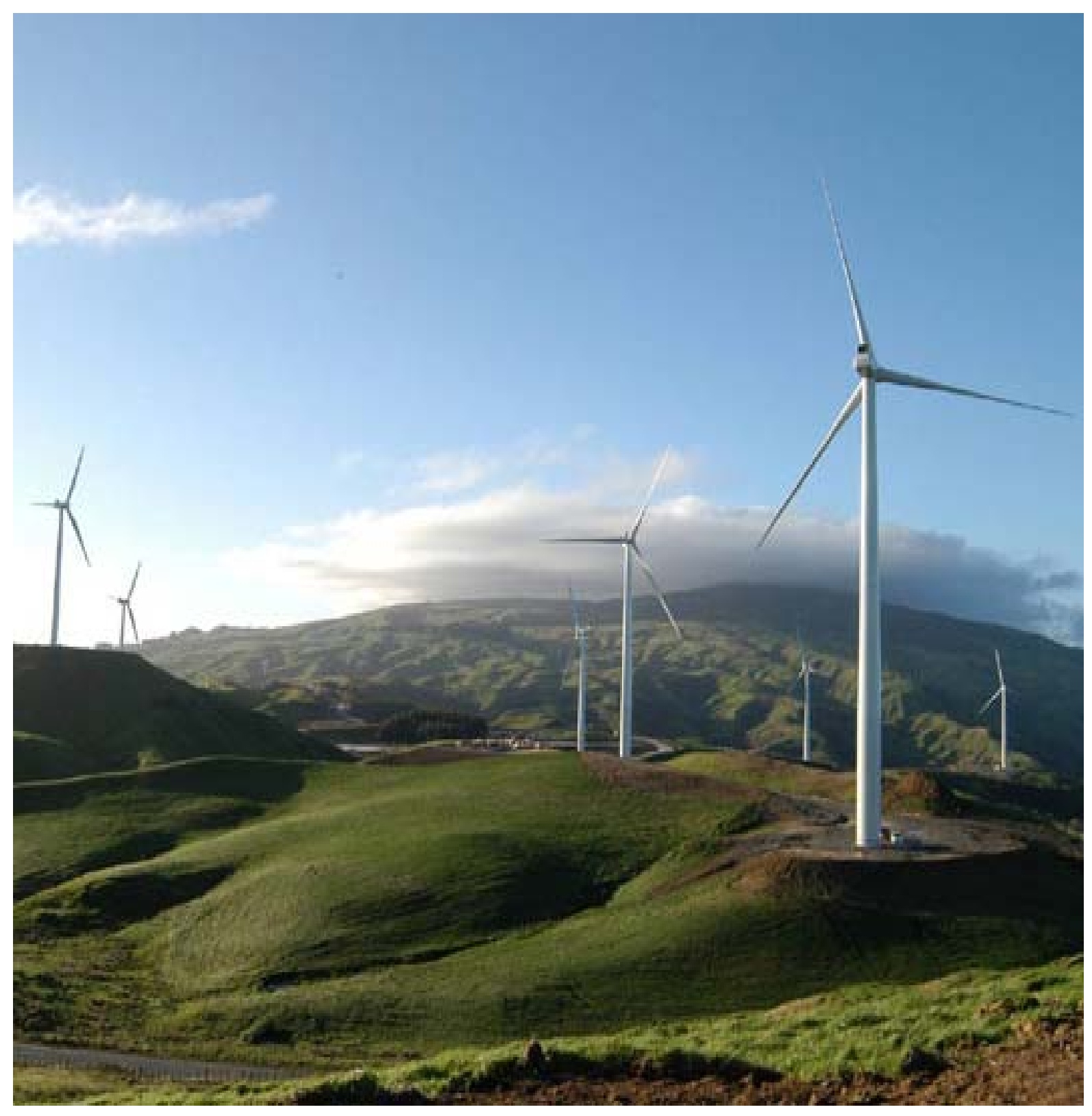


B.2. Wind Farm (Purcell, n.d.).

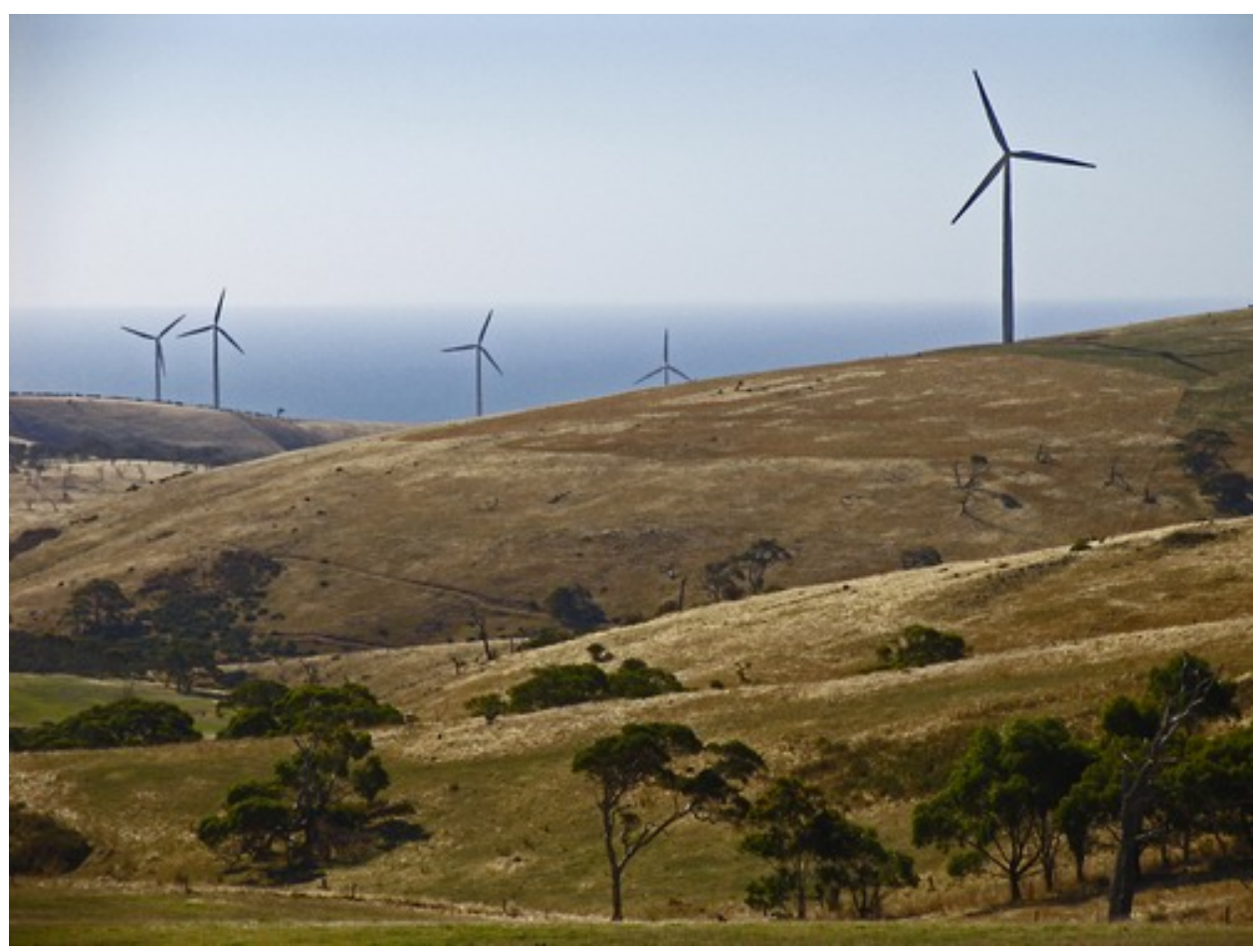

B.3. Meridian01 (Haefner, n.d.).

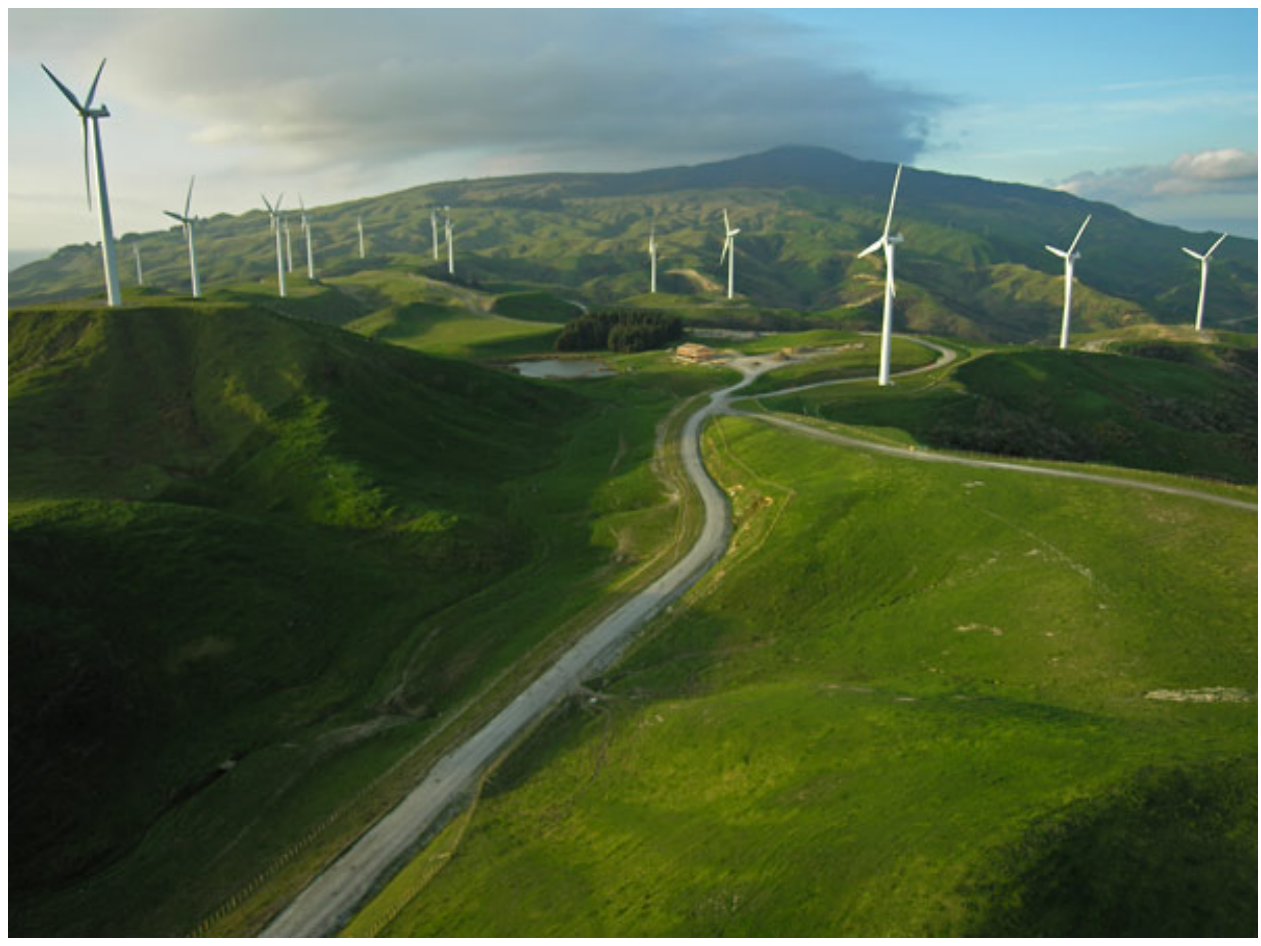


B.4. Wind Farm (Balthazor, 2006).

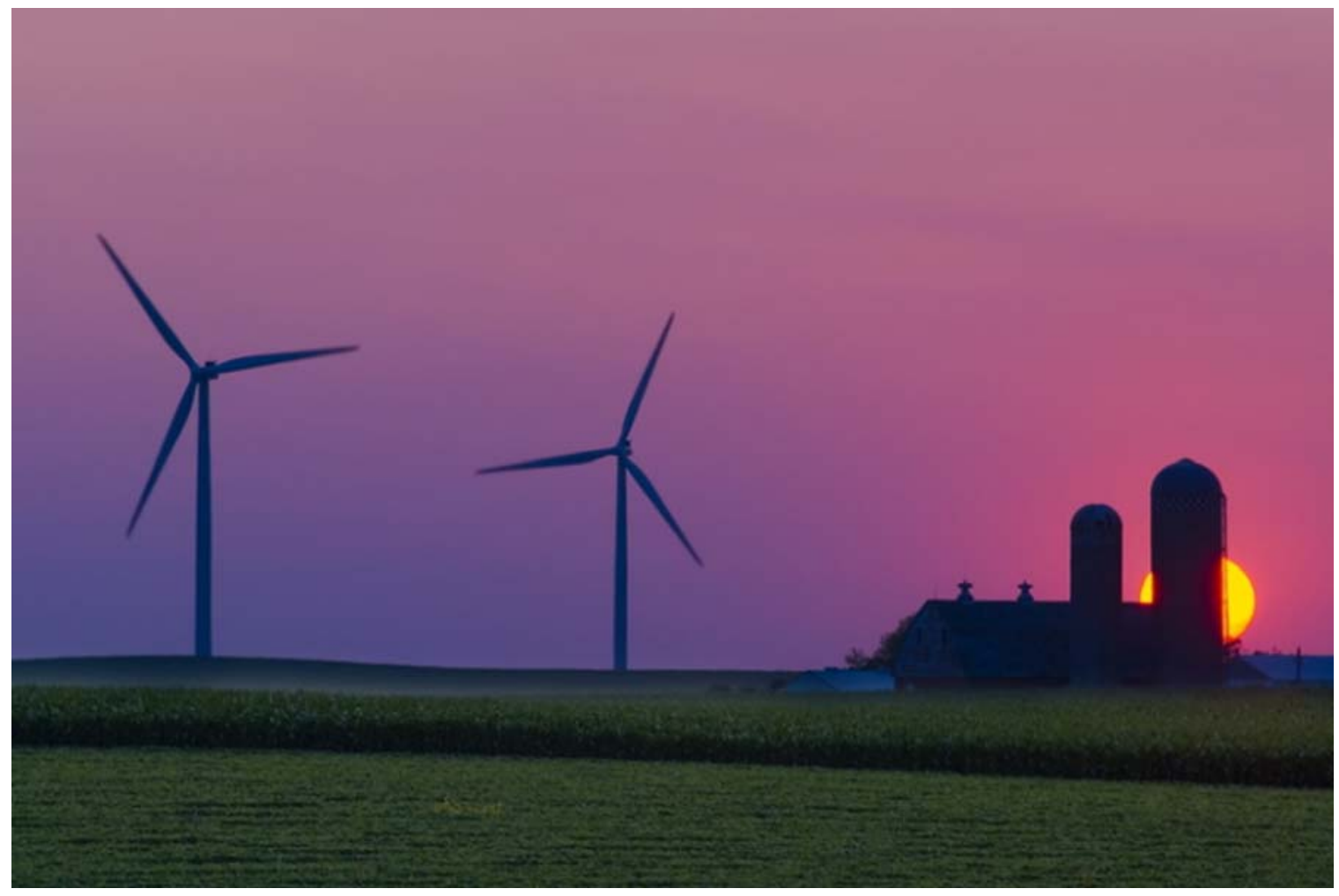

B.5. Wind Farms of Madison County, NY. (Albany Aerial Photo.com, n.d.).

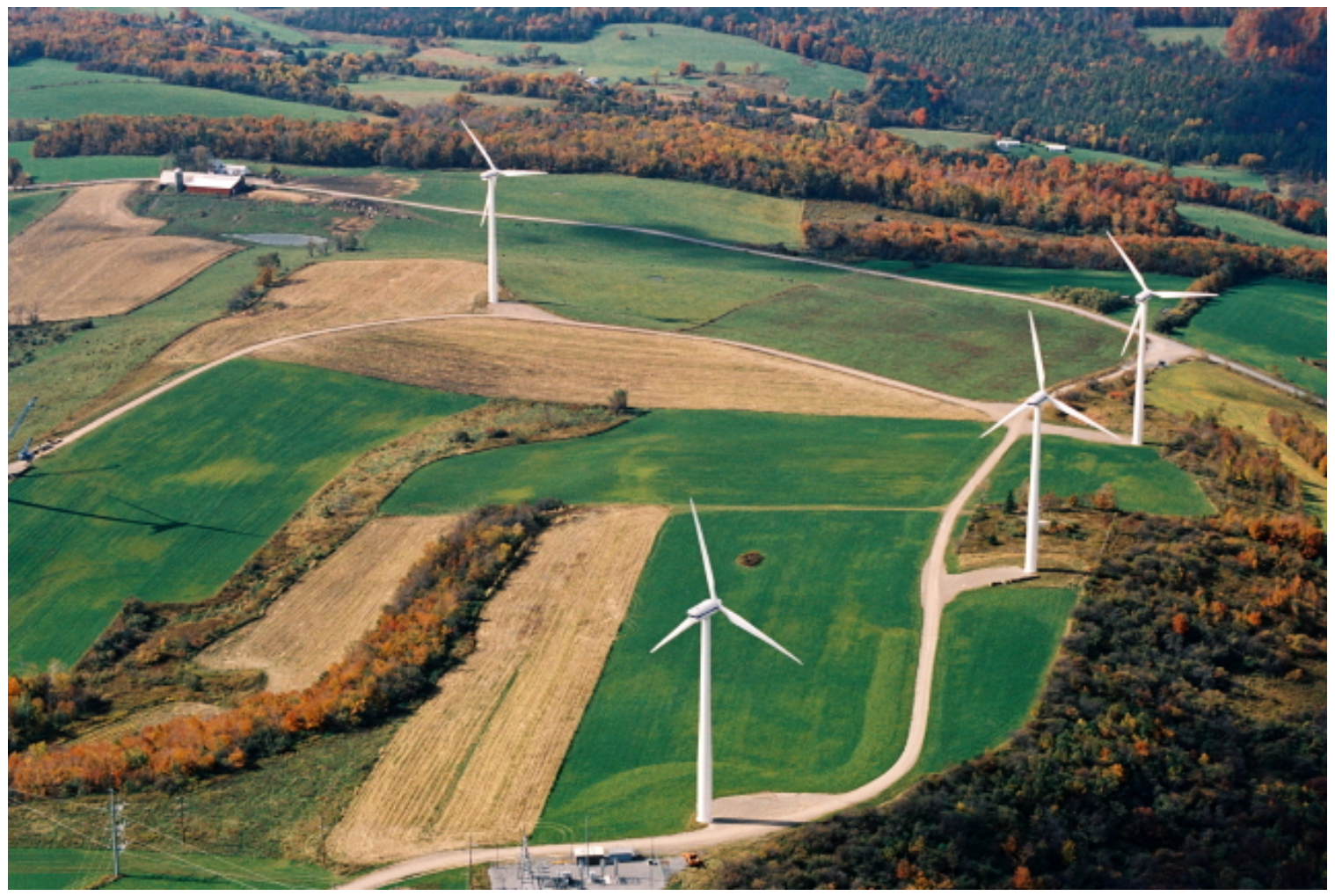


B.6. Wind Farms of the World (Paul Gipe, n.d.).
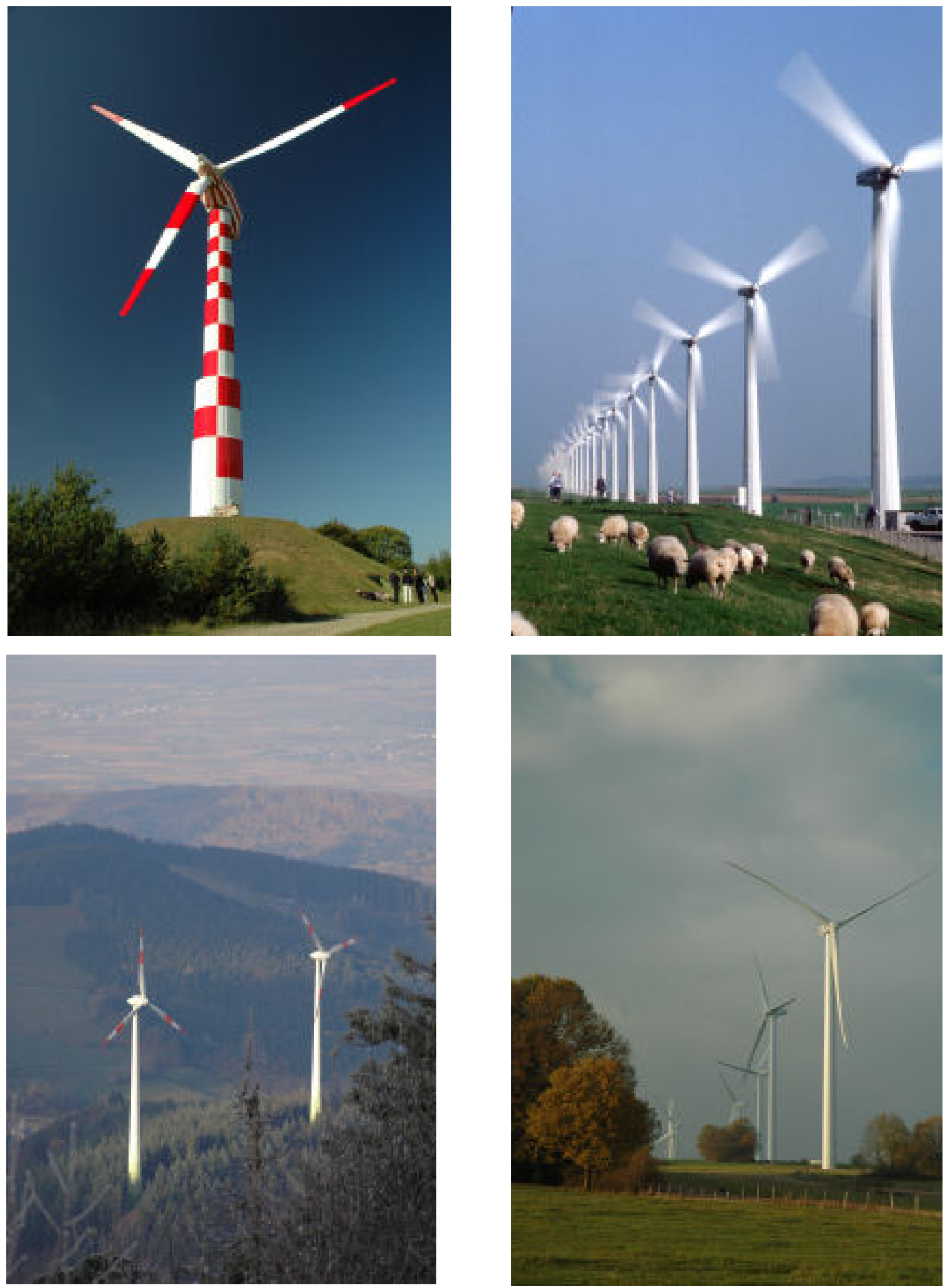
B.7. Wind Farm Photo Gallery (PPM Energy, n.d.).
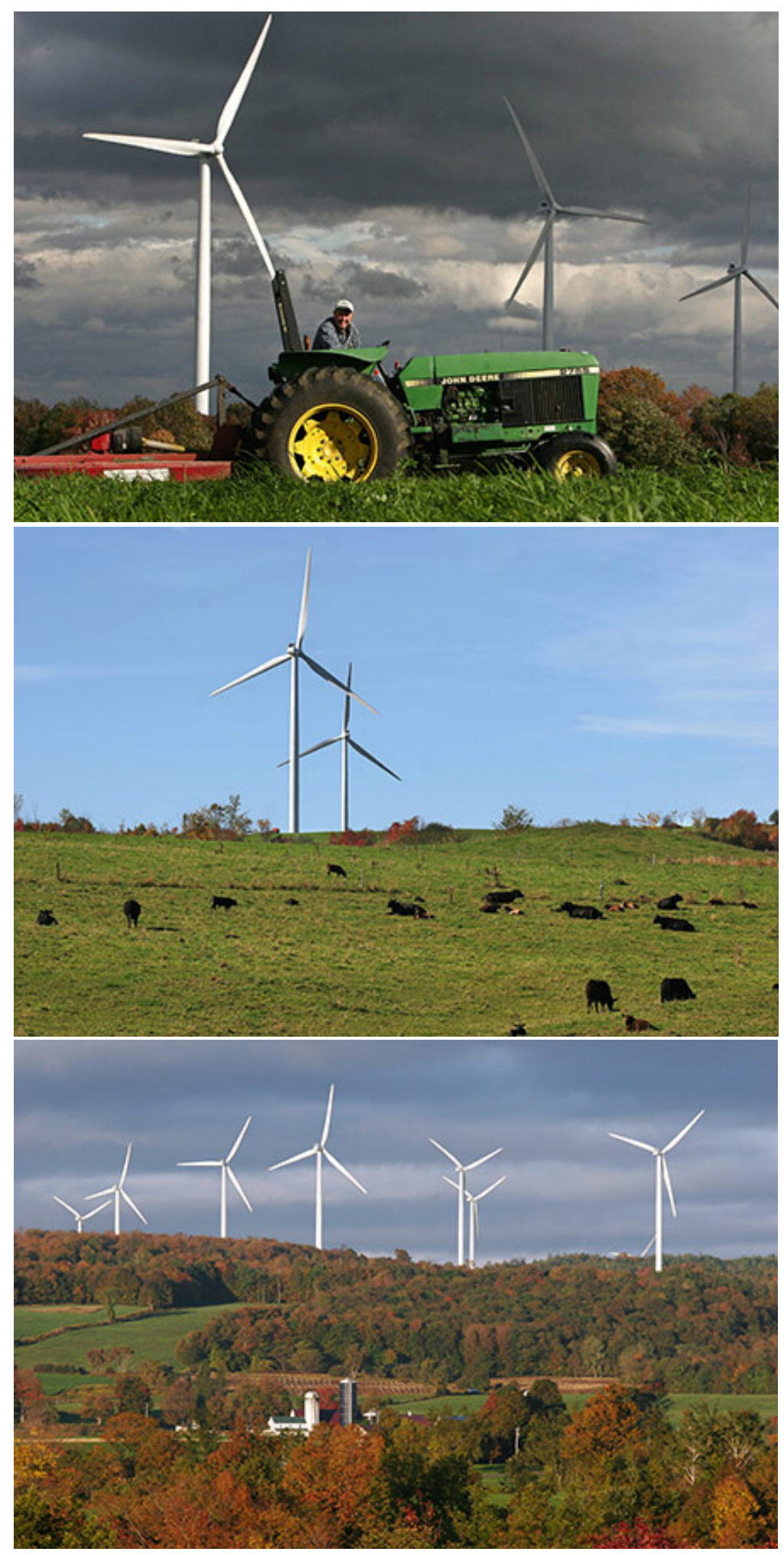
B.8. 3.6 megawatt Turbine (General Electric, n.d.).

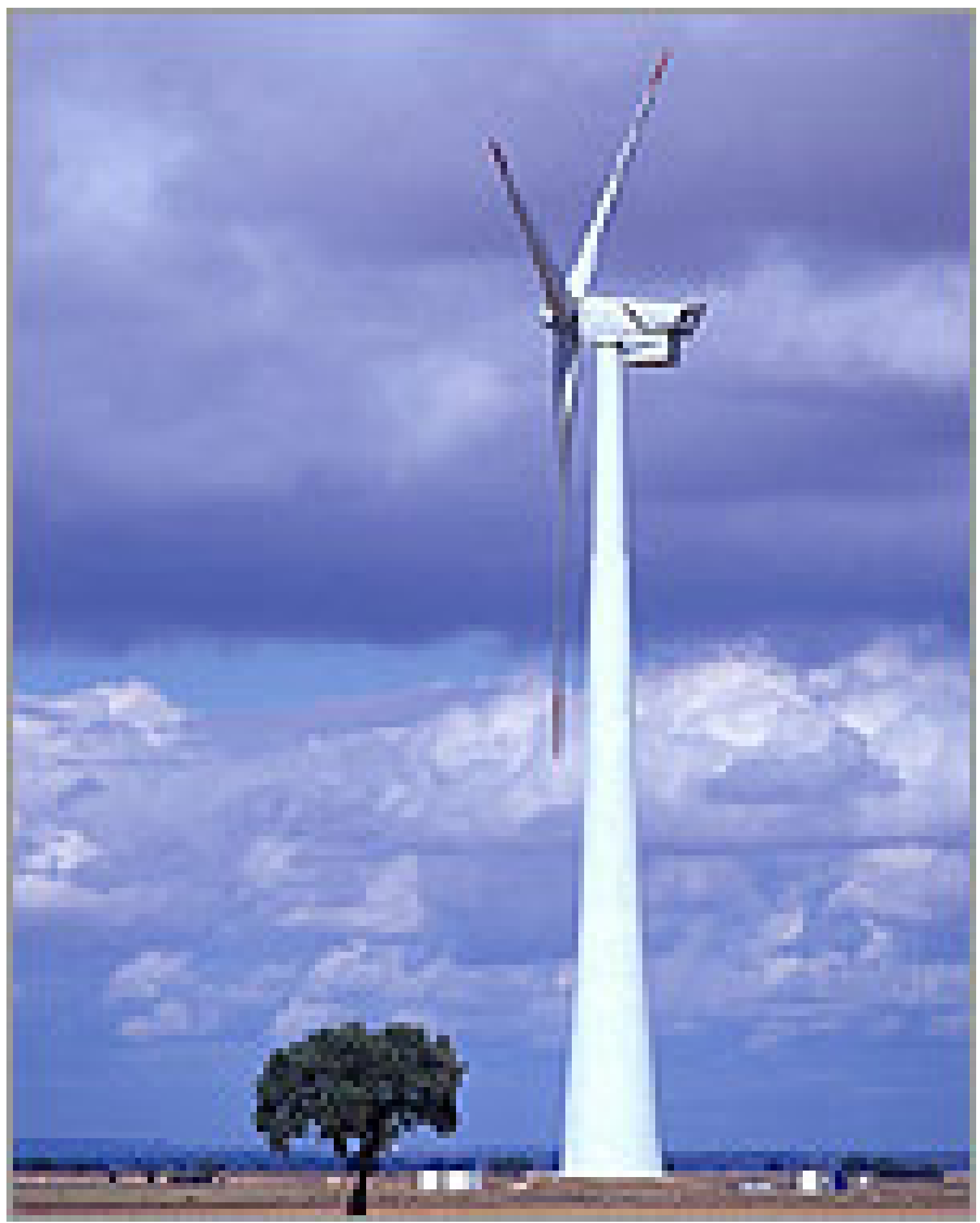


B.9. Novar (Npower Renewables, n.d.).

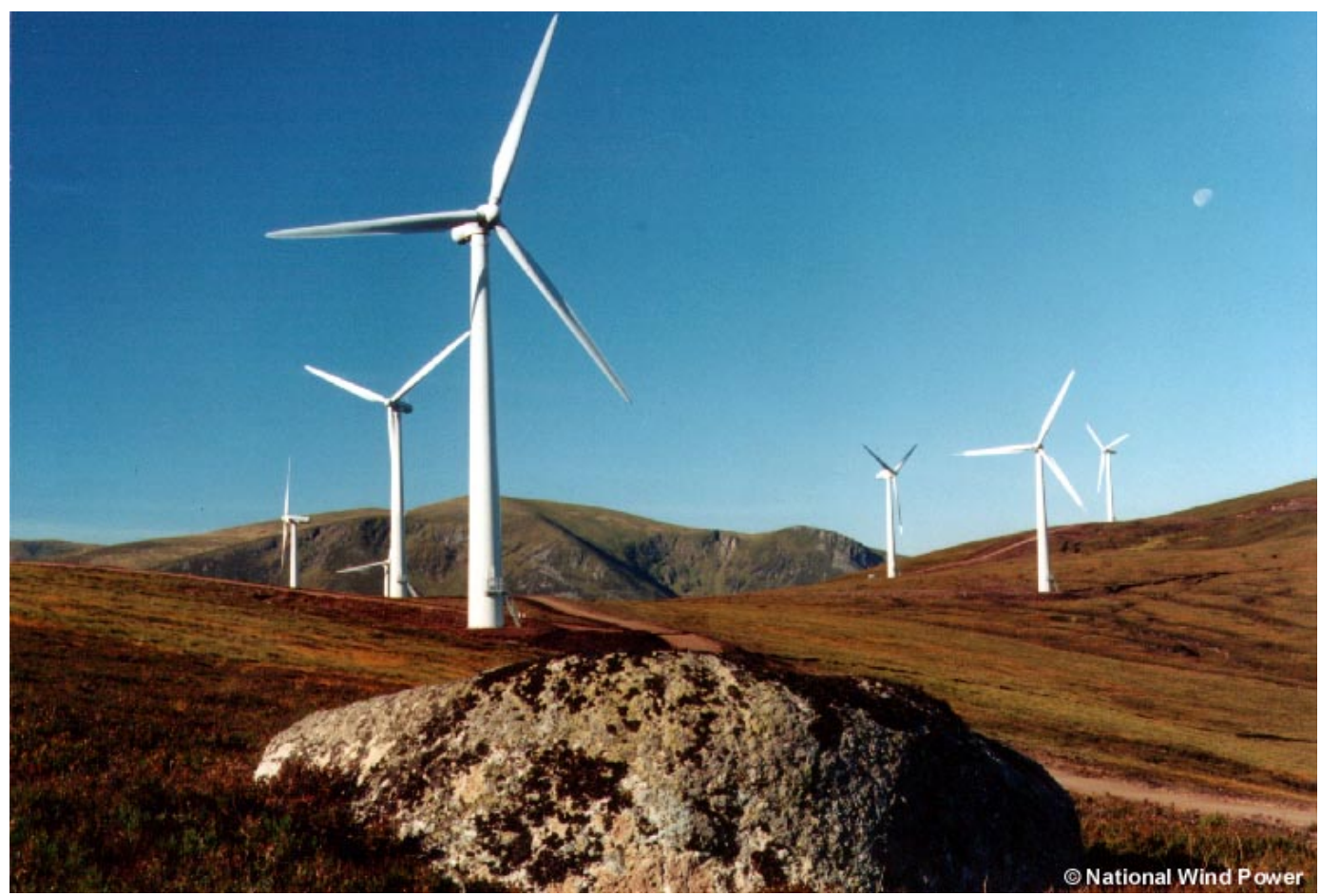

B.10. Construction (Collett Transport Ltd, n.d.).

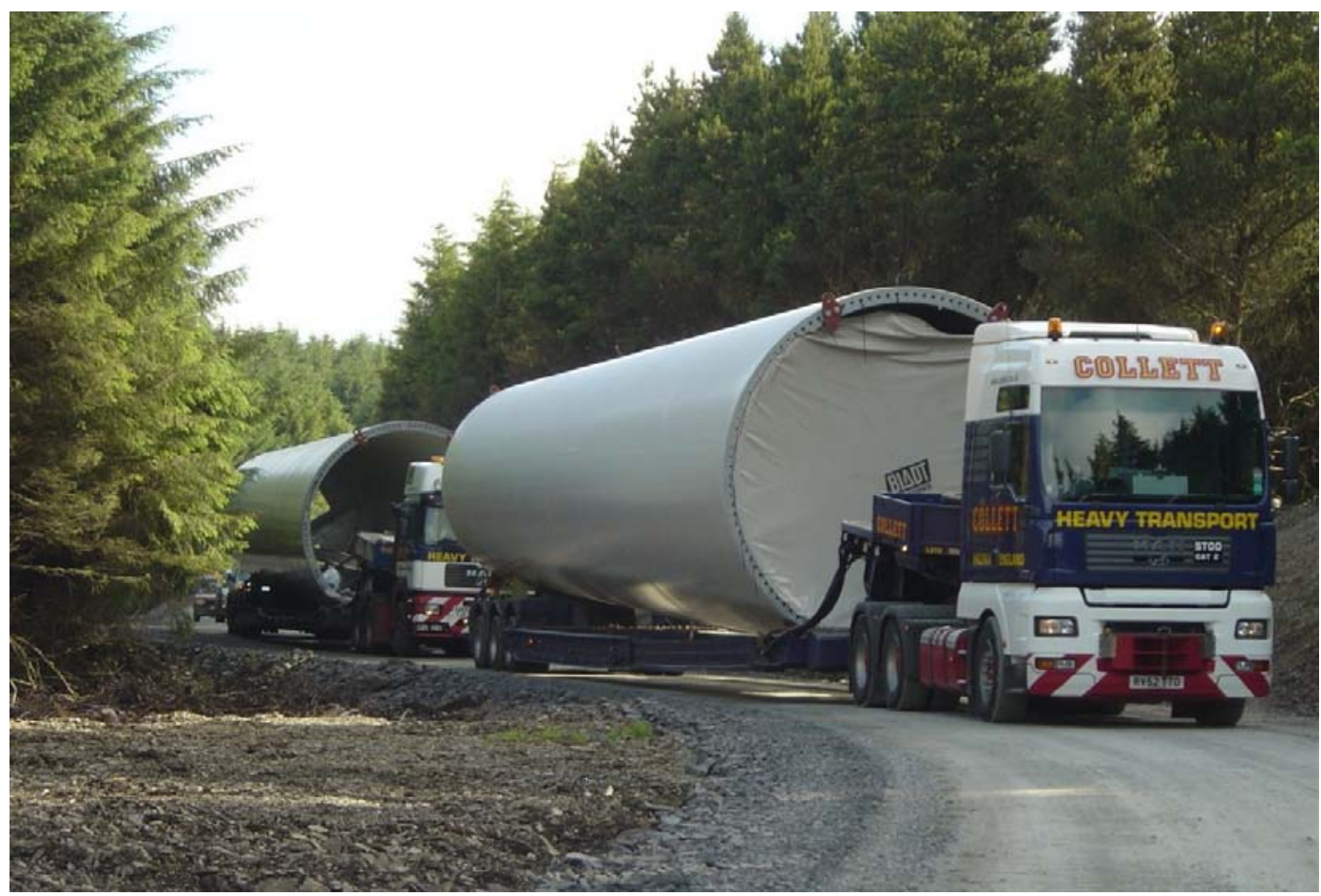


B.11. Construction (Collett Transport Ltd. n.d.).
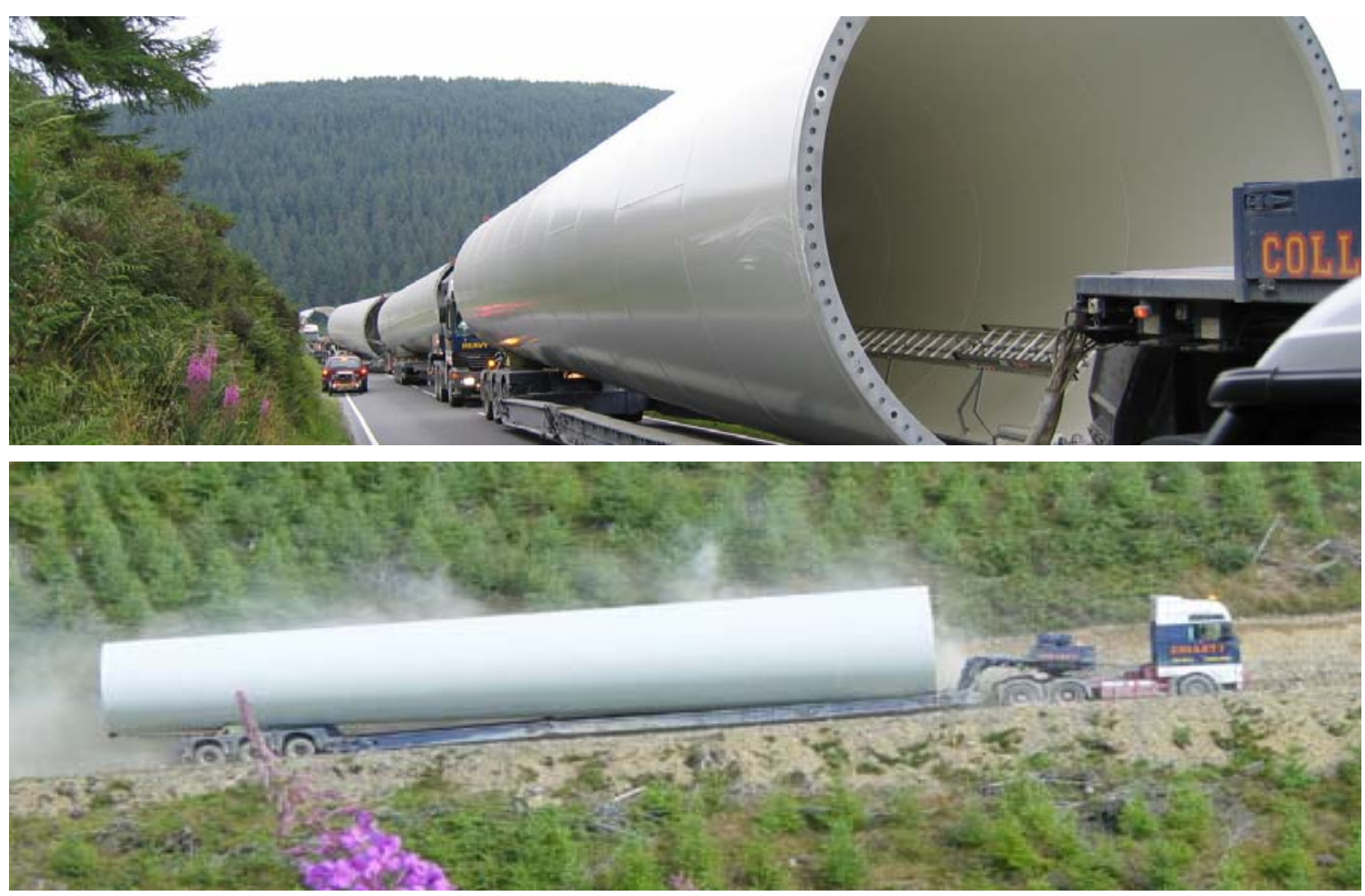

B.12. Blade Factory in Nakskov Denmark (Vestas n.d.).

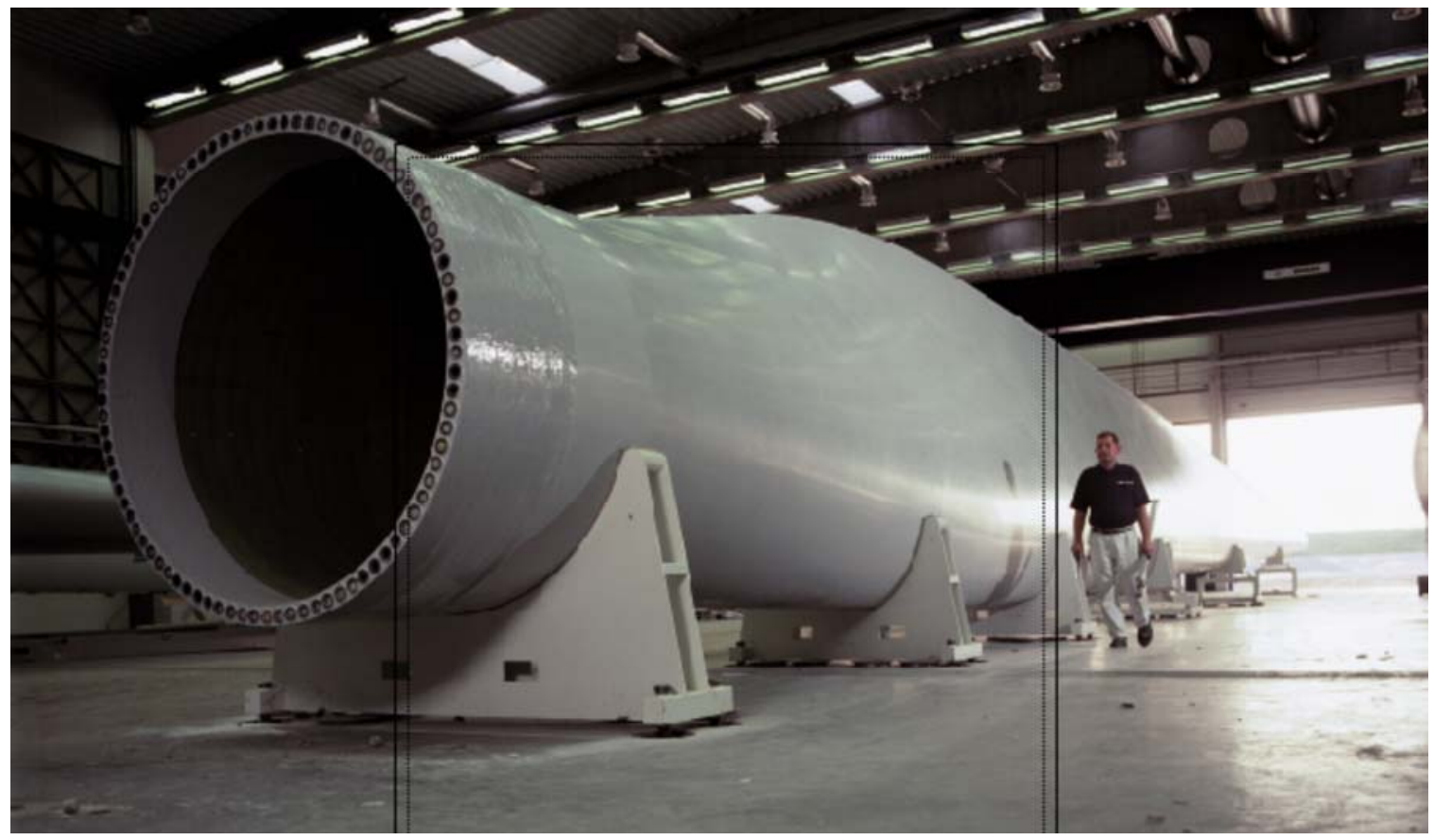


B.13. Construction (Windustry, n.d.).
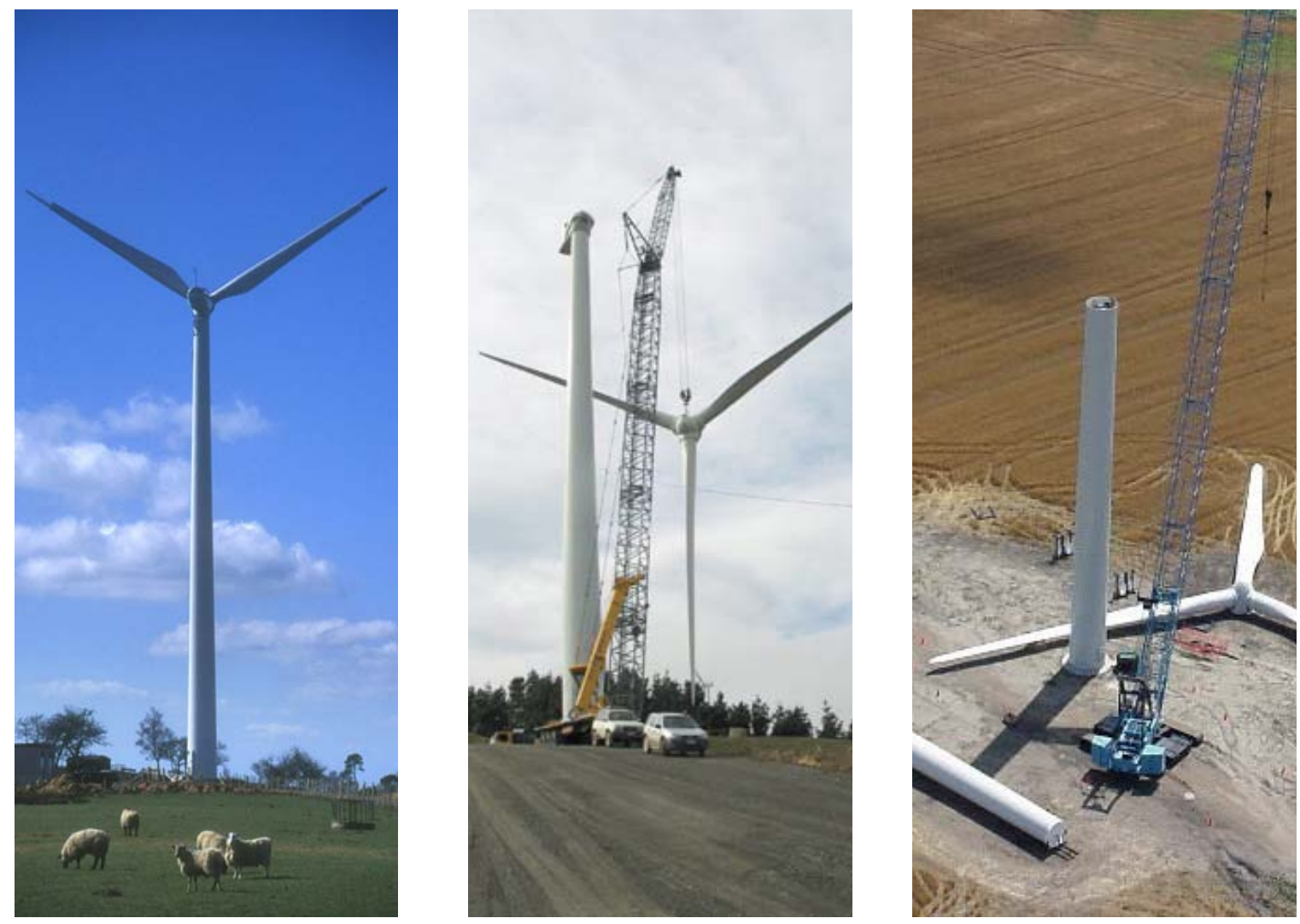